\begin{abstract}
Title of Thesis:

EFFECTS OF DIRECT-FED MICROBIAL SUPPLEMENTATION ON DIGESTIBILITY AND FERMENTATION END-PRODUCTS IN HORSES FED LOW- AND HIGH-STARCH CONCENTRATES

Kelcey L Swyers, Master of Science, 2007

Dissertation directed by: $\quad$ Dr. Amy Burk

Department of Animal and Avian Sciences
\end{abstract}

This research evaluated the viability of lactic acid bacteria (LAB) intended for in vivo application as direct-fed microbial (DFM) supplements in two experiments during feed processing (Exp. 1) and storage (Exp. 2) and determined the efficacy of DFM on the digestibility and hindgut fermentation of horses during and after an abrupt increase in starch (Exp. 3). In Exp. 1, lactobacilli survived feed processing and a commercial enumeration method was validated. In Exp. 2, viable colony forming units of LAB were assessed and remained viable during 12 weeks of storage. Controls in both experiments had high levels of naturally-occurring bacteria present. In Exp. 3, a high-starch concentrate caused fecal $\mathrm{pH}$ to decrease, and fecal propionate and digestibility of many nutrients to increase. The DFM induced minimal improvements in digestibility or fermentation parameters and data provided no clear evidence to support the use of a multiple versus a single strain DFM preparation. 


\title{
EFFECTS OF DIRECT-FED MICROBIAL SUPPLEMENTATION ON \\ DIGESTIBILITY AND FERMENTATION END-PRODUCTS IN HORSES FED LOW- AND HIGH-STARCH CONCENTRATES
}

\author{
by \\ Kelcey L. Swyers \\ Thesis submitted to the Faculty of the Graduate School of the \\ University of Maryland, College Park in partial fulfillment \\ of the requirements for the degree of \\ Master of Science \\ 2007
}

Advisory Committee:

Dr. Amy Burk, Chair

Dr. Tom Hartsock

Dr. Richard Kohn

Dr. Emilio Ungerfeld 
CCopyright by

Kelcey L. Swyers

2007 


\section{ACKNOWLEDGEMENTS}

Probiotic bacteria live in a symbiotic relationship with the host species they inhabit. I, like probiotic bacteria, could not have survived this graduate experience without the village of people I had around me! I equate grad school to my quality control pilot study, where probiotics had to prove they could pass difficult "stress" points to prove they could stay in the game. Deep gratitude goes to my advisory committee who did an excellent job of pushing me through and keeping me in check: Dr. Tom Hartsock, Dr. Rick Kohn, and Dr. Emilio Ungerfeld, with Dr. Amy Burk sitting at the helm. Amy, thank you for letting me dream big dreams, for teaching me, and for not giving up on "this cowgirl!" I applaud and thank the synergistic efforts, hard work and dedication of Dr. Mark Young, Kevin Poorman and Bob Adams at Star-Labs, and of Dr. Roy Johnson, Dr. Mark Newcomb, Dr. Jason Shelton and crew (Kate, Rima and lab techs) at the Cargill Animal Nutrition Innovation Center...the purpose of my research was only made stronger by having such robust industry support. Thank you also to Dr. Scott Weese, Dr. Limin Kung, Dr. Frank Siewerdt and to "thee statistics wizard” Dr. Larry Douglass for unselfishly sharing your knowledge and counsel. A special note of gratitude to my friend, Dr. Roselina Angel for her sage advice, mentorship and interest both in my research and success at the University of Maryland. Lastly, I give deep appreciation to those who were my "prebiotics:" my fellow grad students (Rachael Quinn and Jessica Suagee--thank you for 'running through the quad with me'), the "boss" (Janah Schreiber, her crew, "the boys," and the farm truck), help and humor relief courtesy of Tim Shellem, and of the perpetual support of my family, my friends and most unselfishly from my "husband of husbands"... Jonathan Hunt. 


\section{TABLE OF CONTENTS}

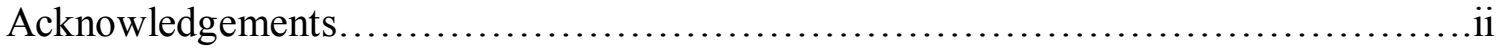

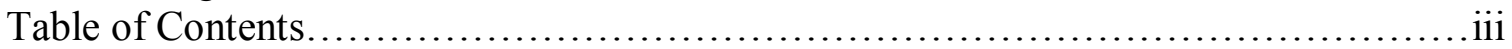

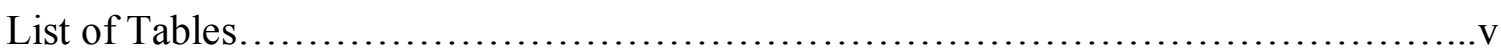

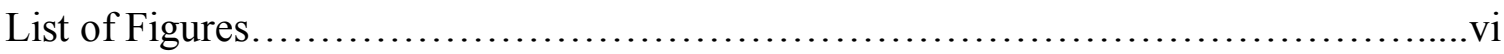

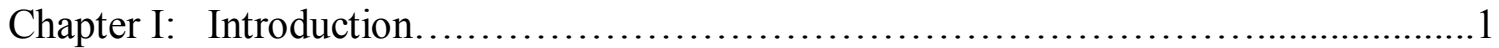

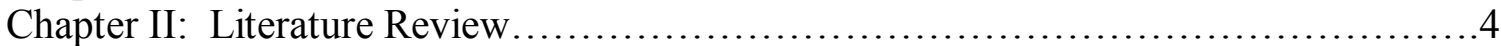

Probiotics in Animal Nutrition............................................5 5

Direct-Fed Microbials..............................................5

Required Properties of a Probiotic..................................8

Quality Control.................................................

Extrapolated Dosage for Equine................................... 10

Microbiology Review................................................... 10

Prokaryotes.................................................. 10

Gram-Positive versus Gram-Negative..............................11

Normal Flora........................................................13

Amylolytic Bacteria...............................................14

Cellulolytic Bacteria..............................................15

Lactic Acid Bacteria (LAB) .................................... 16

Fermentation......................................................... 17

Physiology of Fermentation....................................... 17

Pathways of Fermentation........................................ 18

Volatile Fatty Acids................................................ 19

Lactate......................................................... 21

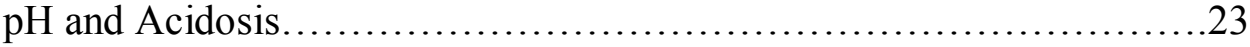

A Theory on Starch....................................................... 24

The Domino Effect...........................................24

Chapter III. Viability of Lactic Acid Bacteria in Animal Feed After

Pelleting and Storage..............................................27

Abstract............................................................... 28

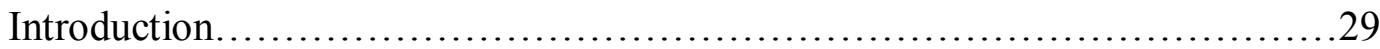

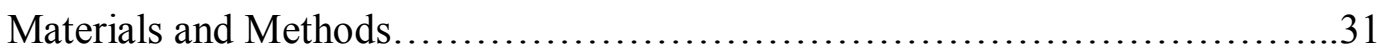

Results ................................................................ 40

Discussion............................................................ 42

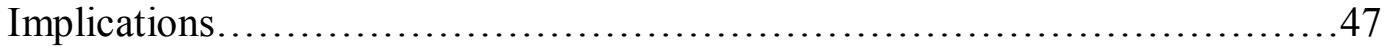

Literature Cited ........................................................ 48

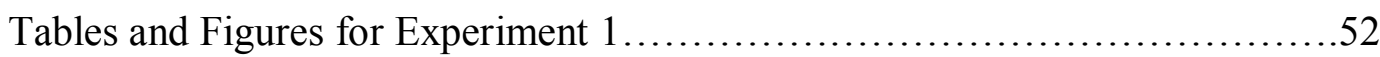

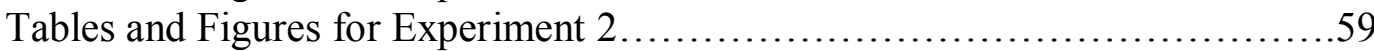

Chapter IV. Effects of Direct-Fed Microbial Supplementation on Digestibility and Fermentation End-Products in Horses Fed Low- and High-Starch Concentrates.....................................................61

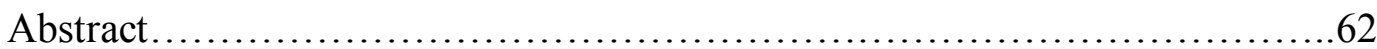

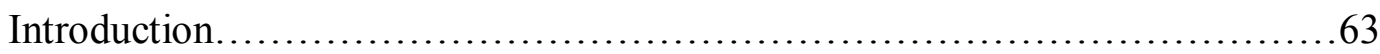

Materials and Methods...................................................65

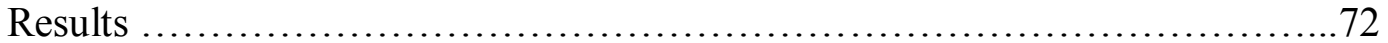




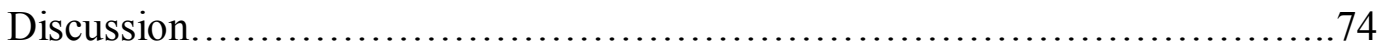

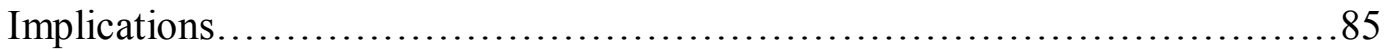

Literature Cited....................................................... 86

Tables and Figures.......................................................... 93

Chapter V. Appendix.................................................... 101

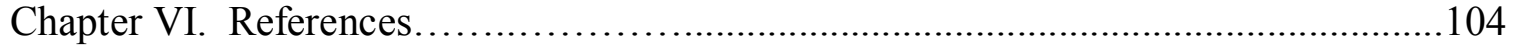




\section{iii. LIST OF TABLES}

1. Broiler diet ingredient and nutrient composition of basal formula used in Exp. 1 .52

2. Pelleting run times, average temperature at the conditioner, pelleting exiting, during pellet drying and of ambient for the five batches in Exp. 1 with or without lactic acid bacteria inclusion.

3. Bacteria species identification performed on control batch of animal feed stored for 12 weeks from June to September, Exp. 2.

4. Nutrient composition of grass hay and low- and high-starch concentrates fed to Thoroughbred geldings. ...

5. Body weight and body condition scores of Thoroughbred geldings consuming low- and high-starch concentrates containing either no (Control), one strain (LAC1), or four strains (LAC4) of a lactic acid producing bacteria DFM $(n=15)$

6. Daily intakes of geldings consuming low- and high-starch concentrates containing either: no (Control), one strain (LAC1), or four strains (LAC4) of a lactic acid producing bacteria DFM ( $\mathrm{n}=15)$

7. Interaction (starch $\mathrm{x}$ treatment) effects of low- and high-starch concentrates containing either: no (Control), one strain (LAC1), or four strains (LAC4) of a lactic acid producing bacteria DFM on apparent total tract digestibility of nutrients, fecal $\mathrm{pH}$ and fecal VFA concentration of Thoroughbred geldings $(n=15)$.

8. Main effects of low- and high-starch concentrates containing either: no (Control), one strain (LAC1), or four strains (LAC4) of a lactic acid producing bacteria DFM on apparent total tract digestibility of nutrients, fecal $\mathrm{pH}$ and fecal VFA concentration of Thoroughbred

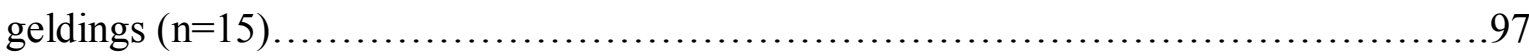

9. Average fecal $\mathrm{pH}$ and fecal VFA concentrations at time of collection of Thoroughbred geldings. 


\section{iv. LIST OF FIGURES}

1. Average viable lactobacilli colony forming units $\left(\mathrm{CFU}, \log _{10}\right)$ by level of inclusion of direct-fed lactic acid bacteria in batches of animal feed during processing at a feed mill,

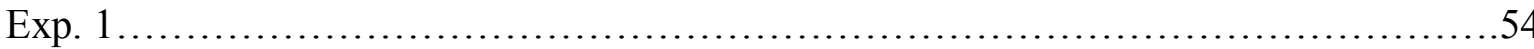

2. Mean counts of viable lactobacilli colony forming units (CFU, $\left.\log _{10}\right)$ in animal feed samples at different collection points during feed processing using SL-01 and AOAC

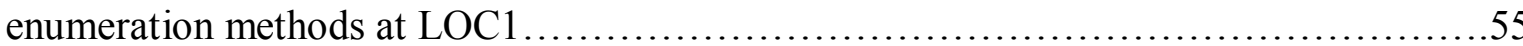

3. Best fit linear regression analysis representing differences between SL-01 and AOAC enumeration methods at LAB1 for determination of viable lactobacilli colony forming units $\left(\mathrm{CFU}, \log _{10}\right)$ in animal feed samples during feed processing

4. Mean counts of viable lactobacilli colony forming units $\left(\mathrm{CFU}, \log _{10}\right)$ in animal feed samples at different collection points during feed processing at LOC1 and LOC2 using the

SL-01 enumeration method

5. Best fit linear regression analysis representing differences between LOC1 and LOC2 using the SL-01 method for enumeration of viable lactobacilli colony forming units (CFU, $\left.\log _{10}\right)$ in animal feed samples during feed processing....................................58

6. Effect of time (week) on number of viable colony forming units (CFU, $\log _{10}$ ) of lactobacilli, enterococci, and bifidobacteria in separate batches of animal feed stored for 12-weeks from

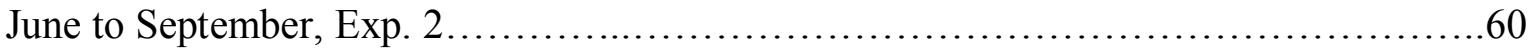

7. Experimental timeline of each 26 -day period.................................... 99

8. Relationship between collection time of day to $\mathrm{pH}$ and fecal propionate concentration of geldings consuming low- and high-starch concentrates with and without direct-fed lactic acid producing bacteria 100

9. Illustration of the layers found in Gram-positive and Gram-negative bacteria.... 103 
10. Percentage of lactobacilli colonies that were Gram-stain positive and catalase negative from animal feed samples made in the following order: $\mathrm{CON}=$ lactic acid bacteria (control), PRIM2 $=0.91 \mathrm{~kg} / \mathrm{ton}$ inclusion of PrimaLac, PRIM3 $=1.36 \mathrm{~kg} / \mathrm{ton}$ inclusion of

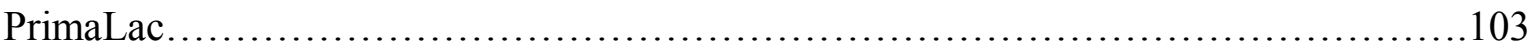


CHAPTER 1

INTRODUCTION 


\section{INTRODUCTION}

In equine, starch that surpasses digestion in the small intestine and reaches the hindgut (cecum and/or colon) disrupts the normal flora ecology (Bailey et al., 2003) causing an acidotic digestive upset that can lead to ulcers (Andrews et al., 2005), colic (King, 1999; de Fombelle et al., 2001), endotoxemia (Sprouse et al., 1987, Clarke et al., 1990), and/or laminitis (Garner et al., 1977; Sprouse et al., 1987; Mansmann and King, 2000). In recent years, equine nutritionists have worked toward a solution to reduce the risks associated with feeding high-starch concentrates to horses. Feedlot cattle fed highconcentrate diets supplemented with direct-fed microbials (DFM) had reduced risk of acidosis (Ghorbani et al., 2002); this may have some relevance in negating the acidotic risks associated with high starch in the equine diet. The DFM, also referred to as "probiotics," are feed additives that serve as a source of live, naturally occurring microorganisms (bacteria and/or yeast) that once fed, enhance intestinal microbial balance and digestive health in the host animal (Fuller, 1989; Yoon and Stern, 1995). Lactic acid-producing bacteria species (LAB), predominantly from the Lactobacillus genus are the most commonly used bacteria species in animal DFM preparations (Kung, 1999; Weese, 2001; Krehbiel et. al., 2003). Despite the wide use of LAB in DFM preparations intended for equine, no peer-reviewed research has validated the efficacy of either a single strain or a multiple strain LAB-based DFM, particularly as it relates to digestion and hindgut fermentation in mature horses. However, while DFM are generally regarded as safe (GRAS; FDA, 1995), reports of commercial products not containing either the species, number, or purity of organisms stated on the label (Gilliland and Speck, 1977; Canganella et al., 1997; Hamilton-Miller et al., 1999; Hamilton-Miller and 
Shah, 2002; Weese and Arroyo, 2003; Coeuret et al., 2004; Drisko et al., 2005) has risen the concern on the integrity of commercial DFM preparations intended for animal use. These studies focused on 'after market' viability of DFM in commercial products and not of the viability during or after feed processing or through a period of storage. Before consistent in vivo dosage and efficacy trials can be conducted, bacterial organisms intended for DFM application must first demonstrate the ability to survive the stress of feed processing and storage (Weese, 2001, 2002, 2003). Three experiments were conducted with the objectives of:

- Determination of the viability and degree of loss of lactobacilli colony forming units (CFU) during feed processing and validation of an enumeration method used in a commercial lab (Exp. 1).

- Determination of the viability of lactic acid bacteria (LAB) in pelleted animal feed during summer storage (Exp. 2).

- Determination of the efficacy of single versus multiple strain direct-fed LAB supplementation on nutrient digestibility and hindgut fermentation of horses when the starch content of the diet abruptly increases (Exp. 3). 
CHAPTER 2

LITERATURE REVIEW 


\section{PROBIOTICS IN ANIMAL NUTRITION}

\section{Direct-Fed Microbials}

In the last decade, nutritionists have become acutely aware of the normal flora that inhabit the gastrointestinal (GI) tract of mammals and the benefits it exerts upon the host. Of primary interest is to understand, characterize and optimize the fermentative action of the normal flora across mammalian species. Much of this effort has been focused around the therapeutic action of "probiotics." Probiotics were first recognized by Metchnikoff (1907) following his observation on the longevity of Bulgarian peasants who consumed large amounts of fermented milk (yogurt). He speculated that harmful bacteria, detrimental to humans, were inhibited by beneficial organisms present in yogurt. It was later confirmed by Rettger and Chaplin (1921) that Lactobacillus acidophilus in the yogurt acted as an antibiotic. Lilley and Stillwell (1965) first defined probiotics as substances secreted by one organism that stimulates the growth of another. More recently, probiotics have been defined as microorganisms that beneficially affect the host animal by providing intestinal microbial balance (Fuller, 1989). The U.S. Office of Regulatory Affairs of the Food and Drug Administration(FDA, 2003) and the Association of American Feed Control Officials (AAFCO, 1999) have narrowed the definition of probiotics to "a source of live, naturally occurring microorganisms" (Yoon and Stern, 1995) and require feed manufacturers to use the term "direct-fed microbial" (DFM).

The uses of DFM are particularly appealing for accommodating the modern public's demand for "natural" or "alternative therapy" approaches on digestive health and 
veterinary remedies. There is increasing evidence that supports such therapies in domestic animals. In ruminants, microbial cultures have shown to decrease the instance of ruminal acidosis (Huffman et al., 1992, Ghorbani et al., 2002), improve feed efficiency and daily gain in beef cattle (Ware et al., 1988; Swinney-Floyd et al., 1999), potentially replace or reduce the use of antibiotics in neonatal and stressed calves (Bechman et al., 1977; Maeng et al., 1987; Fox, 1988; Abu-Tarboush et al., 1996), and enhance milk production in dairy cows (Komari et al., 1999; Gomez-Basauri et al., 2001). In poultry, probiotic supplements given to laying hens improved egg production, feed consumption, feed conversion, eggshell thickness, and yolk color, in addition to decreased yolk cholesterol (Mohan et al., 1995; Yeo and Kim, 1997; Li et al., 2006). Probiotics offered to humans enhanced the immune response, reduced serum cholesterol levels and colon cancer, improved calcium absorption, vitamin synthesis, and lactose tolerance (Fuller, 1989; Mitsuoka, 1990; Gibson and Roberfroid, 1995; Kailasapathy and Rypka, 1997; Tannock, 1999, Isolauri et al., 2001), as well as reduced diarrhea in children (Van Niel et al., 2002).

Lay authors and commercial marketers suggest that probiotic supplements intended for horses may aid in supporting digestive health, promote efficient digestion (thereby reducing feed costs), inhibit the growth of pathogenic bacteria, reduce sideeffects associated with antibiotic administration, increase lactation in mares, increase growth in foals, and reduce the incidence of colic (Horsefeeds UK). Moore Agri-Sales, a maker of a commercial probiotic called Fastrack ${ }^{\circledR}$, claims that "probiotics promote efficient digestion and feed utilization, reduce the potential for colic, ensure efficient 
nutrition, enhance performance and endurance, improve hair coat, enhance appetite and improve hoof quality in horses." Vets Plus, Inc., the maker of Probios ${ }^{\circledR}$, claims that their product "increases intake, feed efficiency, average daily gain (ADG) and body condition scores (BCS) in horses.” It is claimed that Probios ${ }^{\circledR}$ has been tested in 95 studies on 30,000 animals, yet this information is not publicly available. Vets Plus, Inc. also claims that, "not all probiotics are the same. Products can differ in strain origin, purity, viability, stability, consistency and clinical documentation, all of which influence product performance.”Star-Labs, the makers of PrimaLac ${ }^{\circledR}$, only state that their probiotic preparation is "stable and can survive pelleting." Star-Labs lists a number of studies that have been conducted on their product and are available upon request. Despite advertising claims on commercial probiotics, no studies have reported beneficial effects in horses following probiotic adminstration (Weese, 2001 and 2004).

A review of all studies published on probiotic evaluation in horses provides only conflicting results and raises more questions. Weese et al. $(2003,2004,2005)$ published a series of studies evaluating probiotics for horses. First they, administered L. rhamnosus (casei) strain GG, a strain extensively studied in humans for treatment of diarrhea, to mature horses and foals at three and two dosage levels respectively for $5 \mathrm{~d}$. They concluded that $L$. rhamnonsus appeared to colonize the hindgut of foals but not of mature horses and questioned its efficacy for equine due to intestinal colonization only achieved at a prohibitively high dose (Weese et al., 2003). Then, they screened 47 bacterial organisms from the equine intestine to be used as a potential LAB probiotic and isolated L. pentosus WE7 to be subjectively superior in demonstrating acid-and bile-tolerance, 
aerotolerance, and inhibition against more than one pathogen in vitro (Weese et al., 2004). Lastly, they administered L. pentosus WE7 to neonatal foals for the prevention of diarrhea, but resulted in exacerbated diarrhea, raising concerns about the number of untested probiotic products for horses that are available on the market (Weese and Rousseau, 2005). Results from other authors are contradictory, where one found no benefit to foals receiving a LAB probiotic at weaning (Swanson et al., 2003), while another study reported decreased instance of diarrhea when host-specific Lactobacillus strains were offered to foals (Yuyama et al., 2004). Additionally, probiotics administered to horses for the prevention of Salmonella did not have any effect (Parraga et al., 1997; Kim et al., 2001). Regardless of the lack of efficacy found in equine, it seems likely that DFM have a role in equine nutrition based on extrapolation from research in other species.

\section{Required Properties of a Probiotic}

It has been stated that probiotics are likely host species-specific; it is likely that not all probiotic preparations would exhibit benefits across-species (Gibson and Fuller 2000). Explanations for a lack of effect of DFM in equine studies could include inadequate dosing, poor survival of organisms during gastro intestinal (GI) transit or use of organisms with no beneficial properties to equine. Selection of organisms with desirable properites is critical to the development of DFM applications for horses (Weese 2001 and 2004). For example, aerotolerance and survivability during commercial processing and storage must first be demonstrated. Once ingested, DFM must survive transit through the acidic environment of the stomach, resist bile digestion, attach to 
intestinal tract epithelial cells, colonize the gut mucosa (Dunne et al., 1999; Ouwehand et al., 1999; and Gorbach, 2000), produce antimicrobial factors against one or more pathogens (Gibson and Fuller, 2000; Dunne et al., 2001), and cause no harmful effects to the host animal regardless of dose (Kailasapathy and Chin 2000). Probiotic bacteria should prevent the growth of pathogenic species by competing for nutrients and attachment sites on the colon epithelium. The attachment of beneficial bacteria may increase the absorptive surface area of the GI tract and enhance nutrient absorption by the host animal (Savage and Fletcher, 1985; Savage, 1991). Because probiotic organisms are not considered a drug and are GRAS, they are frequently used without standards of efficacy or safety. However, the FDA (1995) states an increasing concern about the safety of DFM due to the diversity of microorganisms being used and of the manufacturing processes involved. It is important to assess the ability of DFM to exhibit these properties in order to accurately and consistently conduct much needed dosage and efficacy trials in equine.

\section{Quality Control}

Previous research indicates a significant percentage of probiotic preparations that either did not contain the organism(s) or guaranteed CFU stated on the label, or contained additional species (Gilliland and Speck, 1977b; Canganella et al., 1997; Hamilton-Miller et al., 1999; Hamilton-Miller and Shah, 2002; Weese and Arroyo, 2003; Coeuret et al., 2004; Drisko et al., 2005). None of the 19 commercial pet food diets analyzed by Weese and Arroyo (2003) contained all of the probiotic organisms listed on the label and no relevant microbial growth, ranging from 0 to $1.8 \times 10^{5} \mathrm{CFU} / \mathrm{g}$, was found in 5 of the 
products. They concluded that DFM were not accurately represented on the label. In commercial pharmaceutical products for humans, single species have shown better survivability than multiple strains (Canganella et al., 1997); suggesting an inhibition effect. Hamilton-Miller et al. (1999) concluded, after sub-standard results from the evaluation of probiotic survivability in 21 human supplements, 15 human foods, and eight human 'health-care' products, that improvements are needed in labelling and quality assurance procedures.

\section{Extrapolated Dosage for Equine}

In humans, a dose of $1 \times 10^{8} \mathrm{CFU} / \mathrm{d}$ to $1 \times 10^{10} \mathrm{CFU} / \mathrm{d}$ (100 million to 10 billion viable organisms per day) has been used as a recommendation for a minimum therapeutic dose (Kailasapathey and Chin, 2000). Weese (2001) extrapolated from human dosages, that an average horse $(\sim 450 \mathrm{~kg})$ would likely require $1 \times 10^{9} \mathrm{CFU} / 50 \mathrm{~kg} / \mathrm{d}$ to $1 \times 10^{11}$ $\mathrm{CFU} / 50 \mathrm{~kg} / \mathrm{d}$ of an organism able to colonize the intestinal tract. While the digestive physiology of humans and horses are quite different, this is at least a reference point from which to start future dosage trials.

\section{MICROBIOLOGY REVIEW}

Prokaryotes

The discussion of DFM in this literature review is focused on bacteria fed as probiotics. According to the American Society for Microbiology, bacteria are the most abundant life form on Earth, both in mass and species variation. They are classified as prokaryotes, which are unicellular organisms made up of simple physiology, consisting 
of a cell wall, cytoplasmic membrane, ribosomes, nucleoid (chromosome), external capsule, flagellum and/or surface pili. Unlike eukaryotes, prokaryotes do not have a nucleus compartment, and where most eukaryotic cells are from 10 to $100 \mu \mathrm{m}$ in diameter, a typical bacterial cell is about $1 \mu \mathrm{m}$ in diameter: about the size of a eukaryotic mitochondrion. From a metabolic standpoint, prokaryotes are extraordinarily diverse and exhibit several types of metabolism that are rarely or never seen in eukaryotes (Todar, 2005). For example, the biological processes of nitrogen fixation and methanogenesis are metabolically unique to prokaryotes and have an enormous impact on the nitrogen and carbon cycles in nature. In the human foods industry, lactic acid producing bacteria, such as Lactobacillus and Streptococcus, are used in the manufacturing of dairy products such as yogurt, cheese, buttermilk, sour cream, and butter. Bacterial fermentation can be used to produce lactic acid, acetic acid, ethanol or acetone (Moat, 2002 and Todar, 2005).

\section{Gram-Positive versus Gram-Negative}

Bacteria can be broadly separated into two groups: Gram-positive or Gramnegative. Gram-positive bacteria retain a violet dye when subjected to the Gram-staining procedure (Gram, 1884) due to a cell wall that is uniformly thick and made up of many layers of peptidoglycan (murein). Conversely, Gram-negative bacteria stain a pink color, due to a cell wall that appears thin and composed of many different structures consisting of a relatively thin peptidoglycan sheet between the plasma membrane and a phospholipid-lipopolysaccharide (LPS) outer membrane (Moat 2002). The outer membrane of Gram-negative bacteria (typically found in pathogenic species) is impermeable to large molecules and compounds that have hydrophobic properties, 
providing protection for bacteria from bile salts and other toxic molecules in its environment. The LPS membrane is located on the outermost surface of the cell wall and is responsible for mediating contact with external surroundings. In production livestock, the LPS is most known for the damage it can cause once liberated. For example, when a host animal's GI tract is in an acidotic state, low pH causes lysis of microorganisms, liberating the LPS into the digestive tract. Consequent absorption of the LPS causes the animal's immune system to over-react, igniting a cascade of uncontrolled systemic inflammatory responses that can lead to multiple organ failure and potentially death (Beutler and Rietschel, 2003, and Beutler, 2003). This adverse reaction is commonly referred to as endotoxemia, sepsis or septic shock. Endotoxemia is frequently associated with sudden death syndrome observed in feedlot cattle as they near market weight, due to finishing diets high in carbohydrates (Turner, 1971; Williams, 1976 and 1977).

Furthermore, differences in cell wall structure between Gram-positive and Gramnegative species mitigate antibiotic treatment effectiveness. Antibiotics are secondary substances that are produced by certain groups of microorganisms, particularly Streptomyces, Bacillus, and a few molds like Penicillium and Cephalosporium that are typically found in soils (Todar, 2005). Antibiotic action may kill or inhibit other microbes, where the range of the effect is considered a "spectrum." The LPS of Gramnegative bacteria is the primary target for antibiotic attack (Moat, 2002). Experiments have shown that lactic-acid producing bacteria in particular, have successfully demonstrated antibiotic activity against pathogenic bacteria such as E. coli (Schiffrin et al. 1995) and Salmonella typhirium (Hatcher and Lambrecht, 1993). 
Lastly, Gram-positive streptococci and lactobacilli bacteria are thought to adhere to the gastrointestinal epithelium using polysaccharide capsules or wall lipoteichoic acids to attach to specific receptors on epithelial cells (Moat, 2002), whereas Gram-negative bacteria may attach by means of specific fimbriae that bind to glycoprotein on the epithelial cell surface (Moat, 2002). Consequently, Gram-positive and Gram-negative bacteria compete for attachment sites on the epithelial lining of the GI tract.

\section{Normal Flora}

In a healthy animal, a community of microorganisms that colonize the intestinal tract is referred to as the "normal flora" (Parker, 1974). The makeup of the normal flora depends upon various factors, including genetics, age, sex, stress, nutrition and diet of the host (Todar, 2005). The normal flora consists of fungi, yeasts, protozoa, and some archaea, but the bacteria are the most numerous components. The normal flora of horses has been virtually unexplored, where it has been estimated that only $11 \%$ of bacterial species screened have been sequenced and identified (Daly et al., 2001; Weese, 2004). Furthermore, Amann et al. (1995) states that only a fraction $(<1 \%)$ of species from the rumen have been recovered through isolation and cultivation, suggesting that our understanding of the rumen ecosystem, based on the few strains we have identified, could be misleading.

Within the intestinal lumen, different microenvironments exist. Acidophiles will populate the proximal intestine where acid secreted from the stomach is more persistent, 
while species less tolerant to low $\mathrm{pH}$ inhabit the cecum or distal colon. Some species thrive at the mucosal surface, while others are more stable in the crypts (Ward et al., 1990; Conway et al., 1995; Berg, 1996; Dunne, 2001).

Both host and bacteria are thought to benefit from each other due to the nature of their cohabitative relationship. The normal flora derives from the host a supply of nutrients, a stable environment, constant temperature, protection, and transportation. The host obtains from the normal flora certain nutritional benefits (e.g. water-soluble vitamins and amino acids), stimulation of the immune system, and exclusion of pathogens (O’Sullivan et al., 2005; Todar, 2005).

Amylolytic Bacteria

Forages consumed by herbivores, such as horses, consist predominantly of polysaccharides from two classes: starch, which is the storage polysaccharide of glucose in plants and structural polysaccharides, which compose the fibrous rigidity of cell wall structures. Starch is composed of amylase and amylopectin and is typically found in the grain portion of plants. Where amylose consists of a chain of $\alpha 1,4$ glucose units, amylopectin is larger, with $\alpha 1,6$ linkages and branched structures every $24-30$ glucose monomer units (Whistler and Daniel, 1984). Starch becomes available for digestion after the endosperm and protein matrix surrounding the grain are broken down. Once starch is exposed, it is quickly utilized by amylolytic bacteria due to their ability to secrete exogenous $\alpha$-amylase enzymes. Some of the common amylolytic bacteria found in the GI tract are Streptococcus spp., Lactobacillus spp., Enterococcus spp., and Bifibacterium 
spp. which produce lactic acid as a by-product of fermentation (Dunlop and Hammond, 1965). Amylolytic bacteria are effective in inhibiting pathogens. Amylolytic LAB eliminated intestinal Escherichia coli $0157: \mathrm{H} 7$ through competitive attachment of the intestinal epithelium (Jones and Rutter, 1972, Muralidhara et al., 1977, Zhao et al., 1998;

Ohya et al., 2000; Chaucheyras-Durand et al., 2006) and exhibited antibacterial activity against pathogens such as E. coli, Salmonella typhimurium, Staphylococcus aureus, and Clostridium perfringens (Fuller, 1977; Gilliland and Speck, 1977a, Mann et al., 1980).

\section{Cellulolytic Bacteria}

The cell wall of plants is formed by a complex structure consisting of $\beta 1,4$ linked glucose units that form interlocking layers of cellulose, xylan, and xyloglucan. Whereas mammals do not secrete the cellulase and zylanase enzymes needed for the degradation of cellulose into simple sugar units, bacteria in the cecum and colon do synthesize these enzymes. The predominant cellulolytic bacteria found in the rumen and hindgut of most herbivores are Fibrobacter succinogens, Ruminococcus albus and Ruminococcus flavefaciens (Hobson and Stewart, 1997). Cellulolytic bacteria populations grow in proximity to the plant cell walls they digest. In the rat, amylolytic species are more common in the small intestine, whereas the cellulolytic species were in higher concentrations in the cecum (Macy et al., 1982). The same cellulolytic bacteria common in the rumen are also present in the horse cecum (Julliand et al., 1999); however where $R$. flavefaciens is the most predominant cellulolytic bacteria found in the cecum, $F$. succinogens is the main species of the rumen (Julliand et al., 1999, Michaelet-Doreau et al., 2002). 


\section{Lactic Acid Bacteria (LAB)}

The most common bacteria used in commercial DFM for horses are of the lactic acid-producing species (Enterococcus, Lactobacillus, Bacillus, Bifidobacteria spp.), predominantly from the Lactobacillus genus (Kung, 1999; Weese, 2001; Krehbiel et. al., 2003). Lactobacillus acidophilus in particular, is the most commonly used bacteria offered as a probiotic in animal nutrition and is found in a wide range of commercial livestock and companion animal feeds and supplements. L. acidophilus gets its name from "lacto" meaning milk, "bacillus" meaning rod-like in shape, and "acidophilus" meaning acid-loving (Moat et. al., 2002). It tolerates low $\mathrm{pH}$ and has antibiotic activity against E. coli O157:H7 (Ogawa et al., 2001; Chaucheyras-Durand et al., 2006).

Lactic acid-producing bacteria (LAB) in general are Gram-positive, usually nonmotile, non-spore-forming rods and cocci (Moat, 2002) that produce lactic acid as a major product of fermentation (Moat, 2002). Being aerotolerant anaerobes, they can survive in the presence of oxygen, although they grow under anaerobic conditions (Moat, 2002). This property allows $L A B$ the ability to survive feed manufacturing, processing and storage, therefore warranting inclusion in most mixed commercial probiotic preparations. The LAB have limited biosynthetic ability, requiring pre-formed amino acids, B vitamins, purines, pyrimidines and simple sugars as their predominant carbon and energy sources. These multiple requirements restrict them to habitats where the required compounds are abundant and available simultaneously, like in the GI tract of mammals. Lactic acid bacteria can grow at temperatures between 5 and $45^{\circ} \mathrm{C}$ and are tolerant to acidic conditions, with most strains able to grow at $\mathrm{pH} 4.4$ and higher (Moat, 2002). 
Because most commercial probiotic preparations use combinations of $\mathrm{LAB}$, it is difficult to determine the effects of individual organisms. Despite the research available in other livestock species and the wide availability of LAB-based probiotics for horses, there is a paucity of peer-reviewed research published on the effects of them in mature horses. Information available on probiotics in horses focuses primarily on LAB inhibition effect on pathogens. Parraga et al. (1997) reported no influence from LAB probiotic preparations on the effect of Salmonella sp. shedding, post-operative diarrhea persistence, duration of antibiotic therapy or length of clinic hospitalization in horses with colic. The LAB dosages of the two preparations in that study were $3 \times 10^{8} \mathrm{CFU}(L$. planatarum, L. casei, L. acidophilus and E. faecium) and $4.1 \times 10^{9} \mathrm{CFU}$ (L. acidophilus, S. faecium, Bifidobacterium thermophilum and B. longum). Another study reported no effect on Salmonella spp. shedding when a commercial preparation of $5 \times 10^{9} \mathrm{CFU} / \mathrm{g}$ of L. lactis and E. faecium and $1 \times 10^{9} \mathrm{CFU} / \mathrm{g}$ of live yeast culture was administered to hospitalized horses with colic (Kim et al. 2001). While both of these studies utilized different species at different dosages, there is insufficient research available on appropriate dosages needed for efficacy.

\section{FERMENTATION}

Physiology of Fermentation

No mammal secretes enzymes capable of breaking down the complex molecules of cellulose, hemicellulose, pectin, fructo- and galactic-oligosaccharides and lignin into components suitable for absorption (Frape, 2004). With the exception of lignin, fermentative digestion by the normal flora allows these substrates to become available for 
glandular digestion by the host. Bacteria perform anaerobic fermentation of the sugars released from the hydrolysis of these polymers for cellular maintenance and for the increase of biomass or 'microbial growth.' Microbial growth is directly correlated with substrate availability (Todar, 2005). This must be kept in the mind of nutritionists when formulating diets for livestock as the nutrient needs of the normal flora must also be met in addition to the needs of the host animal.

The principal end-products of anaerobic fermentation are amino acids (arginine, cysteine, and glutamine), short chain fatty acids (SCFA: acetate, propionate, and butyrate), carbon dioxide $\left(\mathrm{CO}_{2}\right)$, methane $\left(\mathrm{CH}_{4}\right)$, ammonia $\left(\mathrm{NH}_{3}\right)$ and hydrogen $\left(\mathrm{H}_{2}\right)$ gases (Cummings et al., 1987; Dunne et al., 2001). Pyruvate originated from glycolysis is eventually metabolized to organic acids such as VFA and lactate. The fermentation of sugars and metabolism of pyruvate are accompanied by the production of hydrogen. Most of the hydrogen is used in the reduction of $\mathrm{CO}_{2}$ to $\mathrm{CH}_{4}$ (Nagaraja et al., 1997).

\section{Pathways of Fermentation}

The elucidation of the glycolytic pathway, the process whereby glucose is converted into pyruvate and adenosine triphosphate (ATP), began in 1860 when Louis Pasteur observed that microorganisms were responsible for fermentation. Building on a series of preceding initial observations, the complete glycolytic pathway was constructed by 1940 by the combined efforts of several scientists, most notably Otto Fritz Meyerhof (Kresge et al., 2005). ATP, consisting of an adenine, a ribose, and a triphosphate unit, is the currency of cell metabolism, acting as the free-energy donor in most energy-requiring 
processes in the body such as physical motion, active transport, or biosynthesis. ATP was first discovered in 1934, by Kurt Lohmann in Meyerhof's laboratory.

The two most common pathways explaining bacterial fermentation are the Embden-Meyerhof pathway and the tricarboxylic acid (TCA) cycle (also known as the citric acid cycle or the Kreb's cycle). The Embden-Meyerhof, also commonly referred to as the glycolysis pathway, yields two moles of pyruvate and two moles of ATP per mole of glucose metabolized. Pyruvate is the central intersection in fermentative pathways and its fate is variable. If oxygen is available, pyruvate is converted into acetyl-coenzyme A, which is then oxidized completely in the TCA cycle. If oxygen is not available, pyruvate is broken down anaerobically, creating lactic acid in animals and ethanol in plants (Berg et al., 2001).

\section{Volatile Fatty Acids}

The principal end-products of carbohydrate fermentation are volatile fatty acids (VFA). Tappeiner (1882-1884) first elucidated that ruminant microorganisms produced fatty acids as a result of cellulolytic fermentation. Elsden et al. (1946) demonstrated that VFA concentrations are associated with microbial numbers in the rumen, which indicates fermentation of plant structural and non-structural carbohydrates. McClymont (1952) found that acetic acid comprised a higher proportion of total VFA in ruminants with fibrous diets and explained that there were differences in the utilization of energy from roughages as compared to concentrate diets. 
VFA include formic, acetic, propionic, isobutyric, butyric, isovaleric, valeric, 2methylbutyric, hexanoic, and heptanoic acids. VFA are considered "volatile" due to their size, because they are small gas molecules, six carbons or smaller. In studies where gaseous emissions are analyzed from manure slurries, rapid decomposition of VFA is shown to occur when air passes through waste samples (Cooper and Cornforth, 1978). The principal VFA produced in the rumen and the hindgut of monogastrics are acetate, propionate, and butyrate where the relative proportions are similar across species (Elsden et al., 1946). The ratio of acetate, propionate and butyrate produced are influenced by the diet where ratios of 70:20:10 are associated with forage-based diets and ratios of 50:40:10 are associated with grain-based diets (Leng, 1970; Zani et al., 1974; SicilianoJones and Murphy, 1989). Ultimately, a change in diet composition would not only alter the microbial population, but also change the concentration and ratio of VFA produced.

Barcroft et al. (1944) demonstrated that VFA absorbed in the rumen and the omasum are the main energy source for ruminants. Bergman (1990) outlined that VFA provide $70 \%$ of caloric requirements in ruminants, approximately $10 \%$ in humans, and around $20-30 \%$ in other omnivorous and herbivorous species. While early research suggested that propionate was used more efficiently (McClymont, 1952; Annison and Armstrong, 1970), it is now believed that energy from all VFA are used with similar efficiency (Orskov et al., 1979, 1991). The VFA are absorbed by the organs in which they are produced, evidenced by concentrations in blood leaving these organs (Barcroft et al., 1944). It was first determined by Elsden et al. (1945) that hindgut fermenters such as horses, swine, rabbits and rats, that VFA are mostly produced and absorbed in the colon 
and cecum. Acetic acid is used by peripheral tissues, especially fat and muscle (Bergman, 1990). Butyric acid is metabolized by intestinal epithelial before being released into portal blood circulation (Bergman, 1971; Kristensen and Harmon, 2004). Propionate is quantitatively the most important single precursor of glucose synthesis (Bergman, 1983; Reynolds et al., 1989).

\section{Lactate}

Aside from VFA, another organic acid, lactic acid, is a common end-product of microbial fermentation and most notably found as a result of feeding horses rapidly fermentable carbohydrates. Under anaerobic conditions, pyruvate is reduced by lactate dehydrogenase to form lactate. This reaction regenerates $\mathrm{NAD}^{+}$(nicotinamide adenine dinucleotide), which allows glycolysis and ATP production to continue (Berg et al., 2001). Lactate, or 2-hydroxypropanoate, was discovered in 1780 by a Swedish chemist, Scheele, who isolated it from sour milk. Lactate is the simplest hydroxycarboxylic acid and exists as 2 stereoisomers (D and $\mathbf{L}$ ). Typically, an enantiomer that rotates light in the clockwise direction is called $\mathbf{D}$, for dextrarotary, and the entantiomer that rotates light counterclockwise is called $\mathbf{L}$, for levorotary. Lactate has a pKa of 3.86 and dissociates freely, yielding a lactate ion to lactate acid ratio of 3000:1 (depending on $\mathrm{pH}$ ). Normal serum lactate is considered entirely L-lactate, which is readily metabolized by liver and heart tissue (Owens et al., 1998). The D-lactate is not well metabolized by mammals due to a lack of D-lactate dehydrogenase, and is therefore metabolised at about one-fifth the rate of L-lactate (Tubbs, 1965) and excreted in the urine (Medzihradsky and Lamprecht, 1966). 
Animals can be exposed to abnormally large quantities of rapidly fermentable carbohydrate during times of high energy needs, such as entry into a feedlot scenario, switching from a bulk diet to a concentrate diet, a quick change in feeds due to performance requirements, exposure to lush or spring pasture for grazing, poor feeding practices, etc. When this happens, a chain reaction begins, where rapid amylolytic fermentation of starches and sugars is turned to glucose. Streptococcus bovis, an inefficient microbe that thrives only in the presense of glucose, begins to produce lactic acid through a process known as lactic acid fermentation. This is principally identified by a low $\mathrm{pH}$, which favors the rapid growth of more lactic acid producing bacteria, such as lactobacilli, and other opportunitistic microbes, including those that decarboxylate amino acids and produce endotoxins or amides (Slyter, 1976; Bailey et al., 2001 and 2002). Owens et al. (1998) noted the high correlation between carbohydrate in the diet and lactic acid concentrations. The combination of low $\mathrm{pH}$ and increased lactic acid results in digestive disturbances with serious concequences to health, performance and well-being of the host animal.

Different species are involved in the fermentation and utilization of lactic acid. Homolactic fermentation performed by Lactobacillus and Streptococci species produce lactic acid. Whereas Propionibacterium and Bifidobacterium both utilize lactic acid and produce propionic acid, acetic acid, and $\mathrm{CO}_{2}$. Furthermore, Enterobacteria execute a mixed acid fermentation that produces a mixture of lactic acid, acetic acid, formic acid, succinate, ethanol and $\mathrm{CO}_{2}$ and $\mathrm{H}_{2}$ gases. Clostrida manufactures butyric acid, acetic 
acid, $\mathrm{CO}_{2}$ and $\mathrm{H}_{2}$ from the fermentation of sugars (Hobson and Stewart, 1997; Moat, 2002).

pH and Acidosis

The process of fermentation lowers the $\mathrm{pH}$ in the colon, due to production of VFA and lactic acid. These acids are absorbed passively across intestinal epithelium against a concentration gradient or osmotic pressure. When high concentration of VFA and lactate are absorbed into tissues lactic acidosis occurs (Koers et al., 1976; Slyter, 1976). Acidosis is the decrease in body fluid $\mathrm{pH}$ (Stedman, 1982). An organism regulates changes in $\mathrm{pH}$ by secreting bicarbonate $\left(\mathrm{HCO}_{3}{ }^{-}\right)$, which serves to neutralize a low $\mathrm{pH}$, maintaining blood pH at 7.4 (Berg et al., 2001). However, during metabolic acidosis, the blood pH falls below 7.35 (Owens et al., 1998). A lowered gut $\mathrm{pH}$ environment favors the growth of species such as Streptococcus bovis and L. acidophilus. In the horse, low hindgut $\mathrm{pH}$ decreased numbers of cellulolytic and hemicellulolytic bacteria (Garner et al., 1978, Goodson et al., 1988; Medina et al., 2002), which significantly decreased forage utilization (Karlsson et al., 2000; McLean et al., 2000; Drogoul et al., 2001). A neutral fecal $\mathrm{pH}$ around 7.0 in the horse is known to support fiber digestion (Hungate, 1966; Hussein et al., 2004), however a cecal pH drop from 6.7 to 6.4 was due to altered fermentation patterns and microbial ecology in the hindgut of the horse fed high-starch concentrates (de Fombelle et al., 2001; Julliand et al., 2001; Medina et al., 2002). In ruminants, lowered rumen $\mathrm{pH}$ of 5.6 to 5.2 is the benchmark used for acidosis (Cooper and Klopfenstein, 1996). 
Streptococcus bovis and lactobacilli, both lactate producing bacteria, have been attributed as the reason for anaphylactic shock and sudden death in cattle (Owens et al., 1998). It has been suggested that inoculation with lactic acid utilizing bacteria, that could withstand low $\mathrm{pH}$, could be used to prevent acid accumulation (Martin and Streeter, 1995; Owens et al., 1998).

\section{A THEORY ON STARCH}

\section{The Domino Effect}

Horses under the stress of certain exercise and production programs require higher energy and nutrient requirements than what can be met by forage alone (NRC, 2007). Concentrate diets are often fed to meet those additional needs. Unfortunately, a rapid intake of large amounts of starch can escape digestion and enter the hindgut of the horse (Clarke et al., 1990; Kienzle, 1994; Rowe et al., 1994; Hussein et al. 2004). Hindgut fermentation of starch creates environments that can result in colic (King, 1999; de Fombelle et al., 2001) and laminitis (Garner et al., 1977; Sprouse et al., 1987; Mansmann and King, 2000). Equine intestinal disorders in the United States have an estimated annual cost of $\$ 115,300,000$ to horse owners (Traub-Dargatz et al., 2001). The most common cause of colic is 'unknown,' followed by gas colic and feed-related factors (National Animal Health Monitoring System, USDA: APHIS 2001).

Changes in the diet can affect the chemistry (profile of fermentation endproducts) and profile microbial populations in the digestive tract (Maki and Foster, 1957; Bryant and Robinson, 1961; Kern et al., 1973; Leedle et al., 1982; Goodson et al., 1988). 
Essentially, as Frape (2004) outlined in horses and Krehbeil et al. (2003) explained in cattle, a chain reaction occurs when a high starch diet is fed. The grain enters the gastro intestinal tract where microbes begin to ferment the feed. The starch digesting amylolytic organisms will predominantly ferment the high starch feedstuffs and produce lactic acid more rapidly than what can be absorbed by the animal. This accumulation of lactic acid in the cecum causes the $\mathrm{pH}$ to become more acidic and Streptococcus bovis proliferates (Nordlund et al., 1995; Owens, 1998). The acidic environment inhibits fiber-digesting bacteria (Medina, 2002). An over-population of $\mathrm{LAB}$ decreases $\mathrm{pH}$, fiber digestion, and VFA production (Pagan, 1998; Kohnke et al., 1999) and has the potential to release endotoxins (Sprouse et al., 1987, Clarke et al., 1990). Ultimately, these changes can cause acidosis, colic, and/or endotoxemia that can lead to laminitis or even instant death (Glock and DeGroot, 1998).

Feeding $3.5 \mathrm{~g}$ of starch per kilogram BW exceeds the capacity of the small intestine to digest starch and allows non-degraded particles to escape and reach the cecum (Potter et al., 1992) where it disturbs the normal flora and their activity. A key strategy to limit the negative consequences of cereal-based diets is to increase starch digestion in the small intestine by providing exogenous sources of amylase through DFM to manipulate the microbial activities of the intestinal ecosystem (Kienzle, 1994). In cattle, feeding L. acidophilus alone decreased the severity of sub acute acidosis (Huffman et al., 1992). They suggested that $5 \times 10^{8} \mathrm{CFU} / \mathrm{d}$ in feedlot cattle reduced the amount of time that ruminal $\mathrm{pH}$ was below 6.0 compared with the control. Similarly, Van Koevering et al. (1994) reported that ruminal concentrations of D-Lactate and total lactate 
were lower in steers fed L. acidophilus. Ghorbani et al. (2002) reported that a top-dress DFM treatment containing E. faecium at $1 \times 10^{9} \mathrm{CFU} / \mathrm{g} / \mathrm{hd} / \mathrm{d}$, decreased the risk of acidosis in feedlot cattle. These studies suggest that offering LAB increases the enzymatic break-down of starch and reduces the negative risks associated with highstarch concentrates. 


\title{
CHAPTER 3
}

\section{VIABILITIY OF LACTIC ACID BACTERIA IN ANIMAL} FEED AFTER PELLETING AND STORAGE

\author{
(Manuscript 1)
}




\title{
VIABILITIY OF LACTIC ACID BACTERIA IN ANIMAL FEED AFTER PELLETING AND STORAGE ${ }^{1}$
}

\author{
K. L. Swyers", C. R. Angel", A. O. Burk", E. M. Ungerfeld", \\ L. W. Douglass", K. L. Poorman ${ }^{\star}$, and R. V. Kapadia ${ }^{\dagger}$ \\ *University of Maryland, College Park, MD, * Star-Labs Forage Research, Inc, \\ Clearwater, FL, ${ }^{\dagger}$ Cargill Animal Nutrition, Innovation Center, Elk River, MN
}

\begin{abstract}
Two experiments were conducted to determine the effects of feed processing and storage on the viability of a commercial lactic acid bacteria (LAB) based direct-fed microbial (DFM) and to validate an alternative enumeration method (SL-01) for the determination of LAB colony forming units (CFU). In Exp. 1, one of three levels of DFM inclusion was added during mixing to a basal broiler diet, and then pelleted. The three treatments in Exp. 1 were: 0 DFM (CON), $0.91 \mathrm{~kg} /$ ton DFM (PRIM2), or $1.36 \mathrm{~kg} /$ ton of a DFM (PRIM3). Two batches were made of PRIM2 and PRIM3 and one of CON. Samples were taken during feed processing from mixed mash, hot conditioner mash $\left(93^{\circ} \mathrm{C}\right)$, and cooled pellets. Feed samples were enumerated for lactobacilli by two labs (LOC1 and LOC2) using two methods (SL-01 and AOAC 14.1: 1995). In Exp. 1, there was no effect of level of DFM inclusion or processing on mean viable lactobacilli CFU. There was also no difference in mean lactobacilli counts between AOAC and SL-01 enumeration methods. When only the SL-01 method was performed, LOC1 tended to report higher $(P$ $=0.09$ ) lactobacilli counts than LOC2. Differences between the labs and methods were also plotted and regressed on mean counts where two-thirds of all differences fell within 1 standard deviation of zero, indicating no difference between methods. In Exp. 2, separate batches of animal feed were pelleted and warehoused for 12 weeks. Weekly
\end{abstract}


samples were collected from batches containing either: no added lactic acid bacteria $(\mathrm{CON}), 1.36 \mathrm{~kg} /$ ton of single strain DFM (SS), or $1.36 \mathrm{~kg} /$ ton of a mixed strain DFM (MIX). Samples were analyzed for viable lactobacilli, enterococci and bifidobacteria CFU. Viable lactobacilli counts were not affected by treatment or time. Viable enterococci and bifidobacteria counts were different in CON, SS and MIX over time (treatment $\mathrm{x}$ time interactions; $P=0.02$ and $P<0.001$ respectively). The LAB used in these experiments remained viable and incurred minimal loss in CFU during feed processing and storage. The SL-01 method is adequate for routine enumeration of LAB. However, ribosomal DNA identification of bacteria in CON from Exp. 2 indicated that naturally-occurring bacterial species were also enumerated. Therefore, more specific enumeration methods that exclude naturally-occurring organisms are needed in order to evaluate added DFM numbers.

Key Words: Direct-fed Microbials, Lactic Acid Bacteria, Pelleting, Probiotics, Viability

\footnotetext{
${ }^{1}$ The authors thank the team at Cargill Animal Nutrition for their collaboration on the study, in addition to laboratory analysis, contribution of the pelleted animal feed, and financial contribution. We thank the team at Star-Labs for donating all strains of DFM for both experiments, laboratory analysis and financial contribution. Counsel from Dr. Scott Weese is gratefully acknowledged.
}

\section{INTRODUCTION}

Probiotics, also referred to as "direct-fed microbials" (DFM), are feed additives that show potential for increased performance and health in production livestock and companion animal species (Krehbeil et al., 2003). Probiotics are defined as a source of 
live, naturally occurring microorganisms (bacteria and/or yeast) that once fed, enhance intestinal microbial balance and digestive health in the host (Fuller, 1989; Yoon and Stern, 1995). While DFM are generally regarded as safe (GRAS; FDA, 1995), reports of substandard quality control have increased concern over the integrity of commercial DFM preparations intended for animal use. In particular, a significant percentage of commercial products tested did not contain either the species, number, or purity of organisms stated on the label (Gilliland and Speck, 1977; Canganella et al., 1997; Hamilton-Miller et al., 1999; Hamilton-Miller and Shah, 2002; Weese and Arroyo, 2003; Coeuret et al., 2004; Drisko et al., 2005). In addition, no studies report the viability of lactic acid bacteria (LAB) used in DFM preparations in animal feed before and after pelleting or through a period of storage. Before in vivo dosage and efficacy trials can be conducted, organisms intended for DFM application must first demonstrate the ability to survive the stress of feed processing and storage.

Two experiments were conducted. The objectives of the first were to determine if lactobacilli would remain viable during feed processing and to validate a novel enumeration method used in a commercial lab. In the second experiment, the aim was to determine the viability of lactic acid bacteria in pelleted animal feed during summer storage. 


\section{MATERIALS AND METHODS}

\section{Experiment 1}

Feed Processing and Sampling. In a completely randomized 3x3 replicated (batches) design, five batches of pelleted feed were made at the United States Department of Agriculture's Beltsville Agricultural Research Center (USDA, BARC, Beltsville, MD) feed mill. The batches were made in the following order: one batch containing no lactic acid bacteria $(\mathrm{CON})$, two batches containing $0.91 \mathrm{~kg} /$ ton of commercially prepared lactic acid bacteria (PRIM2; PrimaLac 454 Feed Grade; Star-Labs, Clarksdale, MO), and two batches containing $1.36 \mathrm{~kg} /$ ton of the same commercially prepared lactic acid bacteria (PRIM3). Each $181 \mathrm{~kg}$ batch consisted of a broiler basal formula (Table 1) used always at $99.85 \%$ of total mixed ration (TMR), LAB added to target inclusion (as discussed above), and Celite®545 (Mallinckrodt Baker, Inc., Phillipsburg, NJ 08865) which was used as a filler to achieve $100 \%$ of TMR.

Batches were mixed in a small batch mixer (horizontal Kelly Duplex, $500 \mathrm{lb}$ mixer, Kelly Duplex Mill \& Manufacturing Co, Springfield, OH) for 10 min, then 10-12 grab samples were taken at the end of each batch mix and sub samples were mixed together. Batches were then augured to the pellet mill where average conditioner temperature was $93^{\circ} \mathrm{C}$. The batches were run at conditions normally used at this plant (2ton run, $82.2^{\circ} \mathrm{C}$ and $20 \mathrm{~s}$ conditioner temperature and time) with a pelleting rate of 22 min/ton (California Pellet Mill Co., Merrimack, NH). Two random grab samples of hot conditioner mash were taken at the hatch between conditioner and pellet die, cooled and mixed. Hot pellets were extracted from the collection flew just below the pellet die to 
determine average pelleting exiting temperatures from the pellet die at 1,3 and 5 min intervals into the run. Temperatures were recorded (Non-Contact Thermometer model \#42529, Extech Instruments, Waltham, MA) and pellets added back into batch. After drying, the pellets moved to a cooler and were allowed to cool for 20 min with forced air within 14 degrees of ambient temperature. Final cooled pellet samples were taken at bagging.

Samples collected were stored in a cooler $\left(4^{\circ} \mathrm{C}\right)$ for four days until they were subsampled in the following order (from lowest expected bacterial inclusion to the highest): CON pellet, CON mash after conditioner, CON mash mix, PRIM2 pellet, PRIM2 mash after conditioner, PRIM2 mash mix, PRIM3 pellet, PRIM3 mash after conditioner, then PRIM3 mash mix. Each sample was spread onto a clean paper sheet where grid lines (3 lateral and 3-4 vertical) were drawn into the sample. Random scoops were taken from the grid pattern to get a representative sub-sample. The sub-samples were collected in triplicate, placed into an air-tight plastic bag, weighed and blindly assigned to a number 1 through 30. Blind assignments were recorded and handled by a technician not involved in microbial count assays. Three sets of samples were made, sorted and shipped overnight in coolers to two different labs for microbial count analysis, and one set retained for back-up. The samples sent to each lab were stored at $4^{\circ} \mathrm{C}$ until enumeration took place.

DFM. The MIX preparation of DFM (PrimaLac 454 Feed Grade, Star-Labs, Clarksdale, MO) contained four species of lactic acid producing bacteria: Lactobacillus acidophilus, L. casei, Bifidobacterium bifidium, and Enterococcus faecium, plus rice 
hulls and calcium carbonate as carriers. The preparation was guaranteed by the manufacturer to contain a minimum of $1.0 \times 10^{8} \mathrm{CFU} / \mathrm{g}$. The manufacturer recommended an inclusion of 0.91 to $1.36 \mathrm{~kg}$ of PrimaLac per ton of TMR.

AOAC Colony Count Method. A set of 30 blind samples were shipped to a commercial lab (LOC1; Cargill Innovation Center, Elk River, MN) for determination of Lactobacilli spp. CFU using an Association of Official Analytical Chemists method (AOAC 14.1:1995 Enumeration of Lactic Acid Bacteria: Colony Counting Technique). The CFU were determined by plating samples on MRS media (de Man, Rogosa and Sharpe, 1960) for determination of Lactobacillus growth. Pelleted feed samples were individually ground using a commercial coffee grinder until samples were of meal consistency ( $\sim 3 \mathrm{~mm})$. One gram of ground sample was added to $99 \mathrm{ml}$ of autoclaved $\mathrm{dH}_{2} \mathrm{O}$ and vortexed. Five dilutions of the mixture were prepared for each sample; the first dilution $\left(10^{2}\right)$ consisted of $1 \mathrm{~g}$ of ground sample in addition to $99 \mathrm{ml}$ of distilled, autoclaved $\mathrm{H}_{2} \mathrm{O}$ in $15 \mathrm{ml}$ centrifuge tubes. For the second dilution $\left(10^{4}\right), 1 \mathrm{ml}$ from $10^{2}$ dilution was pipetted into a separate tube, in addition to $99 \mathrm{ml}$ of $\mathrm{H}_{2} \mathrm{O}$ and so on through $10^{8}$ dilution, where the final $10^{9}$ dilution only consisted of $500 \mu 1$ transferred from the previous. The five dilutions $\left(10^{2}\right.$ to $\left.10^{9}\right)$ were mixed on a rotary shaker at low speed for 1 $\mathrm{h}$ at room temperature. Then, $50 \mu 1$ of each dilution were drawn and plated using a spiral autoplater (AutoPlate 4000, Spiral Biotech Inc., Norwood, MA). The Lactobacilli cultures were grown inverted under anaerobic conditions (anaerobic jars with GasPaks; Becton Dickinson Microbiology Systems, Cockeysville, MD), incubated for $48 \mathrm{~h}$ at $37^{\circ} \mathrm{C}$, on MRS (de Man, Rogosa and Sharpe, 1960) agar. Once growth was visualized, 
numbers of CFU were determined by an automated colony counter (ProtoCOL XR, Protocol Systems, Synoptics Ltd, Cambridge, UK) and numbers were reported as CFU/g.

SL-01 Colony Count Method. A second set of 30 blind samples was shipped to another commercial lab (LOC2; Star-Labs Forage Research, Inc., Clearwater, FL) for determination of Lactobacilli spp. CFU by using the alternative SL-01 method, currently used at Star-Labs for enumeration of LAB cultures. Both LOC1 and LOC2 conducted the following SL-01 method to compare to the AOAC results reported by LOC1. First, samples were individually ground using a commercial coffee grinder until they were of meal consistency $(\sim 3 \mathrm{~mm})$. Ground samples of $25 \mathrm{~g}$ were weighed and placed in a plastic, sealed bag and heat treated in a convection oven at $60^{\circ} \mathrm{C}$ for $2 \mathrm{hrs}$ prior to analysis. This step is designed to eliminate any actively growing bacteria that may be present, as it is assumed the PrimaLac probiotic is in a dormant state, and can survive $60^{\circ} \mathrm{C}$ for $2 \mathrm{~h}(\mathrm{~K}$. Poorman, personal communication). A triplicate plating scheme was used for determination of lactobacilli species. The first dilution $\left(10^{2}\right)$ consisted of $1 \mathrm{~g}$ of heated meal added to $99 \mathrm{ml}$ of distilled water (Biotrace International Bio Products pre-filled sterile dilution bottles with Butterfield's phosphate) and $0.1 \mathrm{~mL}$ of Tween 80 (Mallinkrodt Inc., St. Louis, MO). Samples were mixed for $18 \mathrm{~h}$ at room temperature on rotary shaker at slow speed. Using a blender (Osterizer Galaxie Pulse Matic I6, Sunbeam, Purvis, MS), samples were then mixed in a sterilized jar (eg. Mason canning jar) for $30 \mathrm{~s}$ on the "stir" setting. The next four dilutions were prepared using serial 100 fold dilutions. Samples were plated in triplicate, $1.0 \mathrm{~mL}$ from all dilutions plus an 
additional $0.1 \mathrm{~mL}$ from the $10^{8}$ dilution, creating a final dilution series from $10^{2}$ through $10^{9}$.

At LOC1, $50 \mu 1$ of each dilution were drawn and plated by a spiral autoplater (AutoPlate 4000, Spiral Biotech Inc., Norwood, MA) and used to inoculate MRS agar. Cultures were grown inverted under anaerobic conditions (anaerobic jars with GasPaks; Becton Dickinson Microbiology Systems, Cockeysville, MD), incubated for $48 \mathrm{~h}$ at $37^{\circ} \mathrm{C}$. Once growth was visualized, $\mathrm{CFU}$ were determined by an automated colony counter (ProtoCOL XR, Protocol Systems, Synoptics Ltd, Cambridge, UK) and numbers were reported as $\mathrm{CFU} / \mathrm{g}$.

At LOC2, $1 \mathrm{~mL}$ of each dilution was inoculated into MRS agar (Biotrace International BioProducts Bothell, WA) using a pour plate technique. Lactobacillus cultures were grown under anaerobic conditions (Mitsubishi Rectangular 7L Jar No. 5070) and incubated inverted for $48 \mathrm{~h}$ at $42^{\circ} \mathrm{C}$. Once growth was visualized, the number of CFU was counted by hand on plates containing between 30 and 300 colonies, and numbers were reported as $\mathrm{CFU} / \mathrm{g}$.

\section{Experiment 2}

Feed Processing and Sampling. In a completely randomized design, three treatments were assigned to one of three batches of pelleted feed made at a commercial feed mill (Cargill Animal Nutrition, Lebanon, PA). Although there was no statistical difference between DFM inclusion levels from the results in Exp. 1, we chose the higher 
$(1.36 \mathrm{~kg} / \mathrm{ton})$ inclusion level for Exp. 2. First, a separate multi-ton bulk ration unrelated to the study, but containing no DFM, was run through the pellet mill as the mill's standard operating procedures for "flushing" between runs. Then, the study batches were made in the following order: one containing no lactic acid bacteria $(\mathrm{CON})$, one batch containing $1.36 \mathrm{~kg} /$ ton of single strain L. acidophilus (SS; custom preparation provided by Star-Labs, Clarksdale, MO), and one batch containing $1.36 \mathrm{~kg} /$ ton of a mixture of $L$. acidophilus, L. casei, B. bifidium, and E. faecium (MIX; PrimaLac 454 Feed Grade; StarLabs, Clarksdale, MO). Batches were individually pelleted, bagged, tagged and shipped to a separate location (Clarksville, MD) where rations were warehoused on pallets and fed in an equine study (see Manuscript 2).

Weekly samples ( $200 \mathrm{~g})$ were collected directly from feed bags over a 12-wk period from June to September and retained $\left(\right.$ at $\left.4^{\circ} \mathrm{C}\right)$ for analysis of viability during storage. This was an 85-d study conducted from June to September in Clarksville, MD. The summer climate was typified by temperate, humid days with annual precipitation ranging from 88.9 to $114.3 \mathrm{~cm}$ (precipitation reported on www.weather.com for Clarksville, MD). During our investigation, average air temperatures ranged from 14 to $38^{\circ} \mathrm{C}$ (temperatures reported on www.weather.com for Clarksville, MD).

\section{Enumeration of lactic acid bacteria}

Viable CFU of the LAB were determined by LOC1 using the AOAC (AOAC 14.1:1995) method. Samples were individually ground, and then duplicate $1 \mathrm{~g}$ subsamples were weighed and placed into $15 \mathrm{~mL}$ centrifuge tubes. Nine millimeters of 
autoclaved $\mathrm{dH}_{2} \mathrm{O}$ was added to each tube, and then shaken for $1 \mathrm{~h}$ to mix. One millimeter of the liquid solution was drawn into $15 \mathrm{~mL}$ centrifuge tubes, $9 \mathrm{~mL}$ of distilled, autoclaved $\mathrm{H}_{2} \mathrm{O}$ was added, the solution was vortexed, and then plated by a spiral autoplater (Autoplater 4000, Spiral Biotech). Three plates were prepared for each sample to determine growth of (1) Lactobacillus (2) Enterococcus, and (3) Bifidobacterium. The lactobacilli and bifidobacteria cultures were grown under anaerobic conditions (anaerobic jars with GasPaks; Becton Dickinson Microbiology Systems, Cockeysville, MD), incubated for $48 \mathrm{~h}$ at $37^{\circ} \mathrm{C}$, on MRS agar (de Man, Rogosa and Sharpe, 1960) and modified MRS (mMRS; Simpson et al., 2003) respectively. Enterococcus cultures were grown aerobically on bile esculin azide (BEA; Thomas et al, 2004) agars then incubated for $48 \mathrm{~h}$ at $37^{\circ} \mathrm{C}$. Once growth was visualized, $\mathrm{CFU}$ were determined by an automated colony counter (Protocol XR, Protocol Systems, Synoptics LTD) and numbers were reported as $\mathrm{CFU} / \mathrm{ml}$.

\section{Bacterial species identification}

To identify bacterial species in the CON batch of feed from Exp. 1, analysis of ribosomal DNA using a RiboPrinter ${ }^{\circledR}$ was performed (DuPont Qualicon, Wilmington, DE). Bacteria were isolated and grown on MRS agar at LOC2 according to the SL-01 procedures outlined above. A random selection of colonies was picked and then identified automatically using the RiboPrinter. The RiboPrinter software automatically identifies bacterial species at an $85 \%$ confidence level or higher, in which case a DuPont identification number is assigned and reported in addition to a genus and species name. 


\section{Prevention of cross-contamination}

All pelleted concentrates were processed in the order of least number of bacterial species to most (i.e., CON, then PRIM2, then PRIM3 in Exp.1 and CON, then SS, then MIX in Exp. 2) from mixing, to pelleting, to bagging at the feed mills. Samples were also collected, handled and analyzed in the order of CON, then PRIM2, and then PRIM3 in Exp.1 and CON, then SS, then MIX in Exp. 2. Sterilization with bleach and/or acetone of lab surfaces and equipment between samples was standard procedure.

\section{Statistical Analysis}

The $\log _{10}$ CFU data from Exp. 1 were analyzed as a completely randomized $3 \times 3$ replicated (PRIM2 and PRIM3 batches were replicated, CON was not) design, consisting of two factors with three treatment levels (DFM treatment inclusion levels and feed processing sampling locations). Data were analyzed using the multiway analysis of variance MIXED procedures in SAS (SAS Inst. Inc., Cary, NC). Differences between means were detected using the PDIFF / TUKEY option of the LSMEANS statement in SAS. The model used was:

$$
\begin{aligned}
& \mathrm{Y}_{\mathrm{ijkln}}=\mu+\mathrm{T}_{\mathrm{i}}+\mathrm{B}_{\mathrm{j}}+\mathrm{P}_{\mathrm{k}}+\mathrm{LM}_{1}+\mathrm{B}_{\mathrm{j}(\mathrm{i})}+(\mathrm{B} * \mathrm{P})_{\mathrm{jk}(\mathrm{i})}+(\mathrm{T} * \mathrm{LM})_{\mathrm{il}}+(\mathrm{P} * \mathrm{LM})_{\mathrm{kl}}+(\mathrm{T} * \mathrm{P} * \mathrm{LM})_{\mathrm{ikl}}+ \\
& \varepsilon_{\mathrm{ijkln}}
\end{aligned}
$$

Where $Y_{\mathrm{ijk} k \mathrm{n}}$ is the $\mathrm{n}^{\text {th }}$ observed value of lactobacilli CFU for the $\mathrm{i}^{\text {th }}$ treatment, $\mathrm{j}^{\text {th }}$ batch, $\mathrm{k}^{\text {th }}$ processing location, $1^{\text {th }}$ lab and method; $\mu$ is the overall mean; $T_{i}$ is the fixed effect of treatment; $B_{j}$ is the random effect of batch; $P_{k}$ is the fixed effect of processing location; $\mathrm{LM}_{1}$ is the fixed effect of lab and method (LOC1 1 AOAC, LOC1 1 SL-01, and LOC2 $\mathrm{x}$ 
SL-01); $B_{j(i)}$ is the random effect of $j^{\text {th }}$ batch nested within $i^{\text {th }}$ treatment; $\left(\mathrm{B}^{*} \mathrm{P}\right)_{\mathrm{jk}(\mathrm{i})}$ is the random effect of the interaction between the $\mathrm{j}^{\text {th }}$ batch and $\mathrm{k}^{\text {th }}$ processing locations within $\mathrm{i}^{\text {th }}$ treatment; $\left(\mathrm{T}^{*} \mathrm{LM}\right)_{\mathrm{il}}$ is the interaction between $\mathrm{i}^{\text {th }}$ treatment and $\mathrm{l}^{\text {th }}$ lab and method; $\left(\mathrm{P}^{*} \mathrm{LM}\right)_{\mathrm{kl}}$ is the interaction between $\mathrm{k}^{\text {th }}$ processing location and the $\mathrm{l}^{\text {th }}$ lab and method; $\left(\mathrm{T}^{*} \mathrm{P} * \mathrm{LM}\right)_{\mathrm{iklm}}$ is the interaction between $\mathrm{i}^{\text {th }}$ treatment, $\mathrm{k}^{\text {th }}$ processing location, and the $\mathrm{l}^{\text {th }}$ lab and method; and $\varepsilon_{\mathrm{ijkln}}$ is random error.

Statistical analyses for differences between the two enumeration methods (SL-01 and $\mathrm{AOAC}$ ) and between the two labs (LOC1 and LOC2) were adapted from methods previously described by Peterson and Douglass (2005). The mean of the two enumeration methods as well as the differences between the two enumeration methods were calculated. The difference between the two methods was regressed on the average of the two method means to examine the magnitude of the response. Data were analyzed using a best fit model with GLM procedures in SAS (SAS Inst. Inc., Cary, NC). Backward elimination of non-significant $(P>0.10)$ terms was conducted. Scatter plots of the differences with best fit linear regression lines are presented.

Data in Exp. 2 were analyzed as a repeated measures (with respect to samples taken from same batches of feed over 12-week period) design using the MIXED procedure in SAS (SAS Inst. Inc., Cary, NC), using batches of feed as experimental units. A best fit multiple linear regression model with GLM procedures in SAS was performed. Backward elimination of non-significant $(P>0.10)$ terms was conducted. The model included DFM treatment, time (weeks), ambient temperature and the treatment $\mathrm{x}$ time 
interaction. Ambient temperature was used as a covariate in the model. Average CFU of lactobacilli, enterococci and bifidobacteria were the response varibles. Significance was considered at $P<0.05$, and a tendency was considered at $0.05<P<0.10$.

\section{RESULTS}

\section{Experiment 1}

During feed processing, the pelleting and drying times, plus conditioner, pellet exiting, drying and ambient temperatures were recorded and are summarized in Table 2. Only lactobacilli numbers were determined in this experiment. Results of viable lactobacilli CFU relative to level of inclusion during feed processing are shown in Figure 1. There were no significant differences detected on average viable lactobacilli counts between treatment inclusion levels (CON, PRIM2 or PRIM3) or of feed processing (from mix mash to hot conditioner to cooled pellets).

There was no difference $(P=0.17)$ in mean counts of viable lactobacilli during feed processing between the AOAC and SL-01 enumeration methods performed by LOC1 (Figure 2). However, a best-fit linear regression analysis plotting the differences of mean lactobacilli counts between methods (Figure 3$)$ suggests a difference $(P=$ 0.0003) where SL-01 produced higher counts at low average CFU and AOAC produced higher counts at high average CFU, being in agreement (zero difference) at 8.4 lactobacilli $\log _{10} \mathrm{CFU} / \mathrm{g}$. With respect to variability, the methods were also within 1 standard deviation of the mean from each other approximately $2 / 3$ of the time, which is equal to 1 magnitude (example $10^{9}$ vs. $10^{8}$ ) difference in CFU. 
When only the SL-01 enumeration method was performed, LOC1 tended to report higher $(P=0.09)$ mean counts of viable lactobacilli during feed processing compared to LOC2, particularly at the conditioner and pellet collection points (Figure 4).

Additionally, a best-fit linear regression analysis plotting the differences of mean lactobacilli counts between labs (Figure 5) indicates a difference $(P=0.002)$ where LOC1 detected higher colonies at low CFU counts and LOC2 detected higher colonies at high CFU counts, being equal (zero difference) at 8.4 lactobacilli $\log _{10} \mathrm{CFU} / \mathrm{g}$. With respect to variability, the methods are within 1 standard deviation of the mean from each other approximately $2 / 3$ of the time, which is equal to 1 magnitude (example $10^{9}$ vs. $10^{8}$ ) difference in CFU.

\section{Experiment 2}

After repeated plate growth, four data points were removed from MIX lactobacilli samples due to contamination from a rapidly growing bacterial species that produced spreader colonies on the surface of MRS plates rendering unreliable colony counting

data. Average viable lactobacilli counts were not affected by treatment $(P=0.15)$ or time $(P=0.96)$ (Figure 6a). Average viable enterococci counts differed over time among CON, SS and MIX (treatment $\mathrm{x}$ time interaction; $P=0.02$; Figure $6 \mathrm{~b}$ ): $\mathrm{CON}$ were not different $(P=0.65)$, SS increased $(P=0.07)$, and MIX decreased $(P=0.05)$ viable enterococci counts over the 12 -wk period. Average viable bifidobacteria counts were also differed over time among CON, SS, and MIX (treatment x time interaction; $P<$ 
0.001; Figure 6c): CON increased $(P=0.03)$, SS decreased $(P=0.004)$ and MIX increased $(P<0.001)$ counts in viable bifidobacteria counts over the 12 -wk period.

Enumeration data from both experiments indicated the presence of bacterial species in the controls. Identification of bacterial species, from feed samples in Exp. 2, was performed on bacterial ribosomal DNA and is reported in Table 3. No treatmenttype bacterial species contamination was found in CON.

\section{DISCUSSION}

Various studies have reported that quality control among aftermarket probiotic supplements intended for human or animal use is poor, with a significant percentage of products either not containing the organisms or numbers of organisms stated on the label, or containing additional species (Gilliland and Speck, 1977; Canganella et al., 1997; Hamilton-Miller et al., 1999; Hamilton-Miller and Shah, 2002; Weese and Arroyo, 2003; Coeuret et al., 2004; Drisko et al., 2005; Lin et al., 2005). In a study conducted by Weese and Arroyo (2003) where 19 pet food diets were analyzed for viability of the probiotic organisms listed on the label or packaging, average colony growth ranged from 0 to $1.8 \times$ $10^{5} \mathrm{CFU} / \mathrm{g}$ in 5 of the products. The authors of that study concluded that misrepresentation of DFM on the labels of commercial products was apparent. Additionally, after obtaining sub-standard results from the evaluation of probiotic viability in 21 supplements, 15 foods, and 8 'health-care' products intended for humans, Hamilton-Miller et al. (1999) concluded that inconsistencies in quality control has public 
health implications. These authors suggested that improvements are needed in labelling and quality assurance procedures for products containing probiotic organisms.

The most-used bacteria in commercial DFM preparations intended for animals are lactic acid producing bacteria (LAB), namely of the Lactobacillus genus (Kung, 1999; Weese, 2001; Krehbiel et. al., 2003). For that reason, we chose to base both experiments in this study around the viability of L. acidophilus. In the first experiment, we wanted to determine the concentration of viable lactobacilli before, during and after the feed milling process as a means for determining the survivability of LAB in a commercially prepared DFM. Results from this experiment were to aid in determination of inclusion rates ( 0.91 $\mathrm{kg}$ vs. $1.36 \mathrm{~kg} / \mathrm{ton}$ of PrimaLac) needed to accomplish target CFU dosage intended for equine diets used in a companion application study (see Manuscript 2). In humans, a dose of $1 \times 10^{8} \mathrm{CFU} / \mathrm{d}$ to $1 \times 10^{10} \mathrm{CFU} / \mathrm{d}$ has been used as a recommendation for minimum therapy (Kailasapathey and Chin, 2000). Weese (2001) extrapolated from human dosages that an average horse $(\sim 450 \mathrm{~kg})$ would likely require at least $1 \times 10^{9}$ $\mathrm{CFU} / 50 \mathrm{~kg} \mathrm{BW} / \mathrm{d}$ to $1 \times 10^{11} \mathrm{CFU} / 50 \mathrm{~kg} \mathrm{BW} / \mathrm{d}$ of an organism that is able to colonize the intestinal tract. While the digestive physiologies of humans and horses are quite different, it is at least a reference point from which to start future dosage trials. The preparation of DFM was guaranteed by the manufacturer to contain a minimum of $1.0 \mathrm{x}$ $10^{8} \mathrm{CFU} / \mathrm{g}$ and was recommended to be included in the feed at a rate of 0.91 to 1.36 $\mathrm{kg} / \mathrm{ton}$. Because no difference was found in viable $\mathrm{CFU}$ in the pelleted feed between either inclusion levels of 0.91 to $1.36 \mathrm{~kg} /$ ton suggested that either level would be adequate in achieving a $1.0 \times 10^{8} \mathrm{CFU} / \mathrm{g}$ target dosage. 
The optimum temperature for pelleting starch-based animal feeds is considered to be approximately $82^{\circ} \mathrm{C}$ with $16-17.5 \%$ moisture, which accomplishes gelatinization of starches to serve as a binder for pellet durability (AFIA, 1994) and is effective in eliminating naturally occurring pathogenic bacteria (Furuta et al., 1980). It is essential that LAB applied to batches of animal feed before pelleting be able to survive those temperatures intended to destroy pathogenic bacteria. In Exp. 1, where conditioner and pellet die temperatures exceeded $82^{\circ} \mathrm{C}$, the lactobacilli remained viable and incurred minimal-to-no loss during feed processing. The lactobacilli used in the commercial DFM product used in this study demonstrated the ability to withstand the $\sim 93^{\circ} \mathrm{C}$ and $\sim 84^{\circ} \mathrm{C}$ heat stress of the conditioner and pellet die respectively. This is in contrast to a previous study (Biourge et al., 1998) where inclusion of a lactic acid bacterium was tested in dog food and incurred a $>99 \%$ loss of viable organisms following extrusion, however temperatures during feed processing and extrusion were not reported.

We were also interested in validating the SL-01 enumeration method performed by Star-Labs for commercial quality control purposes. For the purpose of method validation, LOC1 compared the AOAC against the SL-01 enumeration method where differences in lactobacilli CFU were quantified. While the regression analysis (Figure 3) is difficult to explain biologically, the data suggests that these methods are not in absolute agreement except at a range of values around $8.4 \log _{10} \mathrm{CFU} / \mathrm{g}$. Numerical differences suggest that the SL-01 may underestimate CFU. However, because the majority of the time, there is less than a 10 -fold difference in CFU between the two enumeration methods, the SL-01 method is adequate when compared to those results from the AOAC. 
For the purpose of repeatability, two labs conducted the SL-01 enumeration method on feed samples submitted blindly. On the average LOC1 tended $(P=0.09)$ to report higher counts of viable lactobacilli than LOC2 from feed samples taken during feed processing. These differences could be attributed to the different temperatures used during incubation of inoculated plates, where LOC1 incubated at $37^{\circ} \mathrm{C}$, whereas LOC2 incubated at $42^{\circ} \mathrm{C}$. This suggests that the $37^{\circ} \mathrm{C}$ incubation temperature used by LOC1 may be better for the growth of lactobacilli. It is also worth noting that because LOC1 used an automated counting method for determination of CFU whereas LOC2 counted manually, it may have resulted in greater visualization of smaller colonies not otherwise seen by manual determination. The linear relationship of the differences between the lactobacilli numbers reported by the two labs suggests that the automated counter at LOC1 detected more colonies when the average CFU count was toward $\sim 1.0 \times 10^{8}$ $\mathrm{CFU} / \mathrm{g}$. In contrast, it could be said that LOC2 was better able to discern between colonies on highly populated plates because LOC2 reported higher counts when the average CFU was toward $6.31 \times 10^{8} \mathrm{CFU} / \mathrm{g}$. Goss et al. (1973) compared manual and automated colony counting techniques and found that the automated counter had greater variability at higher manual colony counts. They attributed this discrepancy to the automated counter's inability to ascertain between colonies when they were dense and in close proximity on the surface of highly populated plates. This is likely the case with the automated counter used at LOC1 also. 
In the second experiment, we wanted to determine the concentration of viable lactobacilli, enterococci, and bifidobacteria in stored animal feed during summer storage. The 12-week length of the experiment was determined by the time needed to conduct a companion study where the inoculated feed was offered to equine for determination of in vivo effects (see Manuscript 2). The Lactobacillus spp. used in the commercial DFM used in this study remained viable and numbers were unchanged over the 12-week period. On the other hand, while the Enterococcus spp. and Bifidobacterium spp. also remained viable, they behaved differently in the three different treatments over time. In a previous study conducted on commercial pharmaceutical products intended for humans, it was reported that preparations with a single species showed better survivability than those composed of multiple strains (Canganella et al., 1997); this suggests an inhibiting effect of multiple strain DFM preparations, which may explain the differences seen between our treatments.

The identification of naturally-occurring bacterial species in CON from Exp. 2 suggests that these non-lactobacilli species are able to grow anaerobically on MRS agar, rendering unreliable lactobacilli counting data. This represents a quality control problem, as the methods available for enumerating lactobacilli may not be specific enough. Naturally-occurring organisms probably explain the high microbial count in CON from Exp.1. Consequently, we cannot state with complete certainty that the treatment-type bacteria were viable at the guaranteed level in the commercial preparation prior to pelleting which may attribute to the lack of difference detected between treatment groups in both experiments. While there is a paucity of research conducted on presence of 
naturally-occurring microbial species in animal feeds, contamination of animal feed and of milling equipment by pathogens, E. coli and Salmonella, has been widely documented (Cox et al., 1983; Davies and Wray, 1997; Crump et al., 2002; Jones and Richardson, 2004). In a review, Maciorowski et al. (2006) discussed that animal feeds can potentially become inoculated with bacteria either during crop harvesting, processing at the feed mill or during storage. In future quality control studies and in vivo trials, we suggest more extreme measures be taken to identify and exclude the naturally occurring bacteria before enumeration of treatment-type bacteria. Sterilization of feed mill equipment and/or measures to decontaminate the finished "control" feed product might also be worth considering. For example, gamma irradiation methods used for the elimination of pathogenic bacteria in meat and poultry food products industry may be a solution (Spoto et al., 2000).

\section{IMPLICATIONS}

The Lactobacillus acidophilus, L. casei, Enterococcus faecium and Bifidobacterium bifidium in the MIX preparation remained viable in animal feed during feed processing and exhibited shelf-life during a 12-week period of storage. The SL-01 method is adequate for the routine enumeration of viable lactic acid bacteria. However, rigorous exclusion of naturally-occurring bacterial species is needed before enumeration of treatment-type bacteria is conducted. 


\section{LITERATURE CITED}

AFIA. 1994. Feed Manufacturing Technology IV. American Feed Industry Association, Inc. Arlington, VA. http://www.afia.org

AOAC. 1995. Enumeration of lactic acid bacteria: colony count technique. Method 14.1: 1995. CCFRA Microbiological Methods Manual. Official Methods of Analysis. Assoc. Off. Anal. Chem., Arlington, VA.

Biourge, V., C. Vallet, A. Levesque, R. Sergheraert, S. Chevalier, and J. Roberton. 1998. The use of probiotics in the diet of dogs. J. Nutr. 128(Suppl. 1):2730-2732.

Canganella F., S. Paganini, M. Ovidi, A. M. Vettraino, L. Vevilacqua, S. Massa and L. D. Travatelli. 1997. A microbiological investigation on probiotic pharmaceutical products used for human health. Microbiol Res. 152:171-179.

Coeuret, V., M. Gueguen, and J. P. Vernoux. 2004. Numbers and strains of lactobacilli in some probiotic products. Int J Food Microbiol. 97(2):147-56.

Cox, N. A., J. S. Bailey, J. E. Thompson, and B. J. Juven. 1983. Salmonella and other Enterobacteriaceae found in commercial poultry feed. Poult. Sci. 62(11):21692175.

Crump, J. A., P. M. Griffin, and F. J. Angulo. 2002. Bacterial contamination of animal feed and its relationship to human foodborne illness. Clin. Infect. Dis. Food Safety. 35:859-865.

Davies, R. H. and C. Wray. 1997. Distribution of salmonella contamination in ten animal feedmills. Vet. Microbiol. 57:159-169.

DeMan, J., C. M. Rogosa, and E. Sharpe. 1960. A medium for the cultivation of Lactobacilli. J. Appl. Bact. 23:130-135.

Drisko, J., B. Bischoff, C. Giles, M. Adelson, R. V. Rao, and R. McCallum. 2005. Evaluation of five probiotic products for label claims by DNA extraction and polymerase chain reaction analysis. Dig Dis Sci. Jun; 50(6):1113-1117.

Dunne, C., L. Murphy, S. Flynn, L. O’Mahony, S. O’Halloran, M. Feeney, D. Morrissey, G. Thornton, G. Fitzgerald, C. Daly, B. Kiely, E. M. M. Quigley, G. C. O’Sullivan, F. Shanahan, and J. K. Collins. 1999. Probiotics: from myth to reality. Demonstration of functionality in animal models of disease in human clinical trials. Antonie Leeuwenhoeck 76:279-292.

Dunne, C., L. O’Mahony, L. Murphy, G. Thornton, D. Morrissey, S. O’Halloran, M. Feeney, S. Flynn, G. Fitzgerald, C. Daly, B. Kiely, G. C. O’Sullivan, F. Shanahan 
and J. K. Collins. 2001. In vitro selection criteria for probiotic strains Correlation with in vivo findings. Am. J. of Cl. Nut. 73(2):386-392.

FDA. 1995. Office of Regulatory Affairs: Compliance Policy Guides. Sec. 689.100 Direct-Fed Microbial Products (CPG 7126.41). http://www.fda.gov/ora/compliance_ref/cpg/cpgvet/cpg689-100.html. Accessed Feb. 2007.

Finegold, S. M., W. J. Martin and E. G. Scott. 1978. Reagents and Tests. Page 482 in Bailey and Scott's Diagnostic Microbiology. $5^{\text {th }}$ rev. ed. CV Mosby Co., St. Louis, MO.

Fuller, R. 1989. A review: Probiotics in man and animals. J. Appl. Bacteriol. 66:365378.

Furuta, K., I. Oku, and S. Morimoto. 1980. Effect of steam temperature in the pelleting process of chicken food on the viability of contaminating bacteria. Lab Anim. 4:293-296.

Gibson, G. R., and R. Fuller. 2000. Aspects of in vitro and in vivo research approaches directed toward identifying probiotics and prebiotics for human use. J. Nutr. 130(Suppl. 1):391-395.

Gilliland, S. E. and M. L. Speck. 1977. Enumeration and identity of lactobacilli in dairy products. J. Food Prot. 40:760-762.

Gorbach, S. L. 2000. Probiotics and gastrointestinal health. Am J Gastroenterol. 95(Suppl):1-4.

Goss, W. A., R. N. Michaud, and M. B. McGrath. 1974. Evaluation of an automated colony counter. Appl. Microbiol. 27(1):264-267.

Gram, H. C. 1884. Über die isolierte Färbung der Schizomyceten in Schnitt- und Trockenpräparaten. Fortschritte der Medizin. 2:185-89.

Hamilton-Miller, J. M. T., S. Shah, and J. T. Winkler. 1999. Public health issues arising from microbiological and labelling quality of foods and supplements containing probiotic microorganisms. Public Health Nutr. 2(2):223-229.

Hamilton-Miller, J. M. T., and S. Shah. 2002. Deficiencies in microbiological quality and labeling of probiotic supplements. Int J Food Microbiol. 72:175-176.

Jones, F. T. and K. E. Richardson. 2004. Salmonella in commercially manufactured feeds. Poult. Sci. 83(3):384-391. 
Kailasapathy K. and J. Chin. 2000. Survival and therapeutic potential of probiotic organisms with reference to Lactobacillus acidophilus and Bifidobacterium spp. Immunol Cell Biol. 78:80-88.

Krehbiel, C. R., S. R. Rust, G. Zhang, and S. E. Gilliland. 2003. Bacteria direct-fed microbials in ruminant diets: Performance response and mode of action. J. Anim. Sci. 81(E. Suppl. 2):120-132.

Kung, L., Jr. 1999. Direct-fed microbial and enzyme feed additives. Page 37 in DirectFed Microbial, Enzyme and Forage Additive Compendium. S. Muirhead (ed.). Vol. 4. The Miller Publishing Co., Minnetoka, MN.

Lin, W. H., C. F. Hwang, L. W. Chen, and H. Y. Tsen. 2005. Viable counts, characteristic evaluation for commercial lactic acid bacteria products. Food Microbiol. (23):74-81.

Maciorowski, K. G., P. Herrera, F. T. Jones, S. D. Pillai, and S. C. Ricke. 2007. Effects on poultry and livestock of feed contamination with bacteria and fungi. Animal Feed and Science Tech. 133:109-136.

Moat, A. G., J. W. Foster, and M. P. Spector. 2002. Microbial Physiology $4^{\text {th }}$ edition. Wiley-Liss, Inc., New York.

Ouwehand, A. C., P. Niemi, S. J. Salminen. 1999. The normal feacal microflora does not affect the adhesion of probiotic bacteria in vitro. FEMS Microbiol Lett. 177:35-38.

Peterson, A. B., and L. W. Douglass. 2005. Adopting new techniques: statistical procedures to determine the agreement between two laboratory methods. Pages $1-13$ in $18^{\text {th }}$ Northeast SAS Users Group Proc., Portland, ME.

Riordan, D. C. R., G. Duffy, J. J. Sheridan, R. C. Whiting, I. S. Blair, and D. A. McDowell. 2000. Effects of acid adaptation, product $\mathrm{pH}$, and heating on survival of Escherichia coli 0157:H7 in pepperoni. Appl. Environ. Microbial. 66:17261729 .

SAS Institute Inc. SAS Online Doc. Version 9.1.2. SAS User's Guide, 2004 Cary, NC.

Spoto M. H. F., C. R. Gallo, A. R. Alcarde, M. S. A. Gurgel, L. Blumer, J. M. M. Walder, and R. E. Domarco. 2000. Gamma irradiation in the control of pathogenic bacteria in refrigerated ground chicken meat. Scientia Agricola. 57(3):389-394.

Star-Labs. PrimaLac 454 Feedgrade. Clarksdale, MO. http://www.primalac.com/probiotics.html. 
Weese, J. S. 2001. A Review of Probiotics: Are They Really "Functional Foods"? AAEP Proc. 47:27-31.

Weese J.S. 2002. Microbiologic evaluation of commerical probiotics. J Am Vet Med Assoc. 220:794-797.

Weese, J. S. and L. Arroyo. 2003. Bacteriological evaluation of dog and cat diets that claim to contain probiotics. Can Vet J. March. 44(3):212-215.

Yoon, I. K., and M. D. Stern. 1995. Influence of direct-fed microbials on ruminal fermentation and performance of ruminants: a review. Australia J. Anim. Sci. 8:533-555. 


\section{TABLES AND FIGURES FOR EXPERIMENT 1}

Table 1. Broiler diet ingredient and nutrient composition of basal formula used in Exp. 1

\begin{tabular}{lc}
\hline \hline Item & Diet \\
\hline Ingredient, \% & \\
$\quad$ Corn & 60.4 \\
Soybean Meal & 30.9 \\
Corn Gluten Meal & 4.7 \\
Soy Oil & 3.0 \\
Salt & 0.5 \\
L Lysine & 0.2 \\
DL Methionine & 0.1 \\
Vitamin Premix & 1 \\
Mineral Premix ${ }^{2}$ & 0.1 \\
Choline Chloride & 0.1 \\
$\quad$ Total & 0.1 \\
Nutrient, \% & 100.0 \\
Crude Protein & 22.4 \\
Ether Extract & 5.1 \\
Crude Fiber & 2.6 \\
\hline
\end{tabular}

${ }^{1}$ Provided per kg of diet: 18,739 IU vitamin A from retinyl acetate; 6,614 IU vitamin $\mathrm{D}_{3}$ from cholecalciferol; 66,138 IU vitamin E from DL- $\alpha$-tocopheryl acetate; $20 \mathrm{mg}$ of riboflavin; $80 \mathrm{mg}$ niacin from nicotinic acid; $30 \mathrm{mg}$ D-pantothenic acid from calcium pantothenate; $4.0 \mathrm{mg}$ vitamin $\mathrm{K}$ from menadione sodium bisulfite; $2.7 \mathrm{mg}$ folic acid; $7.7 \mathrm{mg}$ pyridoxine from pyridoxine hydrochloride; $5.5 \mathrm{mg}$ thiamine from thiamine mononitrate; 0.4 mg of Se from $\mathrm{Na}_{2} \mathrm{SeO}_{3} ; 0.17 \mathrm{mg}$ of D-biotin.

${ }^{2}$ Provided per kg of diet: $80.0 \mathrm{mg} \mathrm{Ca}$ from $\mathrm{CaCO}_{3}, 210.0 \mathrm{mg} \mathrm{Zn}$ from $\mathrm{ZnO}, 120.0 \mathrm{mg} \mathrm{Mn}$ from $\mathrm{Mn}_{3} \mathrm{O}_{4}$ and $\mathrm{MnSO}_{4}$ in equal concentration, $40.0 \mathrm{mg}$ of $\mathrm{Fe}$ from $\mathrm{FeSO}_{4}, 20.0 \mathrm{mg}$ of Cu from $\mathrm{CuO}, 3.0 \mathrm{mg}$ of iodine from $\mathrm{CaI}_{2} \mathrm{O}_{6}$, and $50.0 \mu \mathrm{g}$ of $\mathrm{Co}$ from $\mathrm{CoCO}_{3}$. 
Table 2. Pelleting run times, average temperature at the conditioner, pellet exiting, during pellet drying and of ambient for the five batches in Exp. 1 with or without lactic acid bacteria DFM inclusion ${ }^{1}$

\begin{tabular}{lcccccc}
\hline \hline Batch & $\begin{array}{c}\text { Pelleting } \\
\text { Run Time }\end{array}$ & $\begin{array}{c}\text { Conditioner } \\
\text { Temp }{ }^{\circ} \mathrm{C}\end{array}$ & $\begin{array}{c}\text { Pellet Exit } \\
\text { Temp }{ }^{\circ} \mathrm{C}\end{array}$ & $\begin{array}{c}\text { Drying } \\
\text { Temp }{ }^{\circ} \mathrm{C}\end{array}$ & $\begin{array}{c}\text { Drying } \\
\text { Time, min }\end{array}$ & $\begin{array}{c}\text { Ambient } \\
\text { Temp }{ }^{\circ} \mathrm{C}\end{array}$ \\
\hline CON, run 1, batch 1 & $6: 39$ & 88 & 83 & 20 & $5: 02$ & 21 \\
PRIM2, run 2, batch 1 & $7: 25$ & 96 & 84 & 21 & $5: 49$ & 22 \\
PRIM2, run 3, batch 2 & $7: 47$ & 93 & 86 & 22 & $5: 33$ & 23 \\
PRIM3, run 4, batch 1 & $7: 31$ & 93 & 83 & 22 & $5: 41$ & 25 \\
PRIM3, run 5, batch 2 & $7: 52$ & 93 & 84 & 22 & $5: 10$ & 26 \\
\hline
\end{tabular}

${ }^{1}$ Batches were made in the following order: one batch containing no lactic acid bacteria $(\mathrm{CON})$, two batches containing $0.91 \mathrm{~kg} / \mathrm{ton}$ of commercially prepared lactic acid bacteria

(PRIM2; PrimaLac 454 Feed Grade; Star-Labs, Clarksdale, MO), and two batches containing

$1.36 \mathrm{~kg} / \mathrm{ton}$ of the same commercially prepared lactic acid bacteria (PRIM3; PrimaLac 454

Feed Grade; Star-Labs, Clarksdale, MO). 


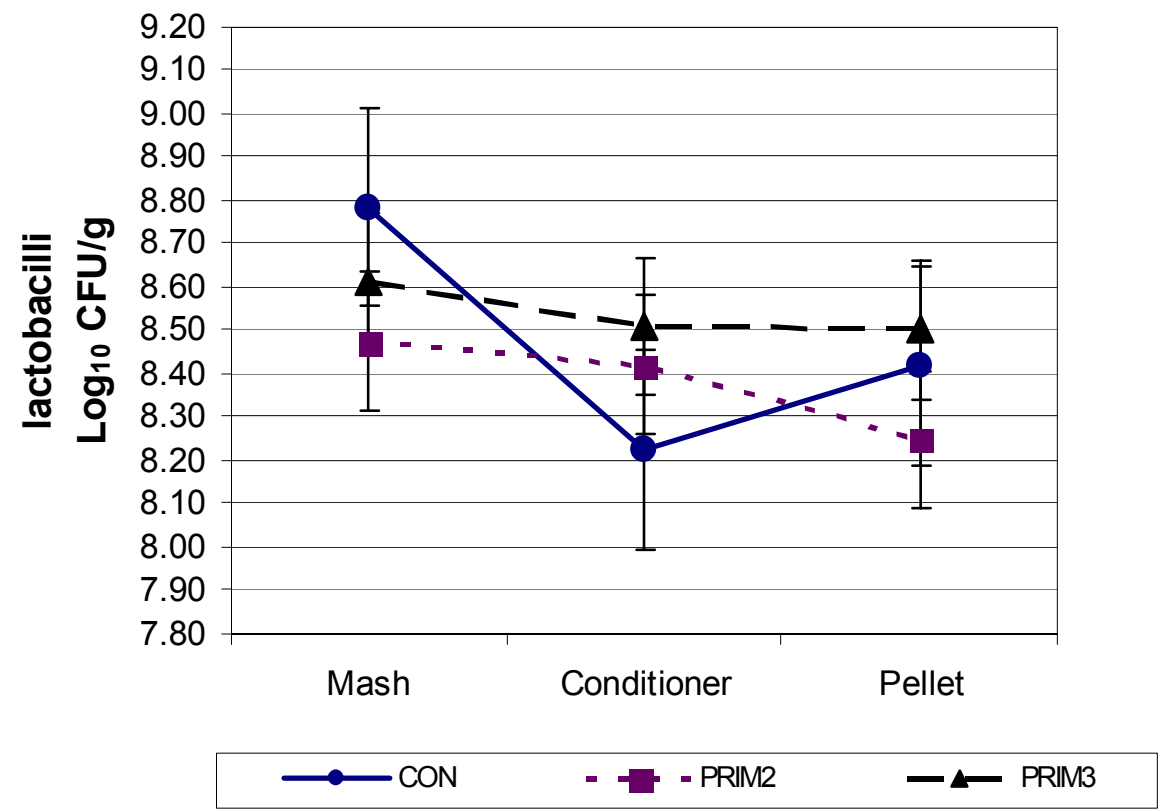

Figure 1. Average viable lactobacilli colony forming units $\left(\mathrm{CFU}, \log _{10}\right)$ by level of inclusion of direct-fed lactic acid bacteria in batches of animal feed during processing at a feed mill, Exp. 1. Values for each observation are an average of CFU reported from two labs using two enumeration methods. No significant differences were detected between treatment means at any of the sampling locations. Batches of feed were made in the following order: one batch with no added lactic acid bacteria $(\mathrm{CON})$, two batches containing $0.91 \mathrm{~kg} / \mathrm{ton}$ of commercially prepared lactic acid bacteria (PRIM2; PrimaLac 454 Feed Grade; Star-Labs, Clarksdale, MO), and two batches containing $1.36 \mathrm{~kg} /$ ton of the same commercially prepared lactic acid bacteria (PRIM3). Mash= sample of initial batch mix, Conditioner= sample of hot mash extracted at the "hatch" between conditioner and pellet die, and Pellet= sample of cooled pellets taken at bagging. 


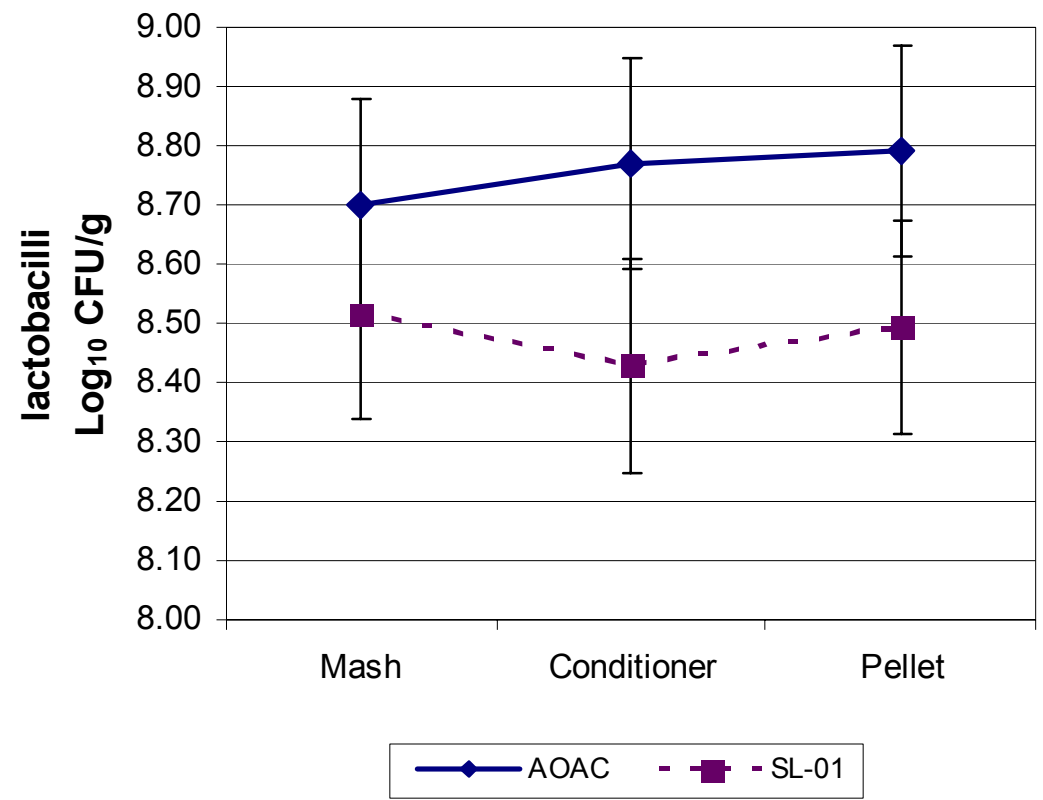

Figure 2. Mean counts of viable lactobacilli colony forming units $\left(\mathrm{CFU} / \mathrm{g}, \log _{10}\right)$ in animal feed samples at different collection points during feed processing using SL-01 and AOAC enumeration methods at LOC1, Exp.1. When only LOC1 conducted both enumeration methods, there was no difference detected $(P=0.17)$ in mean lactobacilli counts reported between AOAC and SL-01. LOC1 = commercial lab; Cargill Innovation Center. Mash= sample of initial batch mix, Conditioner= sample of hot mash extracted at the "hatch" between conditioner and pellet die, and Pellet= sample of cooled pellets taken at bagging. 


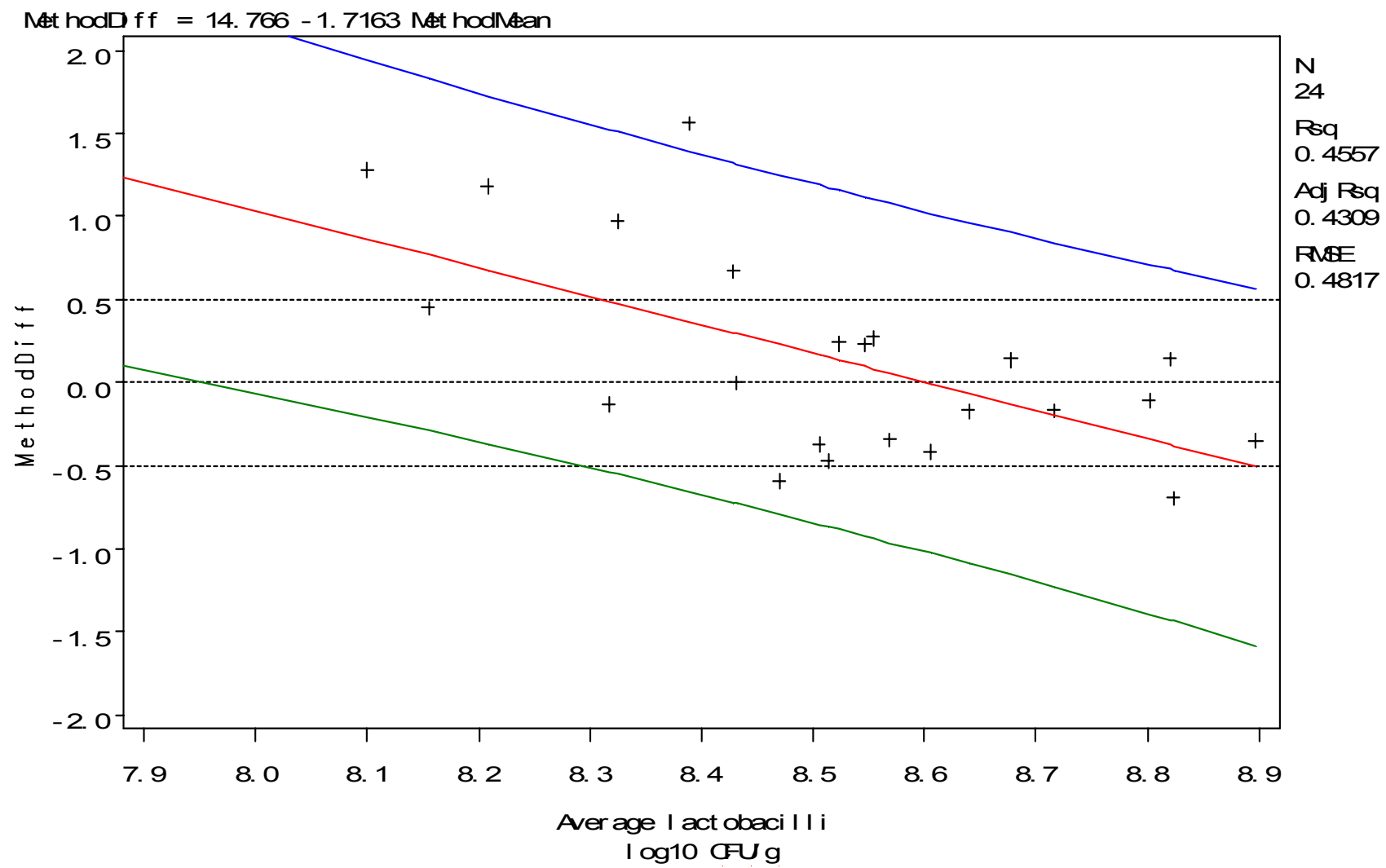

Figure 3. Best-fit linear regression analysis representing differences between SL-01 and AOAC enumeration methods at $\mathrm{LOC} 1$ for determination of viable lactobacilli colony forming units $\left(\mathrm{CFU} \log _{10}\right)$ in animal feed samples during feed processing, Exp. 1. LOC1= Cargill Animal Nutrition commercial lab. MethodDiff indicates the difference between AOAC and SL-01 methods relative to the average lactobacilli CFU reported by LOC1, where "0.0" would indicate "no difference." Negative $(+)$ indicate where LOC1 reported higher CFU than LOC2 and positive $(+)$ indicate where LOC2 reported higher average lactobacilli CFU. Dashed line (-------) at \pm 0.5 indicates one magnitude of difference in CFU (or 1 standard deviation from " 0.0 " or "no difference." ${ }^{3}$ Best fit linear regression line (red----) shows negative $(P=0.0003)$ trend between AOAC and SL-01 differences. Confidence belts (black---- and blue----) are representative of 95\% of average lactobacilli CFU data range. 


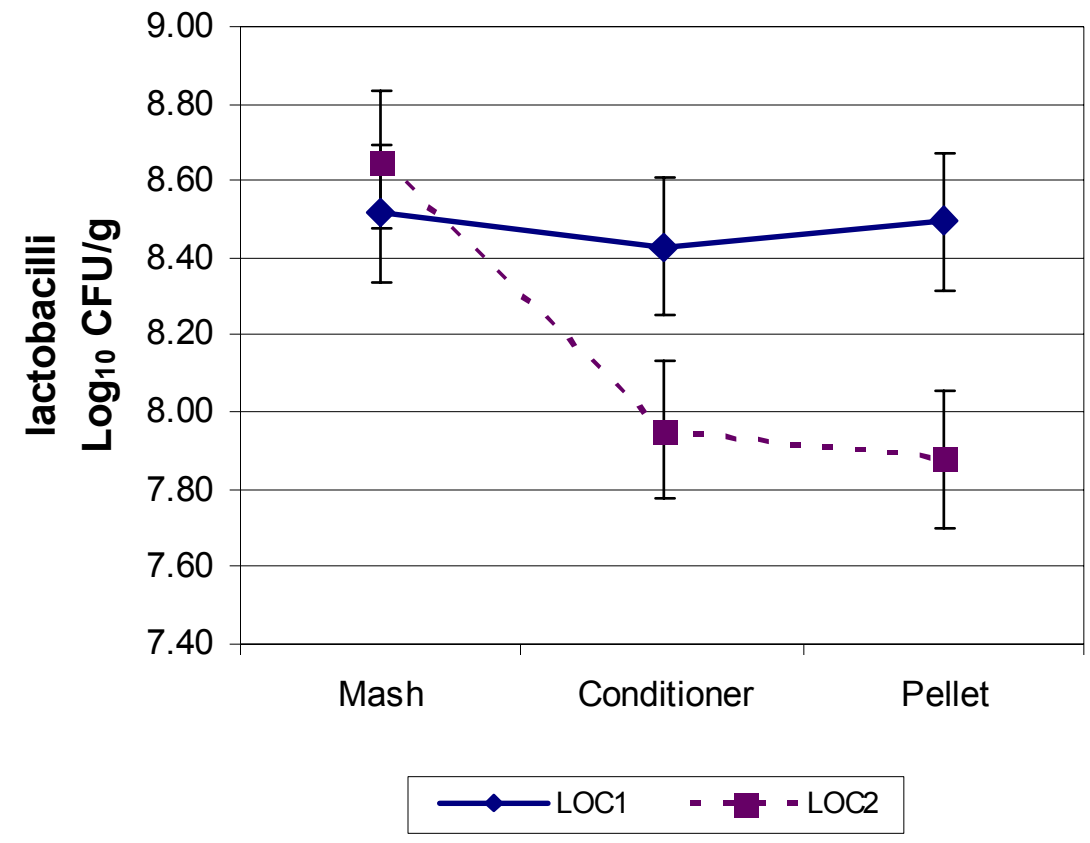

Figure 4. Mean counts of viable lactobacilli colony forming units $\left(\mathrm{CFU} / \mathrm{g}, \log _{10}\right)$ in animal feed samples at different collection points during feed processing at LOC1 and LOC2 using the SL-01 enumeration method, Exp. 1. When only the SL-01 method was performed, LOC1 tended to report higher $(P=0.09)$ lactobacilli counts than LOC2. Mash= sample of initial batch mix, Conditioner= sample of hot mash extracted at the "hatch" between conditioner and pellet die, and Pellet= sample of cooled pellets taken at bagging. $\mathrm{LOC} 1=$ commercial lab; Cargill Innovation Center, LOC2= commercial lab; Star-Labs. 


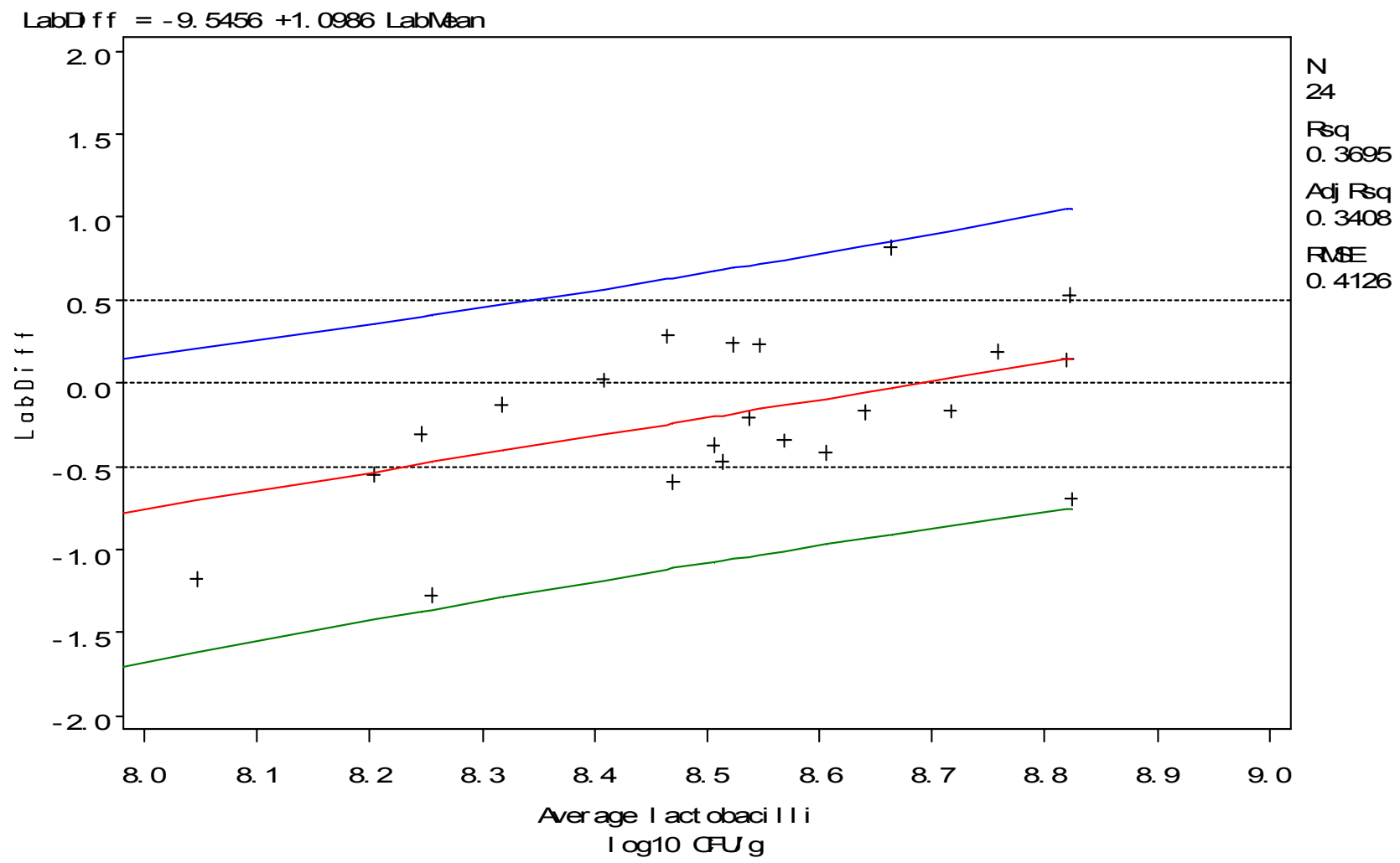

Figure 5. Best-fit linear regression analysis representing differences between $\mathrm{LOC} 1$ and $\mathrm{LOC} 2^{1}$ using the SL-01 method for enumeration of viable lactobacilli colony forming units (CFU $\left.\log _{10}\right)$ in animal feed samples during feed processing, Exp. 1. LOC1 $=$ Cargill Animal Nutrition commercial lab and LOC2 $=$ Star-Labs Forage Analysis commercial lab. LabDiff indicates the difference between LOC1 and LOC2 relative to the average lactobacilli CFU reported between the two labs, where " 0.0 " would indicate "no difference." Negative (+) indicate where LOC1 reported higher CFU than LOC2 and positive $(+)$ indicate where LOC2 reported higher average lactobacilli CFU. Dashed line (-------) at \pm 0.5 indicates one magnitude of difference in CFU (or 1 standard deviation from " 0.0 " or "no difference." Best-fit linear regression line (red----) shows positive $(P=0.002)$ trend between LOC1 and LOC2 differences.

Confidence belts (black---- and blue----) are representative of 95\% of average lactobacilli CFU data range. 


\section{TABLES AND FIGURES FOR EXPERIMENT 2}

Table 3. Bacteria species identification ${ }^{1}$ performed on control batch ${ }^{2}$ of animal feed stored for 12 weeks from June to September, Exp. 2

\begin{tabular}{llc}
\hline \hline Item & Bacteria Identification $^{1}$ & DuPont No. $^{3}$ \\
\hline Control & Bacillus licheniformis & 13235,16694 \\
& Bacillus thuringiensis & 16676 \\
& Bacillus cereus & 6003 \\
& Leuconostoc mesenteroides & 5407,5408 \\
& Paenibacillus polymyxa & 11066 \\
\hline
\end{tabular}

${ }^{1}$ Identification performed on bacterial ribosomal DNA using a RiboPrinter ${ }^{\circledR}($ DuPont Qualicon, Wilmington, DE).

${ }^{2}$ Control=no inclusion of lactic acid bacteria (the treatment bacteria used in this experiment were : L. acidophilus, L. casei, B. bifidium, and E. faecium).

${ }^{3}$ DuPont identification numbers are automatically assigned by the RiboPrinter and reported at $85 \%$ confidence. 

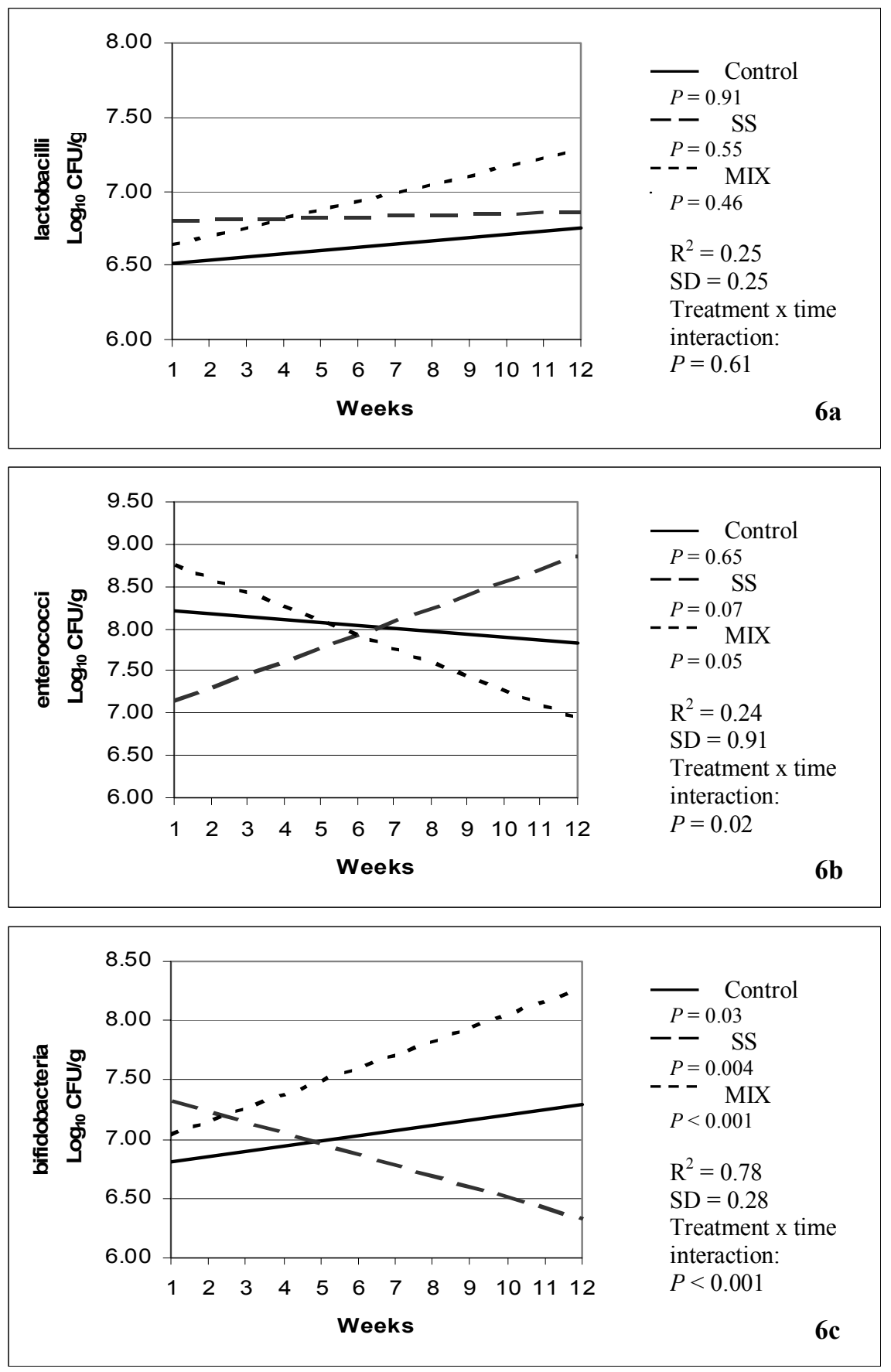

Figures 6 (a-c). Effect of time (week) on number of viable colony forming units (CFU, $\left.\log _{10}\right)$ of lactobacilli, enterococci, and bifidobacteria in separate batches of animal feed stored for 12-weeks from June to September, Exp. 2. Control=no inclusion of lactic acid bacteria, $\mathrm{SS}=1.36 \mathrm{~kg} / \mathrm{ton}$ of single strain $L$. acidophilus, and MIX = containing $1.36 \mathrm{~kg} /$ ton of a mixture of L. acidophilus, L. casei, B. bifidium, and E. faecium (MIX; PrimaLac 454 Feed Grade; Star-Labs, Clarksdale, MO). Samples were collected during a companion study where two levels of starch were administered in the following fashion: week 1-2 (lowstarch; LS), wk 3-4 (high-starch, HS), wk 5-6 (LS), wk 7-8 (HS), wk 9-10 (LS), wk 11-12 (HS).

Regression lines were corrected for effects of ambient temperature, which used as a covariate in the model. 
CHAPTER 4

EFFECTS OF DIRECT-FED MICROBIAL SUPPLEMENTATION ON

DIGESTIBILITY AND FERMENTATION END-PRODUCTS IN HORSES FED LOW-

AND HIGH-STARCH CONCENTRATES

(Manuscript 2) 


\title{
EFFECTS OF DIRECT-FED MICROBIAL SUPPLEMENTATION ON DIGESTIBILITY AND FERMENTATION END-PRODUCTS IN HORSES FED LOW- AND HIGH-STARCH CONCENTRATES ${ }^{1}$

\author{
K. L. Swyers ${ }^{*}$, A. O. Burk ${ }^{*}$, T. G. Hartsock ${ }^{*}$, E. M. Ungerfeld" and J. L. Shelton ${ }^{\dagger}$ \\ *University of Maryland, College Park, MD, \\ ${ }^{\dagger}$ Cargill Animal Nutrition, Innovation Center, Elk River, $M N$
}

\begin{abstract}
A study was conducted to determine whether bacterial direct-fed microbials (DFM) could be used to increase digestibility and minimize the risk associated with feeding a highstarch concentrate to mature horses. Fifteen mature Thoroughbred geldings were randomly assigned to one of three treatments in a 3 x 3 Latin square design balanced for carry-over effects. Within each $26-\mathrm{d}$ period, horses were offered grass hay + low-starch concentrate (LS; $1.2 \mathrm{~g} \mathrm{starch/kg} \mathrm{BW/meal)} \mathrm{from} \mathrm{d} \mathrm{1-13,} \mathrm{and} \mathrm{then} \mathrm{abruptly} \mathrm{changed} \mathrm{to}$ hay + high-starch concentrate (HS; $2.4 \mathrm{~g}$ starch/kg BW/meal) on d 14 continuing through d 26. The DFM treatments were offered in concentrate pellets at target dosage of $1 \times 10^{8}$ cfu/50kg of BW/d as follows: no DFM (CON), Lactobacillus acidophilus (LAC1), or a mixture of L. acidophilus, L. casei, Bifidobacterium bifidium, and Enterococcus faecium (LAC4). Total fecal collection, using collection harnesses, was performed over $72 \mathrm{~h}$ on $\mathrm{d}$ 11-13 (LS), on d 15-17 (AC), and at the end of each experimental period, d 24-26 (HS). Data collected consisted of total DM intake and total fecal output, plus fecal $\mathrm{pH}$, acetate, and propionate concentrations. All geldings maintained their initial BW and BCS throughout the study. With the exception of Fe digestibility, there was no significant starch by DFM treatment interaction on nutrient digestibility or on fecal $\mathrm{pH}$, acetate or propionate. There was a main effect of starch level $(P<0.002)$ across most nutrient digestibilities except of $\mathrm{CP}, \mathrm{Mg}, \mathrm{K}$ and $\mathrm{Zn}(P>0.05)$. Horses receiving either DFM
\end{abstract}


supplement had increased $(P<0.05) \mathrm{EE}, \mathrm{Cu}$, and Fe digestibility compared to $\mathrm{CON}$ horses. Fecal $\mathrm{pH}$ decreased $(P<0.001)$ and concentrations of fecal propionate and acetate increased $(P<0.001)$ as the starch content of the diet changed from LS to HS. There was a tendency $(P=0.06)$ for elevated fecal $\mathrm{pH}$ in LAC1 horses. These results suggest that offering a higher starch concentrate to horses may enhance nutrient digestibility of the diet and alter hindgut fermentation as indicated by changes in fecal $\mathrm{pH}$ and VFA observed in this study. However, supplementing equine with either a single or mixed strain direct-fed lactic acid bacteria had minimal effects on increasing nutrient digestibility or reducing potential acidotic risks associated with feeding high-starch concentrates to horses.

Key Words: Digestibility, Direct-fed Microbials, Horses, Lactobacillus acidophilus, Probiotics, Starch

\footnotetext{
${ }^{1}$ The authors thank Dr. Roy Johnson and the team at Cargill Animal Nutrition for their collaboration on the study and laboratory analyses, contribution of the pelleted horse feed used during the trial, and financial contribution. We thank Dr. Mark Young and the team at Star-Labs for donating both strains of DFM for this study, conducting laboratory analyses and for their financial contribution. Counsel from Dr. Scott Weese and Dr. Larry Douglass are gratefully acknowledged. The assistance of the staff and students at the Central Maryland Research and Education Center are greatly appreciated.
}

\section{INTRODUCTION}

It is common practice among most horse owners to supplement roughage diets with starch-based concentrates to meet nutrient requirements under the guidelines of the Nutrient Requirements for Horses (NRC, 2007). When non-degraded starch escapes small intestine digestion and reaches the hindgut (cecum and/or colon), a sequence of events has been documented where gut microbial populations are altered, $\mathrm{pH}$ drops, 
propionate concentration elevates, and fiber digestion decreases resulting in an increased risk for acidosis, gastric ulcers, and potentially colic and/or laminitis (Hoffman, 2003; Bailey et al., 2003). Reduced risk of acidosis in feedlot cattle fed high-concentrate diets with direct-fed microbials (DFM; Huffman et al., 1992, Ghorbani et al., 2002) may have some relevance in the potential of DFM negating the risks associated with feeding highstarch concentrates to horses. The DFM, also referred to as probiotics, are a source of live, naturally occurring microorganisms (Yoon and Stern, 1995) that are believed to beneficially affect the host animal by providing intestinal microbial balance (Fuller, 1989). Lactic acid-producing bacteria (LAB), predominantly from the Lactobacillus genus, are the most widely used bacteria in DFM preparations and show promise toward enhancing digestive health in other species (Kung, 1999; Weese, 2001; Krehbiel et. al., 2003). Because most DFM preparations have combinations of bacterial species, it is difficult to assess the effects of individual species. Despite the research available in other species, and the availability of DFM supplements on the market intended for horses, no peer-reviewed research has been published on the effects of direct-fed LAB offered to mature horses. The objective of this study was to investigate the efficacy of a single strain versus multiple strain direct-fed LAB supplementations on nutrient digestibility and hindgut fermentation of mature horses when the starch content of the diet is abruptly increased. 


\section{MATERIALS AND METHODS}

\section{Animals and Diets}

All experimental procedures were conducted according to the University of Maryland's Institutional Animal Care and Use Committee (IACUC).

Fifteen mature Thoroughbred geldings at rest (average initial age 10 years; average initial BW $556.68 \mathrm{~kg}$ ) were randomly assigned to one of three treatments arranged in a $3 \times 3$ Latin square split-plot (starch level and collection time) experiment balanced for carry-over effects with repeated measures within each period. All geldings were vaccinated against Ehrlichia Risticii Bacterin (Potomac Horse Fever), West Nile virus, Eastern/Western/Venezuelan Encephalomyelitis, and Tetanus Toxoid (Fort Dodge Animal Health, Fort Dodge, IA) and dewormed against large and small strongyles, encysted cyathostomes, ascarids, pin worms, hair worms, large mouth stomach worms and bots (Moxidectin; Fort Dodge Animal Health, Fort Dodge, IA) before the start of the study. Horses were weighed using a livestock platform scale (Digi-Star, Ft. Atkinson, WI) and assigned a body condition score (BCS; 1-9 scale; Henneke, 1983) at the beginning and end of each experimental period. The geldings were housed in individual $3.6 \mathrm{~m}^{2}$ box stalls with rubber mats and wood shavings (American Wood Fibers, Jessup, MD) at the University of Maryland's Equine Research Unit located at the Central Maryland Research and Education Center in Ellicott City, MD. Horses received their diets in two equal meals twice daily at 0800 and 1700 . The geldings were taken out of their stalls and walked $(1.3 \mathrm{~m} / \mathrm{s})$ once daily at 1600 for 10 to $35 \mathrm{~min}$ (depending on heat index) using an automated six-horse exerciser (Priefert, Mt. Pleasant, TX), alternating 
directions each day. The geldings were brought in from pasture $7 \mathrm{~d}$ prior to the start of the study to allow for acclimation to the housing, feeding, and exercise protocol. During acclimation, horses were fed mixed grass hay and given a step-wise introduction to the control diet, fed to meet daily DE requirements for maintenance (NRC, 2007).

Horses were randomly assigned to one of three treatments for each of the three experimental periods. The treatments consisted of: a control diet of grass hay + pelleted concentrate $(\mathrm{CON})$, grass hay + pelleted concentrate with L. acidophilus at $1 \times 10^{8}$ cfu/50kg/d (LAC1; custom preparation provided by Star-Labs, Clarksdale, MO), or grass hay + pelleted concentrate with a commercial DFM mixture of LAB at $1 \times 10^{8} \mathrm{cfu} / 50 \mathrm{~kg} / \mathrm{d}$ (LAC4; PrimaLac 454; Star-Labs, Clarksdale, MO). The experiment consisted of three consecutive 26-d feeding periods (Figure 1) such that all horses received all treatments. The first 10 days of each period were considered a wash-out of the previous treatment and an adaptation to the new treatment. Pelleted concentrates contained either 20\% (low starch; LS) or 38\% starch (high starch; HS) to achieve a target intake of 1.2 and $2.4 \mathrm{~g}$ starch $\cdot \mathrm{kg}^{-1} \mathrm{BW} \cdot \mathrm{meal}^{-1}$ for the first and last 13 days of each period, respectively, with an abrupt change (AC) from LS to HS on d 14. Starch level was increased in the HS concentrate with an increased proportion of corn meal in place of wheat middlings such that concentrates remained isonitrogenous and isoenergetic. Custom pellets were supplied by Nutrena Feeds (Cargill Animal Nutrition feed plant, Lebanon, PA) and fed at a rate of $0.25 \mathrm{~kg} / 50 \mathrm{~kg} \mathrm{BW} /$ day. Composition of feeds is outlined in Table 1 based on information provided by the manufacturer and from independent analysis of feeds by Dairy One Forage Testing Laboratory (Ithaca, NY). Horses were fed hay and concentrate 
to meet or slightly exceed their individual daily requirements for DE relative to BW (NRC, 2007).

The DFM treatments were included in the LS and HS pelleted concentrates, resulting in six total formulas for the study: low and high-starch control (no DFM), low and high-starch LAC1, and low and high-starch LAC4. All probiotic preparations were included in the concentrate ration before pelleting. The dose of probiotic inclusion was determined given manufactures minimum guarantee of $1.0 \times 10^{8}$ colony forming units (CFU) of Lactobacillus organisms per gram. A $1.36 \mathrm{~kg} / \mathrm{ton}$ inclusion level of each probiotic preparation was determined before the start of the study based on results from a pilot study conducted earlier at the United States Department of Agriculture (USDA; Beltsville, MD). All finished pelleted concentrates with and without DFM inclusion were sampled weekly for enumeration and identification of bacterial species. Hay was fed using stationary wooden box feeders affixed to each stall, and concentrate was offered in canvas feed bags (Derby Originals, North Canton, $\mathrm{OH}$ ) to avoid wastage. Hay and concentrate offered and refused was collected, weighed and recorded daily to determine total dry matter intake (DMI). Water and salt blocks (sodium chloride) were available ad libitum.

This was an 85-d study conducted from June to September in Clarksville, MD. The summer climate is typified by temperate, humid days with annual precipitation ranging from 88.9 to $114.3 \mathrm{~cm}$ (precipitation reported on www.weather.com for 
Clarksville, MD). During our investigation, average air temperatures ranged from 14 to $38^{\circ} \mathrm{C}$ (temperature reported on www.weather.com for Clarksville, MD).

\section{Sample Collection}

Total collection of hay, concentrate, and feces was performed on d 11-13 (LS), 15-17(AC), and 24-26 (HS) within each experimental period. Length of the collection period was based on $95 \%$ of digesta passing by 65 h post feeding (Van Weyenberg et al., 2005). Samples of concentrate and hay ( $200 \mathrm{~g})$ were collected every $7 \mathrm{~d}$ throughout the study. Concentrate and hay samples were weighed, dried in a forced air oven $\left(105^{\circ} \mathrm{C}\right.$ for $72 \mathrm{hrs}$ ), and reweighed for calculation of DM. Stalls were stripped of all shavings, feedstuffs, and manure at 1500 on d 11, 15 and 24 and were swept and hosed daily after the 0700 total collection. Each gelding was equipped with a collection harness (Equisan, Australia) for total fecal collection to reduce potential for hay, concentrate, urine, and fecal mixing in the stall. Horses were accustomed to wearing the harnesses prior to the start of the study. The harnesses were fitted to each horse the evening before total fecal collection began. Urine and feces were removed from the harnesses thrice daily ( 0700 , 1200 , and $1600 \mathrm{~h}$ ) and horses were checked and treated, as needed, for minor abrasions caused by harnesses. Feces were removed from the harnesses into individual plastic tubs with plastic bag liners and were closed after collection to reduce moisture loss. At each collection, grab samples of fresh feces $(\sim 500 \mathrm{~g})$ were removed from the harness bags prior to emptying so that the most recently defecated feces were sampled. Grab samples were weighed over each $24 \mathrm{~h}$ collection period for determination of total fecal output. Grab samples were immediately analyzed for $\mathrm{pH}$, dried for determination of digestibility 
or stored at $-20^{\circ} \mathrm{C}$ in $120 \mathrm{~mL}$ ( $4 \mathrm{oz}$ Hi-Profile, Delmar, Newark, DE) plastic containers for pending analysis. Feces obtained from 1200 and 1600 collections were analyzed for VFA and lactate concentrations, with $10 \mathrm{~g}$ sub samples added to $40 \mathrm{~mL}$ of $1 N \mathrm{HCL}$ and stored in an air-tight $120 \mathrm{~mL}$ container $\left(4 \mathrm{oz}\right.$ Hi-Profile, Delamar, Newark, DE) at $-20^{\circ} \mathrm{C}$ for pending analysis. The $\sim 200 \mathrm{~g}$ fecal grab samples were weighed, dried in a forced air oven $\left(55^{\circ} \mathrm{C}\right.$ for $\left.72 \mathrm{~h}\right)$, reweighed for determination of DM, then stored for pending nutrient analysis.

\section{Sample Analysis}

Dried fecal, hay and concentrate samples were ground in a Wiley Mill (Thomas ${ }^{\circledR}$ Model 4, Swedesboro, NJ) using a 1-mm screen. Fecal samples for each horse over each total collection period were composited and sub-samples were sent for nutrient analysis (Cargill Innovation Center, Elk River, MN). Samples were analyzed for the determination of DM, OM, CP, ADF, NDF, EE, $\mathrm{Ca}, \mathrm{P}, \mathrm{Mg}, \mathrm{K}, \mathrm{Cu}, \mathrm{S}, \mathrm{Cl}, \mathrm{Fe}, \mathrm{Mn}, \mathrm{Na}$, and $\mathrm{Zn}$ using AOAC methods with modifications (CP, AOAC 968.06; ADF and NDF, AOAC 2002.04/973.18, total starch, AOAC 996.11; EE, AOAC 920.39; ash, AOAC 942.05; and minerals, AOAC 968.08, ManSci Inc, Tonawanda, NY). Chloride analysis was conducted by titration using the PC-titrate system (ManSci Inc, Tonawanda, NY). Samples were also sent for analysis of soluble sugars (water soluble carbohydrates; WSC) starch to Dairy One (Ithaca, NY). For starch analysis, sugars were pre-extracted by incubation in water bath and filtered on Whatman 41 filter paper then determined using AOAC methods (AOAC 989.03) on an YSI analyzer (YSI 2700 SELECT Biochemistry Analyzer, YSI Inc., Yellow Springs, OH). Sugar was determined 
according to Hall et al. (1999). Total DM intake (DMI, kg/d) and fecal output (FO, kg/d) were used to calculate apparent DM digestibility (DMD, \%) using the equation: $\mathrm{DMD}=$ 1- FO/DMI. Digestibility measurements were made at the fecal level, and therefore, calculations include disappearance of nutrients through absorption.

Fecal $\mathrm{pH}$ was determined on fresh feces collected $(\sim 100 \mathrm{~g})$ thrice daily ( 0700 , 1200 and $1600 \mathrm{~h}$ ) on $\mathrm{d} 11-13,15-17$, and 24-26. The $\mathrm{pH}$ was determined within 30 minutes of collection with a portable $\mathrm{pH}$ meter (model 13704, Denver Instruments, Arvada, CO). The probe (Orion Semi-micro electrode model 91-16, Thermo Electron Corp, Beverly, MA) was submerged in the solid fecal mixture until the reading stabilized. Readings were performed in triplicate for each sample and averaged for each collection time. The $\mathrm{pH}$ meter was calibrated at 0700 before the start of each collection day in $\mathrm{pH} 4$ and 7 stock solutions. A back-up hand-held $\mathrm{pH}$ meter was used when intermittent mechanical failures occurred with the first (model IQ400, Scientific Instruments, Carlsbad, CA).

For the analysis of VFA, frozen samples of feces suspended in $\mathrm{HCl}$ were thawed at room temperature, poured into $30 \mathrm{~mL}$ centrifuge tubes, and centrifuged at $22,000 \mathrm{x} \mathrm{g}$ at $4^{\circ} \mathrm{C}$ for $15 \mathrm{~min}$. A $1-\mathrm{mL}$ supernatant aliquot was transferred to $5-\mathrm{mL}$ centrifuge tubes. One millimeter of constantly stirred $\mathrm{CaOH}$ was added to each tube and vortexed, after which, $0.5 \mathrm{~mL}$ of $\mathrm{CuSO}_{4}$ was added and the solution was vortexed again. Samples were then centrifuged at $16,000 \mathrm{xg}$ at $4^{\circ} \mathrm{C}$ for 15 minutes, after which, $1.5 \mathrm{~mL}$ of supernatant were transferred to a new $5-\mathrm{mL}$ tube, followed by the addition of $20 \mu \mathrm{L}$ of concentrated sulfuric acid was added, after which they were centrifuged at $16,000 \mathrm{x} g$ at $4^{\circ} \mathrm{C}$ for 15 
minutes. Sample extracts were filtered through a $4 \mathrm{~mm} 0.45 \mu$ syringe to remove particulate matter. The VFA concentrations were determined using HPLC in an Aminex HPX-874 ion exclusion column $300 \mathrm{~mm} \times 7.8 \mathrm{~mm}$ (Biorad) at $1000 \mathrm{psi}$ at $42^{\circ} \mathrm{C}$ and a refractive index detector. Concentrations of individual short chain fatty acids were determined relative to passage rate of individual molecules eluting through an ion exclusion column. The VFA concentrations were reported as $\mathrm{mg} / \mathrm{mL}$ and a ratio of acetate to propionate (A:P) was calculated.

\section{Prevention of Cross-Contamination}

Measures to minimize cross-contamination of treatment groups were taken throughout the study. All pelleted concentrates were processed in the order of least number of added bacterial species to most (i.e., CON, then LAC1, then LAC4) from mixing to pelleting and bagging at the feed mill. Upon delivery of concentrate at research facility, the storage, weighing and handling of feed to horses was separated and conducted in the order of CON, then LAC1, then LAC4. Additionally, handling of horses for grooming, exercising, cleaning of stalls or collection of data purposes was conducted using separately labeled tools, and again handled in the previously stated order. Treatment groups were physically separated and unable to make nose-to-nose contact as to prevent cross-contamination from horse to horse. All handlers were instructed to collect data, feed and work with horses in the order of CON, LAC1, then LAC4 wearing gloves and tall rubber boots. If this order needed to be altered, handlers were instructed to disinfect clothing, boots, and hands with bleach scrub stations placed throughout the barn and feed preparation areas prior to handling horses or equipment. 
Feed preparation area was disinfected at the end of each shift. Samples were also collected, handled and analyzed in the order of CON, LAC1 and LAC4.

\section{Statistical Analysis}

The trial was analyzed as a $3 \times 3$ Latin square design balanced for carry-over

effects with repeated measures (collections: LS, AC and HS) within each period. Fifteen horses $(n=15)$ were randomly assigned to one of five squares. Each $26 \mathrm{~d}$ period was divided into three sequential collections where starch level and sampling time were treated as split plots. Data were analyzed using mixed model procedures in SAS (SAS Inst. Inc., Cary, NC). The model included the fixed effects of period, DFM, starch and the interaction of DFM*starch level, and random effects of squares, horses within squares, and horse*latin square*period*treatment interaction. Tukey's mean comparison procedure was used to test differences between least squares means. Signifance was considered at $P<0.05$, and a tendency was considered at $0.05<P<0.10$.

\section{RESULTS}

\section{Intake and Digestibility}

All geldings maintained their initial BW and BCS throughout the study (Table 2). One horse had to be removed from the study at the end of the third period (during HS on the LAC4 treatment, $\mathrm{n}=14$ ) for health reasons unrelated to study treatments. Intake of hay and concentrate (DM basis) was not different among treatments and averaged 6.5 and $2.4 \mathrm{~kg} / \mathrm{hd} / \mathrm{d}$ respectively (Table 3). Average intake of starch was higher during AC and 
HS $(0.91 \mathrm{~kg} / \mathrm{d}, \mathrm{SEM} \pm 0.02)$ compared to LS $(0.55 \mathrm{~kg} / \mathrm{d}, \mathrm{SEM} \pm 0.02)(P<0.001$; data not shown).

With the exception of Fe digestibility, there was no significant interaction of starch and DFM on nutrient digestibilities (Table 4). While significant differences were detected within treatment means between starch levels on Table 4, those effects are most likely explained by the main effects shown in Table 5. There was a main effect of starch level on the digestibility of all nutrients $(P<0.02)$ except for $\mathrm{CP}, \mathrm{Mg}, \mathrm{K}$ and $\mathrm{Zn}$ (Table 5). Feeding the high-starch concentrate was associated with higher digestibilities of DM, OM, NDF, ADF, $\mathrm{P}, \mathrm{Cu}, \mathrm{Fe}, \mathrm{Mn}$ and $\mathrm{Na}(P<0.001$; Table 5). The abrupt change in starch resulted in the highest digestibility of EE $(P=0.002)$, whereas feeding the HS sustained for 12-d resulted in the highest digestibility of $\mathrm{S}(P<0.001$; Table 5). Sugar digestibility was the lowest during HS, whereas starch digestibility was lowest during AC $(P<0.001$; Table 5). The LAC1 supplemented horses had increased $(P<0.01) \mathrm{Cu}$ and Fe digestibility and LAC4 supplemented horses had increased $(\mathrm{P}<0.05) \mathrm{EE}, \mathrm{Cu}, \mathrm{Fe}$ digestibility and a tendency for decreased $\mathrm{Na}(P=0.07)$ digestibility compared to $\mathrm{CON}$ horses (Table 5).

\section{Fecal pH}

There was not a significant starch by DFM interaction on fecal $\mathrm{pH}$ (Table 4), however there was a main effect of $\operatorname{starch}(P<0.001)$ and a trend for a main effect of DFM $(P=0.06)$ on fecal pH (Table 5$)$. Fecal pH decreased $(P<0.001)$ as the starch content of the diet increased (Table 5). With respect to DFM, horses supplemented with 
LAC1 had a trend for a higher fecal $\mathrm{pH}$ (Table 5). Fecal $\mathrm{pH}$ was lowest $(P<0.001)$ across all treatment groups at the 0700 collection (Table 6). When fecal $\mathrm{pH}$ was averaged over the entire study for the three times of the day it was assessed, fecal $\mathrm{pH}$ was higher at hours 1200 and 1600 than at $0700(\mathrm{P}<0.05)$. There was also a starch by time of sampling interaction on fecal $\mathrm{pH}(P=0.04$; Figure $2 \mathrm{a})$.

\section{Fecal VFA}

Concentrations of fecal lactate and other VFA were below the level of detection and are therefore not reported. There was no starch by treatment interaction on fecal acetate and propionate concentrations or on the A:P molar ratio (Table 4). While fecal concentrations of acetate and propionate increased $(P<0.001)$ with an abrupt increase in starch, the acetate to propionate $(\mathrm{A}: \mathrm{P})$ molar ratio decreased $(P<0.001)$ with sustained high-starch (Table 5). Also shown in Table 5, there were no differences detected in fecal acetate or propionate when horses were supplemented with either LAC1 or LAC4. There was an effect of time of sampling on fecal acetate concentrations, where acetate was lower $(P<0.001)$ at the 1600 collection than at 0700 (Table 6). There was a starch by time interaction $(P=0.003)$ on fecal propionate concentration (Figure $2 \mathrm{~b}$ ).

\section{DISCUSSION}

\section{Effect of Excess Starch on Hindgut Fermentation}

The horse has a limited ability to digest starch in the small intestine (Pagan, 1998). Potter et al. (1992) determined that feeding $3.5 \mathrm{~g}$ of starch/kg of BW/meal exceeds the capacity of the horse's small intestine to digest starch, allowing nondegraded particles to reach the cecum. Upon reaching the cecum, starch elicits a series of 
chain reactions that alters the biochemistry and microbial ecology of the hindgut (Julliand et al., 2001). Hindgut fermentation of starch creates a highly acidic environment, leading to digestive disturbances that negatively affect the health and well-being of equine athletes (Bailey et al., 2003).

Because microbial growth is directly correlated with substrate availability, the presence of starch in the cecum serves as a rapidly fermentable substrate for starchdigesting LAB. Consequently, a starch overload in the horse can cause rapid growth of lactobacilli and streptococci bacteria in the hindgut (Bailey et al., 2003). The LAB produce organic acids (i.e. pyruvate, succinate and lactate) and short-chain fatty acids (VFA: acetate, propionate, and butyrate), in addition to carbon dioxide, methane, ammonia and hydrogen gas (Cummings et al., 1987; Dunne et al., 2001). When starch is available in large amounts in the hindgut, lactic acid is produced more rapidly than what can be absorbed by the animal or metabolized by lactate-utilizers, which causes the $\mathrm{pH}$ to decrease and makes it too harsh for fiber-digesting cellulolytic organisms to survive (Medina et al., 2002). Increased lactic acid also serves as a substrate for lactic-acid utilizing bacteria, such as Propionibacteria spp., to produce more propionic acid (Milinovich et al., 2006). This unbalanced microbial population associated with the production of lactic acid causes two problems: first, a decrease in $\mathrm{pH}$ that depresses fiber digestion (Pagan, 1998; Kohnke et al., 1999; Julliand et al., 2001) and secondly, has the potential to release endotoxins (Sprouse et al., 1987, Clarke et al., 1990). Ultimately, these disturbances can perpetuate acidosis, which in the horse can lead to ulcers (Andrews et al., 2005), colic (King, 1999; de Fombelle et al., 2001), endotoxemia 
(Sprouse et al., 1987, Clarke et al., 1990), and/or laminitis (Garner et al., 1977; Sprouse et al., 1987; Mansmann and King, 2000).

Reports of a reduced risk of acidosis in feedlot cattle fed high-concentrate diets supplemented with DFM prompted our interest in the potential of DFM to reduce the negative effects associated with feeding high-starch concentrates to horses. Ware et al. (1988) was the first to report increased feed efficiency when L. acidophilus was fed to yearling steers on high-concentrate diets. Huffman et al. (1992) found that feeding $L$. acidophilus at a dose of $5 \times 10^{8} \mathrm{CFU} / \mathrm{d}$ decreased the incidence of sub-acute acidosis in feedlot cattle by reducing the amount of time that ruminal $\mathrm{pH}$ was below 6.0. Ruminal pH below 5.6 has been associated with acidosis (Cooper and Klopfenstein, 1996).

Similarly, Van Koevering et al. (1994) reported that ruminal concentrations of D-lactate and total lactate were lower in steers fed L. acidophilus. Ghorbani et al. (2002) found that a daily top-dress of a LAB species plus a lactic acid utilizing species fed together at a dose of $10^{9} \mathrm{CFU} / \mathrm{g} / \mathrm{hd} / \mathrm{d}$ might decreased the risk of acidosis. While it can be argued that the digestive physiologies of cattle and horses are different, Kern et al. $(1973 ; 1974)$ demonstrated that the bacterial populations in the rumen and equine cecum are similar.

\section{DFM Research in Equine}

Similar studies conducted on equine are limited, with no studies published that indicate a benefit toward improved digestion or hindgut fermentation following DFM administration. When a LAB-based probiotic was administered to Thoroughbred foals during weaning, higher lactate and lower acetate concentrations in the feces were 
reported (Swanson et al., 2003). Berg et al. (2005) found a decrease in fecal pH and an increase in total fecal VFA when nine horses were offered fructooligosaccharides (FOS). While FOS are not DFM they are polysaccharides that escape small intestine digestion and act as a "prebiotic." Prebiotics stimulate the growth of LAB in vivo (Kaplan and Hutkins, 2000). Similarly, Millinovich et al. (2006) demonstrated that an oligofructose prebiotic caused a sharp decline in fecal $\mathrm{pH}$ and induced laminitic lameness $24-32 \mathrm{~h}$ post administration. On the other hand, a yeast culture (Saccharomyces cerevisiae) increased cecal and colonic $\mathrm{pH}$ and acetate and decreased lactic acid in horses when a starch overload was induced (Medina et al. 2002). Like the bacteria in the current study, yeast cultures are considered DFM. Yeast cultures have the potential to increase fiber digestion and reduce the acidogenic effects associated with feeding high-starch diets to ruminants (Martin and Nisbet, 1993; Newbold et al., 1996). With the exception of the yeast study, equine research suggests that the enhancement of LAB either through pro- or prebiotic supplementation further aggravates the starch overload situation in the intestinal ecosystem and could be detrimental to horse health. The discrepancy of equine studies with ruminant studies suggests that further trials are needed for determination of appropriate bacterial species and dosages most effective toward the prevention of acidotic disturbances in horses.

\section{Fecal pH}

Acidosis, by definition, is the decrease in alkali in body fluids relative to the hydrogen ion concentration (Stedman, 1982). The body regulates changes in $\mathrm{pH}$ by secreting bicarbonate $\left(\mathrm{HCO}_{3}^{-}\right)$, which serves to neutralize a low $\mathrm{pH}$, maintaining blood 
pH at 7.4 (Berg et al., 2001). However, during metabolic acidosis, the concentration of blood $\mathrm{HCO}_{3}{ }^{-}$is depressed and blood $\mathrm{pH}$ falls below 7.35 (Owens et al., 1998). Studies reporting that a cecal $\mathrm{pH}$ drop from 6.7 to 6.4 altered fermentation patterns and microbial ecology in the hindgut of the horse (de Fombelle et al., 2001; Julliand et al., 2001; Medina et al., 2002). In the current study, we did not determine cecal $\mathrm{pH}$, however a correlation between cecal and fecal $\mathrm{pH}$ has been reported in rats, with fecal $\mathrm{pH}$ being consistently higher than cecal $\mathrm{pH}$ (Campbell et al., 1997). Fecal responses of $\mathrm{pH}$ and VFA have been previously used as an indication of hindgut $\mathrm{pH}$ and fermentation patterns in horses (Hussein et al., 2004; Berg et al., 2005).

In the current study, fecal pH dropped with an increase in starch (Table 5), from a high of 6.61 on the LS diet to a low of 6.53 on the HS diet, which is within the range reported earlier on cecal pH (Julliand et al., 2001). The tendency for elevated fecal pH in the LAC1 supplemented horses (Table 5) suggests the potential of $L$. acidophilus to reduce the acidogenic effects associated with feeding high-starch concentrates to horses. The $\mathrm{pH}$ values are lower in the present study than what was reported earlier by Hussein et al. (2004), where a decrease in fecal $\mathrm{pH}$ from 7.04 to 6.64 in feces of geldings fed a control diet of alfalfa cubes versus barley (offered at or below $3.2 \mathrm{~g}$ starch $/ \mathrm{kg} \mathrm{BW} / \mathrm{d}$ ) was reported. Medina et al. (2002) reported that hindgut $\mathrm{pH}$ decreased rapidly after feeding a high starch diet, reaching a minimum between 5 to $7 \mathrm{~h}$ post-meal, where hindgut $\mathrm{pH}$ dropped to 6.43 at h-5. This is in contrast to the results of the current study, where fecal $\mathrm{pH}$ was lowest at the 0700 collection point, which would have been $14 \mathrm{~h}$ after the 1700 meal. However, we did not collect hourly samples to determine the true lowest point in $\mathrm{pH}$, so this could be misleading. The difference observed between the studies could also 
be attributed to the inherent delay in gut transit time; whereas Medina et al. (2002) reported minimum $\mathrm{pH}$ data corresponding to cecal samples, our data were from feces.

\section{Fecal VFA}

In addition to the drop in fecal $\mathrm{pH}$ induced by the high-starch concentrate, we also found a change in fecal VFA concentrations. The principal VFA produced in the rumen and the hindgut of monogastrics are acetate, propionate, and butyrate in ratios varying from 75:15:10 to 40:40:20, with relative proportions being similar across species (Elsden et al., 1946; Bergman, 1990). Acetic acid predominates with roughage diets, whereas propionic acid is produced in greater amounts as the grain portion of the diet is increased. Although fecal VFA concentrations may not represent actual hindgut VFA concentrations, they can provide relevant information regarding increases or decreases in VFA production and reflect the difference between production and absorption (Hussein et al., 2004; Berg et al., 2005). Because there was an increase in fecal acetate caused by an abrupt change in starch, a 'high-starch' concentrate ( $\sim 35 \%$ of the pelleted formula) might promote digestibility of the fibrous portion of the diet. In contrast, Medina et al. (2002) reported decreased cecal acetate concentration when horses were switched from a highfiber to a high-starch diet. However, they reported no significant change of acetate in samples taken from the colon. The difference observed between studies could be attributed to differences in the diet and/or fecal versus cecal concentrations of VFA. In another study, FOS supplementated to yearling horses resulted in increased fecal acetate concentrations (Berg et al., 2005). Because FOS acts as a prebiotic for LAB, it could be speculated that the enhancement of the LAB ecology in the horse improves fiber 
digestion. Wallace (1994) suggested that an enhancement of LAB populations in the GI tract improves the viability and number of total anaerobic bacteria including cellulolytics, thereby improving fiber breakdown and increasing acetate concentration. Therefore, the observed increase in acetate may be attributed to the increase in dietary starch, therby increasing anaerobic bacterial populations, and eliciting an increase in total VFA.

Our study supports the hypothesis that an abrupt increase in starch elevates concentrations of fecal propionate, where the greatest increase $(8.9 \mathrm{mmol} / \mathrm{g})$ corresponded to the $\mathrm{CON}$ horses during $\mathrm{AC}$ (Table 5). This is in agreement with Medina et al. (2002), who showed increased cecal propionate when starch was increased in the equine diet. Similarly, Hussein et al. (2004) reported an increase in fecal propionate from 0.9 to $2.0 \mathrm{mg} / \mathrm{g}$ when horses were fed alfalfa cubes versus alfalfa cubes + barley; however in that study they also showed an increase in total VFA with grain supplementation. While there were numerical differences in fecal propionate concentrations when LAC1 and LAC4 were supplemented to horses, there was not a significant increase in proprionate detected when starch was increased in the diet (Table 4). However, fecal propionate concentrations were very similar in CON, LAC1 and LAC4 horses (8.0, 8.1 and $8.2 \mathrm{mmol} / \mathrm{g}$ respectively) during the same HS collection (Table 4).

The fecal A:P molar ratios in the present study ranged from 10.9 to $12.4 \mathrm{mmol} / \mathrm{g}$ and were very high compared to those reported in previous studies (Medina et al, 2002; Hussein et al., 2004). Consequently, a random subset of the fecal VFA samples were 
analyzed for a second time and confirmed at the University of Maryland's Department of Animal and Avian Sciences using gas chromatography (6890N GC, Agilent Technologies, Santa Clara, CA). The high molar ratios in the current study could be attributed to variability caused by the volatility of VFA post-defecation (Merritt and Smith, 1980). The high A:P molar ratio could also reflect the occurrence of reductive acetogenesis at the expense of propionate, as seen in the hindguts of termites (Breznak, 1994) and humans (Wolin and Miller, 1994). Additionally, data from a preliminary study in our laboratory (Bequette and Burk, personal communication) also demonstrated high fecal A:P molar ratios ranging from 17:1 to $20: 1$ from horses consuming timothy or reed canarygrass hay at maintenance. Consequently, it seems that the high A:P molar ratios are biologically relevant and supports that fiber digestion was also high.

\section{Digestibility}

In this study and one other (Medina et al., 2002), low-starch and high-starch concentrates were fed at the same level of DMI such that the amount of NDF in the highstarch diet was lower than in the low-starch diet (i.e., $\sim 17 \%$ vs. $\sim 28 \%$ NDF respectively). The DMI of starch increased with the high-starch concentrate ( $\sim .55$ vs. $\sim 0.91 \mathrm{~kg} / \mathrm{d}$ for low-starch and high-starch diets, respectively). This higher level of starch intake provided by the HS concentrate may have allowed for a greater amount of starch to reach the hindgut (Potter et al., 1992) which is evidenced by the drop in $\mathrm{pH}$ and increase in propionate when horses were switched from LS to HS (Table 5). 
This study hypothesized an interaction between starch level and LAB supplementation on the apparent digestion of nutrients. In agreement with others (Karlsson et al., 2000; Drogoul et al., 2001; Hussein et al., 2004), our results show that DM and OM digestibility increased with HS (Table 5). This response could be attributed to the increased fiber digestibility also seen when horses were fed the high-starch concentrate. Despite decreased hindgut $\mathrm{pH}$ (as illustrated by lowered fecal $\mathrm{pH}$ ), increasing starch in the diet resulted in greater fiber digestibility. A neutral fecal $\mathrm{pH}$ around 7.0 in the horse is known to support fiber digestion (Hussein et al., 2004). Hypothetically, should the fecal $\mathrm{pH}$ drop below 6.0, impaired digestion of ADF and NDF would be expected. Oba and Allen (2003) found no change in fiber digestibility when dairy cows were fed at two concentrations of dietary starch ( 32 and $21 \%$ starch), which is similar to the levels fed in the current study ( 36 and $21 \%$ starch). It is possible that enhancement of LAB populations in the GI tract, either indirectly by increased presence of starch or directly by DFM supplementation, may improve the viability and number of total anaerobic bacteria including those that are cellulolytic, thereby improving fiber digestion (Wallace, 1994) and contributing to increased DM and OM digestibility.

The LAC4 increased the apparent digestibility of EE by $5.1 \%$, regardless of starch level (Table 5). It has been previously reported that lactobacilli are effective in assimilating cholesterol in vivo in pigs and rats (Danielson et al., 1989; Grunewald, 1982; De Rodas et al., 1996). In an anaerobic environment where bile salts are present, as would occur in the small intestine, some lactobacilli strains can deconjugate bile acids and assimilate cholesterol during colony growth where a reduction in serum cholesterol 
has been reported in pigs (De Rodas, 1996). In ruminant studies it has also been shown that certain microbes express lipases and are most active in this hydrolysis when $\mathrm{pH}$ is close to neutral (Hobson and Stewart, 1997). The current study indicates that direct-fed LAB may improve the digestibility of the lipid portion of the diet.

Results on starch digestibility are in agreement with previous research where it has been demonstrated in horses (de Fombelle et al., 2004; Hussein et al., 2004), ruminants (Orskov, 1986; Elizalde et al., 1999; Oba and Allen, 2002; Huntington et al., 2006), and poultry (J. Shelton, personal communication) that total tract apparent digestibility of starch is nearly $100 \%$ (averaging $95 \%, 96 \%$, and $99 \%$ respectively). Starch digestion was lowest during AC (Table 5), suggesting that amylase activity may have been saturated due to an abrupt increase in starch present in the gut. However, because our data shows that there is no difference in starch digestion between the LS and HS time points, it leads us to believe that amylase activity from amylolytic bacteria had adjusted to a higher level after the HS concentrate had been offered for a sustained amount of time.

While all diets were formulated to meet minimum maintenance requirements of $550 \mathrm{~kg}$ horses, negative $\mathrm{P}, \mathrm{Cu}, \mathrm{Fe}, \mathrm{Mn}, \mathrm{Na}$ and $\mathrm{Zn}$ digestibility data indicate greater endogenous losses of these minerals compared with intake, which has been previously observed in horses (Ordakowski-Burk et al., 2006). The trend for increased Ca digestibility during HS when horses were supplemented with LAC4 concurs with a study performed on broiler chickens, where mean Ca retention was increased when a similar 
DFM was fed (Angel et al., 2005). The calcium content of the timothy hay used in this study was similar to that of grass hays used in previous studies investigating digestibility in horses (Crozier et al., 1997; Ordakowski-Burk et al., 2006).

In humans, a therapeutic dose of $1 \times 10^{8} \mathrm{CFU} / \mathrm{d}$ to $1 \times 10^{10} \mathrm{CFU} / \mathrm{d}$ has been recommended (Kailasapathey and Chin, 2000). There were no DFM dose titration studies available to reference for equine. However, Weese (2001) extrapolated from human dosages, that an average horse $(\sim 450 \mathrm{~kg})$ would likely require at least $1 \times 10^{9}$ $\mathrm{CFU} / 50 \mathrm{~kg} \mathrm{BW} / \mathrm{d}$ to $1 \times 10^{11} \mathrm{CFU} / 50 \mathrm{~kg} \mathrm{BW} / \mathrm{d}$ of an organism that is able to colonize the intestinal tract. While the digestive physiology of humans and horses are quite different, it is at least a reference point from which to start future dosage trials from. The DFM used in this study were guaranteed by the manufacturer to contain a minimum of $1.0 \mathrm{x}$ $10^{8} \mathrm{CFU} / \mathrm{g}$ at a recommended inclusion of 0.91 to $1.36 \mathrm{~kg} / \mathrm{ton}$ in diets intended for animal application. We found that treatment-type lactobacilli, enterococci and bifidobacteria remained viable and incurred minimal loss during feed processing and storage in this study, however this cannot be stated with complete certainty due to a high level of naturally-occurring bacterial organisms counted during enumeration (see Manuscript 1). It can be stated however, that no treatment-type bacteria cross-contamination was found in the CON diet (see Manuscript 1).

In summary, the changes associated with supplementing equine diets with directfed LAB were marginal with respect to digestibility. Only the single strain, $L$. acidophilus, showed a tendency toward minimizing the occurrence of acidosis as 
evidenced by increased fecal $\mathrm{pH}$, regardless of starch. This study supports prior evidence that feeding starch to horses has both positive and negative effects; starch elicits higher nutrient digestibilities, but also induces undesirable changes in hindgut $\mathrm{pH}$ and VFA concentrations (as evidenced by changes in the feces). It is possible that the direct-fed LAB treatments would have been more effective had a higher level of starch been offered to horses during the abrupt change. The lack of effects on digestibility and fecal VFA and $\mathrm{pH}$ due to direct-fed LAB may be related to quality control issues associated with the DFM preparation (see Manuscript 1), improper dosage levels chosen, or improper bacterial strains selected for the purpose of improving digestibility and hindgut fermentation variables associated with acidosis in horses.

\section{IMPLICATIONS}

Offering a higher starch concentrate to equine may enhance the nutrient digestibility of the diet and alter hindgut fermentation as indicated by changes in fecal $\mathrm{pH}$ and VFA observed in this study. Supplementing equine with either a single or mixed strain direct-fed lactic acid bacteria had minimal effects on increasing nutrient digestibility or reducing those risks associated with feeding high-starch concentrates to horses. Perhaps exploring alternative bacterial species intended for DFM preparations may enhance digestibility beyond what was observed in the current study. Additionally, dose titration studies for bacterial DFM fed to horses are limited and more are needed. 


\section{LITERATURE CITED}

Andrews, F. M., B. R. Buchanan, S. B. Elliot, N. A. Clariday, and L. H. Edwards. 2005. Gastric ulcers in horses. J. Anim. Sci. 83 (E. Suppl.): E18-E21.

Angel, R., R. A. Dalloul, and J. Doerr. 2005. Performance of broiler chickens fed diets supplemented with direct-fed microbials. Poultry Sci. 84:1222-1231.

Bailey, S.R., M. L. Baillon, A. Rycroft, P. A. Harris, and J. Elliott. 2003. Identification of equine cecal bacteria producing amines in an in vitro model of carbohydrate overload. Appl. Enviro. Microbiol. 69(4):2087-2093.

Beauchemin, K. A., W. Z. Yang, D. P. Morgavi, G. R. Ghorbani, W. Kautz, and J. A. Z. Leedle. 2003. Effects of bacterial direct-fed microbials and yeast on site and extent of digestion, blood chemistry, and subclinical ruminal acidosis in feedlot cattle. J. Anim. Sci. 81:1628-1640.

Berg, J. M., J. L. Tymoczko, and L. Stryer. 2001. Biochemistry, 5th ed. W. H. Freeman and Co. New York, NY.

Berg, E. L., C. J. Fu, J. H. Porter, and M. S. Kerley. 2005. Fructooligosaccharide supplementation on the yearling horse: Effects on fecal $\mathrm{pH}$, microbial content and volatile fatty acid concentrations. J. Anim. Sci. 83:1549-1553.

Bergman, E. N. 1990. Energy contributions of volatile fatty acids from the gastrointestinal tract in various species. Physiol. Rev. 70:567-590.

Breznak, J. A. 1994. Acetogenesis from carbon dioxide in termite guts. Pages 303-330 in Acetogenesis. H. L. Drake, ed. Chapman and Hall, New York, NY.

Campbell, J. M., G. C. Fahey, Jr., and B. W. Wolf. 1997. Selected indigestible oligosaccharides affect large bowel mass, cecal and fecal short-chain fatty acids, $\mathrm{pH}$ and microflora in rats. J. Nutr. 127:130-136.

Clarke, L. L., M. C. Roberts, and R. A. Argenzio. 1990. Feeding and digestive problems in horses: Physiologic responses to a concentrated meal. Vet. Clin. North. Am. 6:433-450.

Cooper, R. and T. Klopfenstein. 1996. Effect of Rumensin and feed intake variation on ruminal $\mathrm{pH}$. Pages A1-A14 in Scientific Update on Rumensin/Tylan/Mycotil for the Professional Feedlot Consultant. Elanco Animal Health, Indianapolis, IN.

Crozier, J. A., V. G. Allen, N. E. Jack, J. P. Fontenot, and M. A. Cochran. 1997. Digestibility, apparent mineral absorption, and voluntary intake by horses fed alfalfa, tall fescue, and caucasian bluestem. J. Anim. Sci. 75:1651-1658. 
Cummings, J. H., Pomare, E. W., Branch, J. W., Naylor, C. P. E., and Macfarlane, G. T. 1987. Short chain fatty acids in human large intestine portal, hepatic and venous blood. Gut. 28(10):1221-1227.

Danielson, A. D., E. R. Peo, K. M. Shahani, A. J. Lewis, P. J. Whalen and M. A. Amer. 1989. Anticholesteremic property of Lactobacillus acidophilus yogurt fed to mature boars. J. Anim. Sci. 67(4):966-974.

de Fombelle, A., V. Julliand, C. Drogoul, and E. Jacotot. 2001. Feeding and microbial disorders in horses: 1 - Effects of an abrupt incorporation of two levels of barley in a hay diet on microbial profile and activities. J. Equine Vet. Sci. 21: 439-445.

de Fombelle, A., L. Veiga, C. Drogoul, and V. Julliand. 2004. Effect of diet composition and feeding pattern on the prececal digestibility of starches from diverse botanical origins measured with the mobile nylon bag technique in horses. J. Anim. Sci. 82:3625-3634.

De Rodas, B. Z., S. E. Gilliland, and C. V. Maxwell. 1996. Hypocholesterolemic action of Lactobacillus acidophilus ATCC 43121 and calcium in swine with hypercholesterolemia induced by diet. J. Dairy Sci. 79:2121-2128.

Drogoul, C., A. de Fombelle, and V. Julliand. 2001. Feeding and microbial disorders in horses: 2-Effects of three hay:grain ratios on digesta passage rate and digestibility in ponies. J. Equine Vet. Sci. 21:487-490.

Dubois, M., K. A. Gilles, J. K. Hamilton, P. A. Reber, and F. Smith. 1956. Colorimetric method for determination of sugars and related substances. Anal. Chem. 28:350356.

Dunne, C., L. O’Mahony, L. Murphy, G. Thornton, D. Morrissey, S. O’Halloran, M. Feeney, S. Flynn, G. Fitzgerald, C. Daly, B. Kiely, G. C. O’Sullivan, F. Shanahan and J. K. Collins. 2001. In vitro selection criteria for probiotic strains Correlation with in vivo findings. Am. J. of Cl. Nut. 73(2):386-392.

Elizalde, J. C., N. R. Merchen, and D. B. Faulkner. 1999. Supplemental cracked corn for steers fed fresh alfalfa: I. Effects on digestion of organic matter, fiber, and starch. J. Anim. Sci. 77:457-466.

Elsden, S. R., M. W. S. Hitchcock, R. A. Marshall, and A. T. Phillipson. 1946. Volatile acid in the digesta of ruminants and other animals. J. Exp. Biol. 22:191-202.

Frape, D. 2004. Pages 20-26 and 162-165 in Equine Nutrition and Feeding, $3^{\text {rd }}$ rev. ed. Blackwell Publishing, Ames, Iowa.

Fuller, R. 1989. A review: Probiotics in man and animals. J. Appl. Bacteriol. 66:365378. 
Galyean, M. L., G. A. Nunnery, P. J. Defoor, G. B. Salyer, and C. H. Parsons. 2000. Effects of live cultures of Lactobacillus acidophilus (Strains 45 and 51) and Propionibacterium freudenreichii PF-24 on performance and carcass characteristics of finishing beef steers. Burnett Center Progress Report No. 8. Available: http://www.afs.ttu.edu/burnett_center/progress_reports/bc8.pdf. Accessed Feb. 2007.

Ghorbani, G. R., D. P. Morgavi, K. A. Beauchemin, and J. A. A. Leedle. 2002. Effects of bacterial direct fed microbials on ruminal fermentation, blood variables, and the microbial populations of feedlot cattle. J. Anim. Sci. 80:1997-1986.

Grunewald, K. K. 1982. Serum cholesterol levels in rats fed skim milk fermented by Lactobacillus acidophilus. J. Food Sci. 47:2078-9.

Hall, M.B., W.H. Hoover, J.P. Jennings and T.K. Miller Webster. 1999. A method for partitioning neutral detergent soluble carbohydrates. J. Sci. Food Agric. 79:2081.

Henneke, D. R., G. D. Potter, J. L. Kreider, and B. F. Yeates. 1983. Relationship between condition score, physical measurements and body fat percentage in mares. Equine Vet. J. 15:371-372.

Hobson, P. N. and C. S. Stewart. 1997. The Rumen Microbial Ecosystem, $2^{\text {nd }}$ ed. Blackie Academic and Professional. Chapman and Hall. New York, NY.

Hoffman, R. M. 2003. Carbohydrate metabolism in horses. In: Recent Advances in Equine Nutrition. S.L. Ralston and H.F. Hintz, ed. IVIS. Ithaca, NY.

Huffman, R. P., K. K. Karges, T. J. Klopfenstein, R. A. Stock, R. A. Britton, and L. D. Roth. 1992. The effect of Lactobacillus acidophilus on subacute ruminal acidosis. J. Anim. Sci. 70(Suppl. 1):87(Abstr.)

Hungate, R. E. 1966. The Rumen and its Microbes. Academic Press Inc., New York.

Huntington, G. B., D. L. Harmon, and C. J. Richards. 2006. Sites, rates, and limits of starch digestion and glucose metabolism in growing cattle. J. Anim. Sci. 84(E. Suppl.):E14-E24.

Hussein, H. S., L. A. Vogedes, G. C. J. Fernandez, and R. L. Frankeny. 2004. Effects of cereal grain supplementation on apparent digestibility of nutrients and concentrations of fermentation end-products in the feces and serum of horses consuming alfalfa cubes. J. Anim. Sci. 82:1986-1996.

Julliand V., A. de Fombelle, C. Drogoul, and E. Jacotot. 2001. Feeding and microbial disorders in horses: 3 -Effects of three hay:grain ratios on microbial profile and activities. J. Equine Vet. Sci. 21:543-546. 
Kaplan, H., and R. W. Hutkins. 2000. Fermentation of fructooligosaccharides by lactic acid bacteria and bifidobacteria. Appl. Environ. Microbiol. 66:2682-2684.

Karlsson, C. P., J. E. Lindberg, and M. Rundgren. 2000. Associative effects on total tract digestibility in horses fed different ratios of grass hay and whole oats. Livest. Prod. Sci. 65:143-153.

Kern, D. L., L. L. Slyter, J. M. Weaver, E. C. Leffel, and G. Samuelson. 1973. Pony cecum vs. steer rumen: The effect of oats and hay on the microbial ecosystem. J. Anim. Sci. 37:463-469.

Kern, D. L., L. L. Slyter, E. C. Leffel, J. M. Weaver, and R. R. Oltjen. 1974. Ponies vs. steers: microbial and chemical characteristics of intestinal ingesta. J. Anim. Sci. 38: $559-563$.

Kim L., P. S. Morley, J. L. Traub-Dargatz, D. Salmana and C. Gentry-Weeks. 2001. Factors associated with Salmonella shedding among colic patients at a veterinary teaching hospital. J. Am. Vet. Med. Assoc. 218(5):740-748.

King, C. 1999. Preventing Colic in Horses. Paper Horse, Cary, NC.

Kohnke, J. R., F. Kelleher, and P. Trevor-Jones. 1999. Feeding Horses in Australia: A Guide for Horse Owners and Managers. Rural Industries Res. \& Development Corp., Barton, Australia.

Krehbiel, C. R., S. R. Rust, G. Zhang, and S. E. Gilliland. 2003. Bacteria direct-fed microbials in ruminant diets: Performance response and mode of action. J. Anim. Sci. 81(E. Suppl. 2):120-132.

Maciorowski, K. G., P. Herrera, F. T. Jones, S. D. Pillai, and S. C. Ricke. 2007. Effects on poultry and livestock of feed contamination with bacteria and fungi. Animal Feed and Science Tech. 133:109-136.

Mansmann, R. A., and C. King. 2000. Preventing Laminitis in Horses. Paper Horse, Cary, NC.

Martin, S. A., and D. J. Nisbet. 1992. Effect of direct-fed microbials on ruminal microbial fermentation. J. Diary Sci. 75:1736-1744.

Medina, B., I. D. Girard, E. Jacotot, and V. Julliand. 2002. Effect of preparation of Saccharomyces cerevisiae on microbial profiles and fermentation patterns in the large intestine of horses fed a high fiber or high starch diet. J. Anim. Sci. 80:2600-2609. 
Merritt, A. M., and D. A. Smith. 1980. Osmolarity and volatile fatty acid content of feces from horses with chronic diarrhea. Am J Vet Res. 41(6):928-931.

Milinovich, G. J., D. J. Trott, P. C. Burrell, A. W. van Eps, M. B. Thoefner, L. L. Blackall., R. A. M. Al Jassim, J. M. Morton, and C. C. Pollitt. 2006. Changes in equine hindgut bacterial populations during oligofructose-induced laminitis. Environ. Microbiol. 8(5):885-898.

NRC. 2007. Nutrient Requirements of Horses. $6^{\text {th }}$ rev. ed. Natl. Acad. Press, Washington, D.C.

Newbold, C. J., R. J. Wallace, and F. M. McIntosh. 1996. Mode of action of the yeast Saccharomyces cerevisiae as a feed additive for ruminants. Brit. J. Nutr. 76:249261.

Oba, M., and M. S. Allen. 2003. Effects of corn grain conservation method on ruminal digestion kinetics for lactating dairy cows at two dietary starch concentrations. J. Dairy Sci. 86:184-194.

Ordakowski-Burk, A. L., R. W. Quinn, T. A. Shellem, and L. R. Vough. 2006. Voluntary intake and digestibility of reed canarygrass and timothy hay fed to horses. J. Anim. Sci. 84:3104-3109.

Orskov, E. R., D. A. Grubb, J. S. Smith, A. J. Webster, and W. Corrigall. 1979. Efficiency of utilization of volatile fatty acids for maintenance and energy retention by sheep. Br. J. Nutr. 41:541-550.

Owens, F. N., D. S. Secrist, W. J. Hill, and D. R. Gill. 1998. Acidosis in cattle; a review. J. Anim. Sci. 76:275-286.

Pagan, J. D. 1998. Carbohydrates in equine nutrition. Pages 57-70 in Advances in Equine Nutrition. J. D. Pagan, ed. Nottingham Univ. Press, Nottingham, U.K.

Parraga, M. E., S. J. Spier, M. Thurmond and D. Hirsh. 1997. A clinical trial of probiotic administration for prevention of Salmonella shedding in the postoperative period in horses with colic. J. Vet. Int. Med. 11:36-41.

Potter, G. D., F. F. Arnold, D. D. Householder, D. H. Hansen, and K. M. Brown. 1992. Digestion of starch in the small or large intestine of the equine. Pferdeheilkunde. 1:107-111.

Rust, S. R., K. Metz, and D. R. Ware. 2000. Effect of Bovamine rumen culture on the performance and carcass characteristics of feedlot steers. Pages 22-26 in Mich. Agric. Exp. Sta. Beef Cattle, Sheep, and Forage Sys. Res. Dem. Rep. No. 569, East Lansing. 
SAS Institute Inc. SAS Online Doc., Version 9.1.2. SAS User's Guide, 2004 Cary, NC.

Sprouse, R. F., H. E. Graner, and E. M. Green. 1987. Plasma endotoxin levels in horses subjected to carbohydrate induced laminitis. Equine Vet. J. 19:25-28.

Star-Labs. 2006. Direct-fed Microbial. http://www.primalac.com/probiotics.html. Clarksdale, MO.

Stedman, T. L. 1982. Stedman's Medical Dictionary. Williams and Wilkins, Baltimore, MD.

Swanson, C. A., D. S. Kronfeld, R. M. Hoffman, and R. K. Splan. 2003. Effects of diet and probiotic supplementation on stress during weaning in Thoroughbred foals. Page 243 in Proc. $18^{\text {th }}$ Equine Nutr. Physiol. Soc. Symp., East Lansing, MI.

Swinney-Floyd, D., B. A. Gardiner, F. N. Owens, T. Rehberger, and T. Parrott. 1999. Effects of inoculation with either strain P-63 alone or in combination with Lactobacillus acidophilus LA53545 on performance of feedlot cattle. J. Anim. Sci. 77(Suppl. 1):77 (Abstr.).

Swyers, K. L., A. O. Burk, C. R. Angel, E. M. Ungerfeld, L. W. Douglass, K. L. Poorman and R. V. Kapadia. 2007. Effects of Viability of lactic acid bacteria in animal feed after pelleting and storage. M. S. Thesis. University of Maryland, College Park.

Van Koevering, M. T., F. N. Owens, D. S. Secrist, R. H. Anderson, and R. E. Herman. 1994. Cobactin II for feedlot steers. J. Anim. Sci. 72(Suppl. 1):83.

Van Weyenberg, S., J. Sales, and G. J. Janssens. 2005. Passage rate of digesta through the equine gastrointestinal tract: A review. Livest. Sci. 99:3-12

Wallace, R. J. 1994. Ruminal microbiology, biotechnology, and ruminant nutrition: progress and problems. J. Anim. Sci. 72:2992-3003.

Ware, D. R., P. L. Read, and E. T. Manfredi. 1988. Pooled summary of eight feedlot trials evaluating performance and carcass characteristics of steers fed Lactobacillus acidophilus strain BT1386. J. Anim. Sci. 66(Suppl. 1):436(Abstr.).

Weese, J. S. 2001. A Review of Probiotics: Are They Really "Functional Foods"? AAEP Proc. 47:27-31.

Weese, J. S., M. E. C. Anderson, A. Lowe, and G. J. Monteith. 2003. Preliminary investigation of probiotic potential of Lactobacillus rhamnosus strain GG in horses: fecal recovery following oral administration and safety. Can. Vet. J. 44:299-302. 
Weese, J. S., M. E. C. Anderson, A. Lowe, R. Penno, T. M. Da Costa, L. Button, and K. C. Goth. 2004. Screening of the equine intestinal microflora for potential probiotic organisms. Equine Vet. J. 36(4):351-355.

Weese, J. S. and J. Rousseau. 2005. Evaluation of Lactobacillus pentosus WE7 for prevention of diarrhea in neonatal foals. J. Am. Vet. Med. Assoc. 226(12):20312034.

Weyenberg, S. V., J. Sales, G. P. J. Janssens. 2006. Passage rate of digesta through the equine gastrointestinal tract: a review. Livest. Sci. 9:3-12

Wolin, M. J. and T. L. Miller. 1994. Acetogenesis from $\mathrm{CO}_{2}$ in the human colonic ecosystem. Pages 365-385 in Acetogenesis. H. L. Drake, ed. Chapman and Hall, New York, NY.

Yoon, I. K., and M. D. Stern. 1995. Influence of direct-fed microbials on ruminal fermentation and performance of ruminants: a review. Austrailia J. Anim. Sci. 8:533-555.

Yuyama, T., S. Yusa, S. Takai, S. Tsubaki, Y. Kado and M. Morotomi. 2004. Evaluation of a host-specific Lactobacillus probiotic in neonatal foals. Int. J. Appl. Res. Vet. Med. 2(1):26-33. 


\section{TABLES AND FIGURES}

Table 1. Nutrient composition of grass hay and low- and high-starch concentrates fed to Thoroughbred geldings ${ }^{1}$

\begin{tabular}{lccc}
\hline \hline & \multicolumn{3}{c}{ Feedstuffs } \\
\hline Item, \% & Hay $^{3}$ & LS $^{3,4}$ & HS $^{3,4}$ \\
\hline $\mathrm{DM}$ & 82.4 & 84.0 & 84.5 \\
$\mathrm{Ash}$ & 3.9 & 8.9 & 8.2 \\
$\mathrm{CP}$ & 7.7 & 14.4 & 14.4 \\
$\mathrm{EE}$ & 1.8 & 7.3 & 6.8 \\
$\mathrm{NDF}$ & 61.6 & 28.1 & 17.1 \\
$\mathrm{ADF}$ & 34.4 & 12.2 & 6.3 \\
Sugar & 3.6 & 3.9 & 3.1 \\
$\mathrm{Starch}$ & 6.3 & 21.4 & 35.8 \\
$\mathrm{Ca}$ & 0.3 & 1.0 & 0.9 \\
$\mathrm{P}$ & 0.2 & 0.7 & 0.8 \\
$\mathrm{Mg}$ & 0.2 & 0.4 & 0.4 \\
$\mathrm{~K}$ & 1.0 & 1.0 & 0.8 \\
$\mathrm{~S}$ & 0.2 & 0.2 & 0.2 \\
$\mathrm{Cl}$ & 0.3 & 0.8 & 0.7 \\
$\mathrm{Na}$ & 0.0 & 0.5 & 0.4 \\
$\mathrm{Cu}, \mathrm{ppm}$ & 4 & 54 & 51 \\
$\mathrm{Zn}, \mathrm{ppm}$ & 15 & 166 & 205 \\
$\mathrm{Fe}, \mathrm{ppm}$ & 64 & 829 & 1011 \\
$\mathrm{Mn}, \mathrm{ppm}$ & 141 & 148 & 166 \\
\hline
\end{tabular}

\footnotetext{
${ }^{1}$ Mean values of weekly samples of feedstuffs taken during 3 treatment periods, reported on a DM basis from Cargill Innovation Center, Elk River, MN. $(\mathrm{n}=12)$

${ }^{2}$ Sugar was reported as water soluble carbohydrates (WSC) from Dairy One, Ithaca, NY.

${ }^{3}$ Hay was fed at $1.5 \%$ of BW and concentrates were fed at $0.5 \% \mathrm{BW}$ on an as-fed basis for a $70: 30$ ratio.

${ }^{4} \mathrm{LS}=$ low-starch pelleted concentrate fed for intake of $1.2 \mathrm{~g}$ starch $\cdot \mathrm{kg}^{-1} \mathrm{BW} \cdot \mathrm{meal}^{-1}$ and

$\mathrm{HS}=$ high-starch pelleted concentrate fed for intake of $2.4 \mathrm{~g} \mathrm{starch} \cdot \mathrm{kg}^{-1} \mathrm{BW} \cdot \mathrm{meal}^{-1}$
} 
Table 2. Body weight and body condition scores of Thoroughbred geldings consuming low- and high-starch concentrates containing either: no (Control), one strain (LAC1), or four strains (LAC4) of lactic acid producing bacteria DFM $(n=15)$

\begin{tabular}{lcccc}
\hline \hline & \multicolumn{4}{c}{ Treatment } \\
\cline { 2 - 5 } Item & Control & LAC1 & LAC4 & SE $^{2}$ \\
\hline BW initial, kg & 565 & 568 & 566 & 2.78 \\
BW final, kg & 570 & 570 & 571 & 1.60 \\
BCS initial & 5.7 & 5.8 & 5.6 & 0.07 \\
BCS final & 5.7 & 5.7 & 5.8 & 0.06 \\
\hline
\end{tabular}

\footnotetext{
${ }^{1}$ The least squares means for the column of data represent $n=14$.

${ }^{2}$ Standard error of the mean, calculated from the error mean square.
} 
Table 3. Daily intakes of geldings consuming low- and high-starch concentrates containing either: no (Control), one strain (LAC1), or four strains (LAC4) of lactic acid producing bacteria DFM $(\mathrm{n}=15)^{1,2}$.

\begin{tabular}{|c|c|c|c|c|c|c|c|c|c|c|c|}
\hline \multicolumn{12}{|c|}{ Treatments } \\
\hline & \multicolumn{3}{|c|}{ Control } & \multicolumn{3}{|c|}{$\mathrm{LACl}$} & \multicolumn{3}{|c|}{ LAC4 } & \multirow[b]{2}{*}{ SE } & \multirow[b]{2}{*}{$P$-value ${ }^{3}$} \\
\hline Item & LS & $\mathrm{AC}$ & HS & LS & $\mathrm{AC}$ & HS & LS & $\mathrm{AC}$ & $\mathrm{HS}^{2}$ & & \\
\hline \multicolumn{12}{|l|}{ DMI, $\mathrm{kg} / \mathrm{d}$} \\
\hline Hay & 6.41 & 6.38 & 6.58 & 6.46 & 6.42 & 6.47 & 6.55 & 6.64 & 6.55 & 0.19 & 0.31 \\
\hline Concentrate & 2.32 & 2.35 & 2.35 & 2.33 & 2.36 & 2.36 & 2.35 & 2.35 & 2.34 & 0.06 & 0.29 \\
\hline Total & 8.73 & 8.72 & 8.93 & 8.79 & 8.78 & 8.83 & 8.90 & 8.99 & 8.89 & 0.24 & 0.29 \\
\hline
\end{tabular}

${ }^{1}$ LS=low starch collection d 10-13, AC=abrupt change to HS collection d 15-17, and HS=high starch collection d 24-26.

${ }^{2} \mathrm{n}=14$

${ }^{3}$ Denotes the level of significance for DFM treatment $\mathrm{x}$ starch interaction. 
Table 4. Interaction (starch $x$ treatment) effects of low- and high-starch concentrates containing either: no (Control), one strain (LAC1), or four strains (LAC4) of a lactic acid producing bacteria DFM on apparent total tract digestibility of nutrients, fecal $\mathrm{pH}$ and fecal VFA concentrations of Thoroughbred geldings $(\mathrm{n}=15)^{1,2}$

\begin{tabular}{|c|c|c|c|c|c|c|c|c|c|c|c|}
\hline \multirow[b]{3}{*}{ Item } & \multicolumn{9}{|c|}{ Treatment } & \multirow[b]{3}{*}{ SE } & \multirow[b]{3}{*}{$P$-value ${ }^{3}$} \\
\hline & \multicolumn{3}{|c|}{ Control } & \multicolumn{3}{|c|}{ LAC1 } & \multicolumn{3}{|c|}{ LAC4 } & & \\
\hline & LS & $\mathrm{AC}$ & $\mathrm{HS}$ & LS & $\mathrm{AC}$ & $\mathrm{HS}$ & LS & $\mathrm{AC}$ & $\mathrm{HS}^{2}$ & & \\
\hline \multicolumn{12}{|l|}{ DMD, $\%$ of intake } \\
\hline $\mathrm{DM}$ & $41.9^{\mathrm{a}}$ & $45.8^{\mathrm{b}}$ & $47.1^{\mathrm{b}}$ & $40.3^{\mathrm{a}}$ & $46.2^{\mathrm{b}}$ & $46.4^{\mathrm{b}}$ & $41.3^{\mathrm{a}}$ & $47.0^{\mathrm{b}}$ & $47.0^{\mathrm{b}}$ & 1.0 & 0.64 \\
\hline $\mathrm{OM}$ & $43.0^{\mathrm{a}}$ & $47.2^{\mathrm{b}}$ & $48.3^{\mathrm{b}}$ & $41.3^{\mathrm{a}}$ & $47.6^{\mathrm{b}}$ & $47.7^{\mathrm{b}}$ & $42.3^{\mathrm{a}}$ & $48.1^{\mathrm{b}}$ & $48.2^{\mathrm{b}}$ & 1.0 & 0.67 \\
\hline $\mathrm{CP}$ & 54.8 & 53.6 & 53.3 & 52.0 & 42.9 & 51.3 & 53.9 & 52.5 & 52.6 & 3.5 & 0.61 \\
\hline $\mathrm{EE}$ & 55.3 & 60.4 & 53.5 & 57.0 & 64.8 & 60.3 & 57.0 & 64.9 & 62.7 & 2.4 & 0.62 \\
\hline NDF & $24.4^{\mathrm{a}}$ & $28.1^{\mathrm{ab}}$ & $31.3^{\mathrm{b}}$ & $22.4^{\mathrm{a}}$ & $28.6^{\mathrm{b}}$ & $30.1^{\mathrm{b}}$ & $23.9^{\mathrm{a}}$ & $29.4^{\mathrm{b}}$ & $30.1^{\mathrm{ab}}$ & 1.4 & 0.69 \\
\hline ADF & $20.0^{\mathrm{a}}$ & $24.5^{\mathrm{ab}}$ & $27.4^{\mathrm{b}}$ & $17.8^{\mathrm{a}}$ & $24.7^{\mathrm{b}}$ & $26.0^{\mathrm{b}}$ & $19.3^{\mathrm{a}}$ & $25.7^{\mathrm{b}}$ & $26.1^{\mathrm{b}}$ & 1.6 & 0.82 \\
\hline Sugar $(\mathrm{WSC})^{4}$ & 91.2 & 91.8 & 90.0 & $92.0^{\mathrm{a}}$ & $91.1^{\text {ac }}$ & $88.7^{\text {bd }}$ & $92.4^{\mathrm{a}}$ & $91.6^{\mathrm{ab}}$ & $89.8^{\mathrm{b}}$ & 0.8 & 0.34 \\
\hline Starch & $95.7^{\mathrm{a}}$ & $92.0^{\mathrm{b}}$ & $95.3^{\mathrm{a}}$ & $95.2^{\mathrm{a}}$ & $92.2^{\mathrm{b}}$ & $94.6^{\mathrm{a}}$ & $96.3^{\mathrm{a}}$ & $91.3^{\mathrm{b}}$ & $94.8^{\mathrm{a}}$ & 1.0 & 0.64 \\
\hline $\mathrm{Ca}$ & 16.4 & 13.0 & 24.5 & 19.2 & 19.3 & 24.6 & $15.1^{\mathrm{c}}$ & $20.0^{\text {cd }}$ & $28.5^{\mathrm{d}}$ & 4.2 & 0.59 \\
\hline $\mathrm{P}$ & -13.2 & -8.8 & -2.1 & $-14.2^{\mathrm{a}}$ & $-4.7^{\mathrm{ab}}$ & $-0.2^{\mathrm{b}}$ & -11.1 & -6.8 & -2.4 & 3.4 & 0.83 \\
\hline $\mathrm{Mg}$ & 18.6 & 15.0 & 20.8 & 16.2 & 17.6 & 20.5 & 17.0 & 18.8 & 24 & 3.2 & 0.50 \\
\hline $\mathrm{K}$ & 49.4 & 49.4 & 50.6 & 50.7 & 48.5 & 48.9 & 54.0 & 48.8 & 50.5 & 2.8 & 0.40 \\
\hline $\mathrm{Cu}$ & -16.4 & -1.3 & 0.0 & 4.0 & 13.0 & 10.1 & 9.30 & 12.1 & -3.8 & 4.8 & 0.84 \\
\hline S & 46.4 & 49.9 & 52.5 & $48.7^{\mathrm{c}}$ & $50.4^{\text {cd }}$ & $55.0^{\mathrm{d}}$ & $47.7^{\mathrm{a}}$ & $51.8^{\mathrm{ab}}$ & $56.8^{\mathrm{b}}$ & 1.8 & 0.79 \\
\hline $\mathrm{Cl}$ & 87.9 & 89.8 & 92.7 & 88.5 & 91.5 & 92.3 & 88.0 & 88.2 & 92.2 & 2.1 & 0.91 \\
\hline $\mathrm{Fe}$ & $-33.2^{\mathrm{a}}$ & $-0.6^{\mathrm{b}}$ & $-1.0^{\mathrm{b}}$ & -1.0 & 3.3 & -2.6 & 4.1 & 7.7 & 3.8 & 4.2 & $<0.001$ \\
\hline $\mathrm{Mn}$ & -12.0 & -0.1 & 4.0 & -8.5 & 8.2 & 10.8 & $-10.9^{\mathrm{a}}$ & $18.9^{\mathrm{b}}$ & $6.4^{\mathrm{ab}}$ & 6.7 & 0.64 \\
\hline $\mathrm{Na}$ & $8.0^{\mathrm{a}}$ & $22.6^{\mathrm{ab}}$ & $31.8^{\mathrm{b}}$ & $-7.7^{\mathrm{a}}$ & $20.5^{\mathrm{b}}$ & $26.6^{\mathrm{b}}$ & 3.2 & 16.0 & 16 & 5.4 & 0.23 \\
\hline $\mathrm{Zn}$ & -0.8 & 2.6 & 10.2 & 9.1 & 17.8 & 19.4 & 7.9 & 23.3 & 15.2 & 6.5 & 0.79 \\
\hline $\mathrm{pH}$ & $6.61^{\mathrm{b}}$ & $6.54^{\mathrm{ab}}$ & $6.50^{\mathrm{a}}$ & 6.63 & 6.60 & 6.55 & 6.60 & 6.56 & 6.52 & 0.03 & 0.84 \\
\hline \multicolumn{12}{|l|}{ VFA, $\mathrm{mmol} / \mathrm{g}^{5}$} \\
\hline Acetate & $80.5^{\mathrm{c}}$ & $92.0^{\mathrm{d}}$ & $83.0^{\text {cd }}$ & 80.2 & 89.2 & 80.6 & $80.0^{\mathrm{a}}$ & $92.3^{\mathrm{b}}$ & $80.6^{\mathrm{a}}$ & 2.80 & 0.96 \\
\hline Propionate & $6.8^{\mathrm{a}}$ & $8.9^{\mathrm{b}}$ & $8.0^{\mathrm{ab}}$ & 6.9 & 7.7 & 8.1 & 7.3 & 8.6 & 8.2 & 0.41 & 0.81 \\
\hline $\mathrm{A}: \mathrm{P}$ & 12.4 & 10.9 & 11.1 & $12.2^{\mathrm{a}}$ & $12.1^{\mathrm{a}}$ & $10.2^{\mathrm{b}}$ & 11.3 & 11.1 & 10.2 & 0.50 & 0.15 \\
\hline
\end{tabular}

${ }^{1} \mathrm{LS}=$ low starch collection d 10-13, AC=abrupt change to HS collection d 15-17, and HS=high starch collection d 24-26.

${ }^{2} \mathrm{n}=14$

${ }^{3}$ Denotes the level of significance for DFM treatment $\mathrm{x}$ starch interaction.

${ }^{4}$ Sugar was reported as water soluble carbohydrates (WSC) from Dairy One, Ithaca, NY.

${ }^{5}$ VFA data was confirmed by a second lab using gas chromatography.

${ }^{\mathrm{a}, \mathrm{b}}$ Within a row and treatment, means that do not have a common superscript differ $(P<0.05)$.

${ }^{\mathrm{c}, \mathrm{d}}$ Within a row and treatment, means that do not have a common superscript differ $(P<0.10)$. 
Table 5. Main effects of low- and high-starch concentrates containing either: no (Control), one strain (LAC1), or four strains (LAC4) of a lactic acid producing bacteria DFM on apparent total tract digestibility of nutrients, fecal $\mathrm{pH}$ and fecal VFA concentrations of Thoroughbred geldings $(n=15)^{1,2}$

\begin{tabular}{|c|c|c|c|c|c|c|c|c|c|c|}
\hline \multirow[b]{3}{*}{ Item } & \multicolumn{7}{|c|}{ Treatment } & \multirow[b]{3}{*}{$\mathrm{LAC}_{4}{ }^{2}$} & \multirow[b]{3}{*}{ SE } & \multirow[b]{3}{*}{$P$-value } \\
\hline & \multicolumn{3}{|c|}{ Starch } & \multicolumn{4}{|c|}{ DFM } & & & \\
\hline & LS & $\mathrm{AC}$ & $\mathrm{HS}^{2}$ & $\mathrm{SE}$ & $P$-value ${ }^{3}$ & $\mathrm{CON}$ & LAC1 & & & \\
\hline \multicolumn{11}{|c|}{ DMD, $\%$ of intake } \\
\hline DM & $41.2^{\mathrm{a}}$ & $46.3^{\mathrm{b}}$ & $46.9^{\mathrm{b}}$ & 0.8 & $<0.001$ & 44.9 & 44.3 & 45.1 & 0.8 & 0.36 \\
\hline OM & $42.2^{\mathrm{a}}$ & $47.6^{b}$ & $48.1^{\mathrm{b}}$ & 0.9 & $<0.001$ & 46.2 & 45.5 & 46.2 & 0.9 & 0.46 \\
\hline $\mathrm{CP}$ & 53.6 & 49.7 & 52.4 & 2.3 & 0.34 & 53.9 & 48.7 & 53.0 & 2.3 & 0.15 \\
\hline $\mathrm{EE}$ & $56.5^{\mathrm{a}}$ & $63.4^{\mathrm{b}}$ & $58.9^{\mathrm{ab}}$ & 1.5 & 0.002 & $56.4^{\mathrm{a}}$ & $60.7^{\mathrm{ab}}$ & $61.5^{\mathrm{b}}$ & 1.5 & 0.03 \\
\hline $\mathrm{NDF}$ & $23.6^{\mathrm{a}}$ & $28.7^{\mathrm{b}}$ & $30.5^{\mathrm{b}}$ & 1.1 & $<0.001$ & 27.9 & 27.0 & 27.8 & 1.1 & 0.54 \\
\hline $\mathrm{ADF}$ & $19.0^{\mathrm{a}}$ & $25.0^{\mathrm{b}}$ & $26.5^{\mathrm{b}}$ & 1.2 & $<0.001$ & 24.0 & 22.8 & 23.7 & 1.2 & 0.50 \\
\hline Sugar $^{5}$ & $91.9^{\mathrm{a}}$ & $91.5^{\mathrm{a}}$ & $89.6^{\mathrm{b}}$ & 0.7 & $<0.001$ & 91.0 & 90.6 & 91.3 & 0.7 & 0.42 \\
\hline Starch & $95.7^{\mathrm{a}}$ & $91.9^{\mathrm{b}}$ & $94.9^{\mathrm{a}}$ & 0.8 & $<0.001$ & 94.4 & 94.0 & 94.1 & 0.8 & 0.78 \\
\hline $\mathrm{Ca}$ & $16.4^{\mathrm{a}}$ & $13.0^{\mathrm{a}}$ & $24.5^{\mathrm{b}}$ & 3.4 & 0.001 & 18.0 & 21.0 & 21.1 & 3.4 & 0.39 \\
\hline $\mathrm{P}$ & $-12.8^{\mathrm{a}}$ & $-6.8^{\mathrm{b}}$ & $-1.6^{\mathrm{b}}$ & 2.4 & $<0.001$ & -8.0 & -6.4 & -6.75 & 2.4 & 0.77 \\
\hline $\mathrm{Mg}$ & 17.3 & 17.1 & 20.8 & 2.6 & 0.08 & 17.2 & 18.1 & 19.9 & 2.6 & 0.32 \\
\hline $\mathrm{K}$ & 51.4 & 48.9 & 50.0 & 2.6 & 0.11 & 49.8 & 49.4 & 51.1 & 2.6 & 0.31 \\
\hline $\mathrm{Cu}$ & $-5.4^{\mathrm{a}}$ & $7.9^{\mathrm{b}}$ & $6.5^{\mathrm{b}}$ & 2.9 & $<0.001$ & $-5.9^{\mathrm{a}}$ & $9.0^{\mathrm{b}}$ & $5.9^{\mathrm{b}}$ & 2.9 & 0.002 \\
\hline S & $47.6^{\mathrm{a}}$ & $50.7^{\mathrm{b}}$ & $54.8^{\mathrm{c}}$ & 1.3 & $<0.001$ & 49.6 & 51.4 & 52.1 & 1.3 & 0.14 \\
\hline $\mathrm{Cl}$ & $88.1^{\mathrm{a}}$ & $89.9^{\mathrm{ab}}$ & $92.4^{\mathrm{b}}$ & 1.5 & 0.02 & 90.2 & 90.7 & 89.5 & 1.5 & 0.71 \\
\hline $\mathrm{Fe}$ & $-10.0^{\mathrm{a}}$ & $3.4^{\mathrm{b}}$ & $0.1^{\mathrm{b}}$ & 2.5 & $<0.001$ & $-11.6^{\mathrm{a}}$ & $-0.1^{\mathrm{b}}$ & $5.2^{\mathrm{b}}$ & 2.5 & $<0.001$ \\
\hline $\mathrm{Mn}$ & $-10.5^{\mathrm{a}}$ & $9.0^{\mathrm{b}}$ & $7.1^{\mathrm{b}}$ & 3.9 & 0.001 & -2.7 & 3.5 & 4.8 & 3.9 & 0.37 \\
\hline $\mathrm{Na}$ & $1.1^{\mathrm{a}}$ & $19.7^{\mathrm{b}}$ & $24.8^{\mathrm{b}}$ & 3.6 & $<0.001$ & $20.8^{\mathrm{c}}$ & $13.1^{\mathrm{cd}}$ & $11.7^{\mathrm{d}}$ & 3.6 & 0.07 \\
\hline $\mathrm{Zn}$ & 5.4 & 14.6 & 14.9 & 4.0 & 0.12 & 3.9 & 15.4 & 15.5 & 4.0 & 0.08 \\
\hline $\mathrm{pH}$ & $6.61^{\mathrm{a}}$ & $6.57^{\mathrm{b}}$ & $6.53^{\mathrm{b}}$ & 2.6 & $<0.001$ & $6.55^{\mathrm{c}}$ & $6.60^{\mathrm{d}}$ & $6.56^{\mathrm{cd}}$ & 2.6 & 0.06 \\
\hline \multicolumn{11}{|l|}{$\mathrm{VFA}, \mathrm{mmol} / \mathrm{g}^{6}$} \\
\hline Acetate & $80.22^{\mathrm{a}}$ & $91.18^{\mathrm{b}}$ & $81.42^{\mathrm{a}}$ & 1.8 & $<0.001$ & 85.17 & 83.33 & 84.32 & 1.8 & 0.70 \\
\hline Propionate & $6.99^{\mathrm{a}}$ & $8.41^{b}$ & $8.10^{\mathrm{b}}$ & 0.3 & $<0.001$ & 7.89 & 7.58 & 8.04 & 0.3 & 0.33 \\
\hline $\mathrm{A}: \mathrm{P}$ & $11.9^{\mathrm{a}}$ & $11.4^{\mathrm{a}}$ & $10.5^{\mathrm{b}}$ & 0.3 & $<0.001$ & 11.5 & 11.5 & 10.9 & 0.3 & 0.18 \\
\hline
\end{tabular}

${ }^{1}$ LS=low starch collection d 10-13, AC=abrupt change to HS collection d 15-17 and HS=high starch collection d 24-26.

${ }^{2} \mathrm{n}=14$

${ }^{3}$ Denotes the level of significance for starch effect.

${ }_{5}^{4}$ Denotes the level of significance for DFM effect.

${ }^{5}$ Sugar was reported as water soluble carbohydrates (WSC) from Dairy One, Ithaca, NY.

${ }^{6}$ VFA data was confirmed by a second lab using gas chromatography.

a,b,c Within a row by effect (Starch or DFM), means that do not have a common superscript differ $(P<$ $0.05)$.

${ }^{\mathrm{d}, \mathrm{e}}$ Within a row by effect (Starch or DFM), means that do not have a common superscript differ $(P<0.10)$. 
Table 6. Average fecal $\mathrm{pH}$ and fecal $\mathrm{VFA}^{1}$ concentrations at time of collection of Thoroughbred geldings

\begin{tabular}{lcccc}
\hline \hline \multicolumn{5}{c}{ Sampling Time } \\
\hline Item & 0700 & 1200 & 1600 & SE \\
\hline $\mathrm{pH}$ & $6.45^{\mathrm{a}}$ & $6.61^{\mathrm{b}}$ & $6.65^{\mathrm{b}}$ & 0.03 \\
Acetate, $\mathrm{mg} / \mathrm{g}$ & $5.54^{\mathrm{a}}$ & $\mathrm{n} / \mathrm{a}$ & $4.88^{\mathrm{b}}$ & 0.09 \\
Propionate, $\mathrm{mg} / \mathrm{g}$ & 0.54 & $\mathrm{n} / \mathrm{a}$ & 0.54 & 0.02 \\
\hline
\end{tabular}

${ }^{1}$ Volatile fatty acid (VFA) data was confirmed by a second lab using GC.

${ }^{\mathrm{a}, \mathrm{b}}$ Within a row and treatment, means that do not have a common superscript differ $(P<0.05)$. 


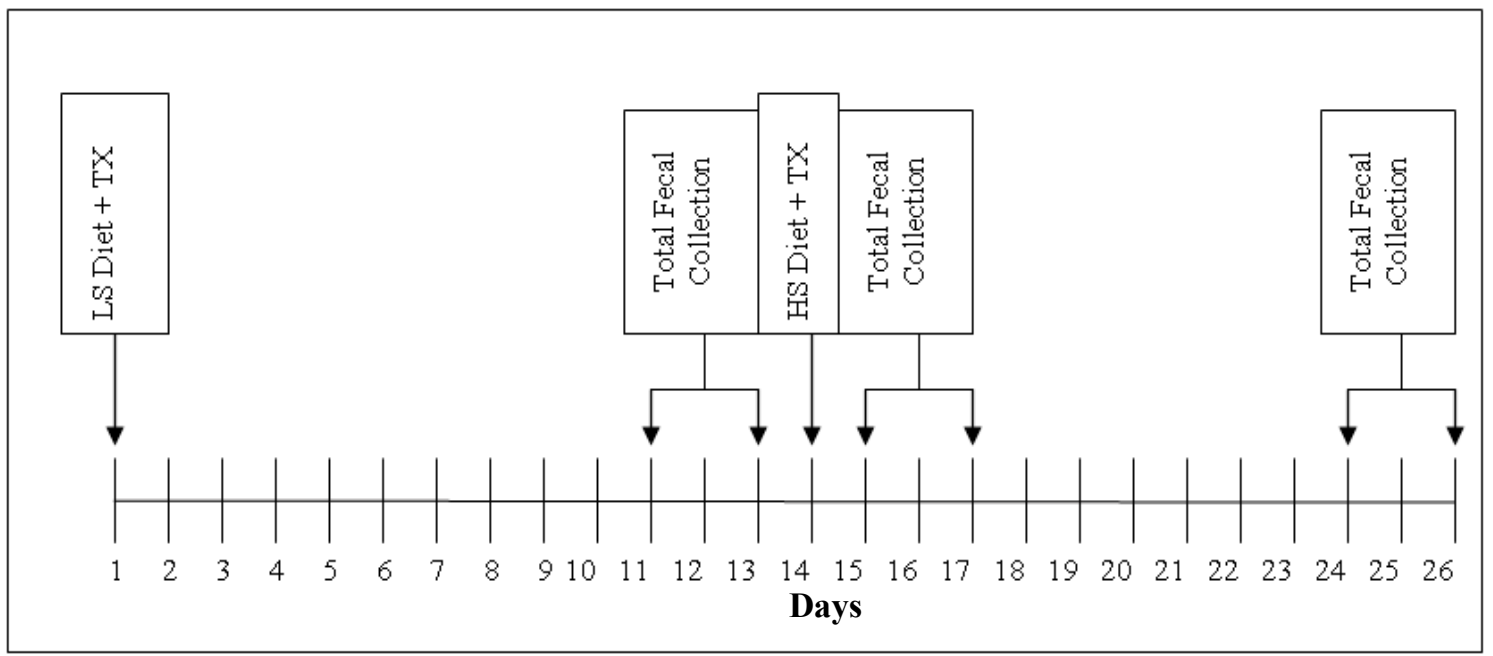

Figure 1. Experimental timeline of each 26-day period. Three total fecal collections were conducted as follows: collection d 10-13 (low starch; LS), collection d 15-17 (abrupt change increase in starch; AC), and collection d 24-26 (high starch; HS). 

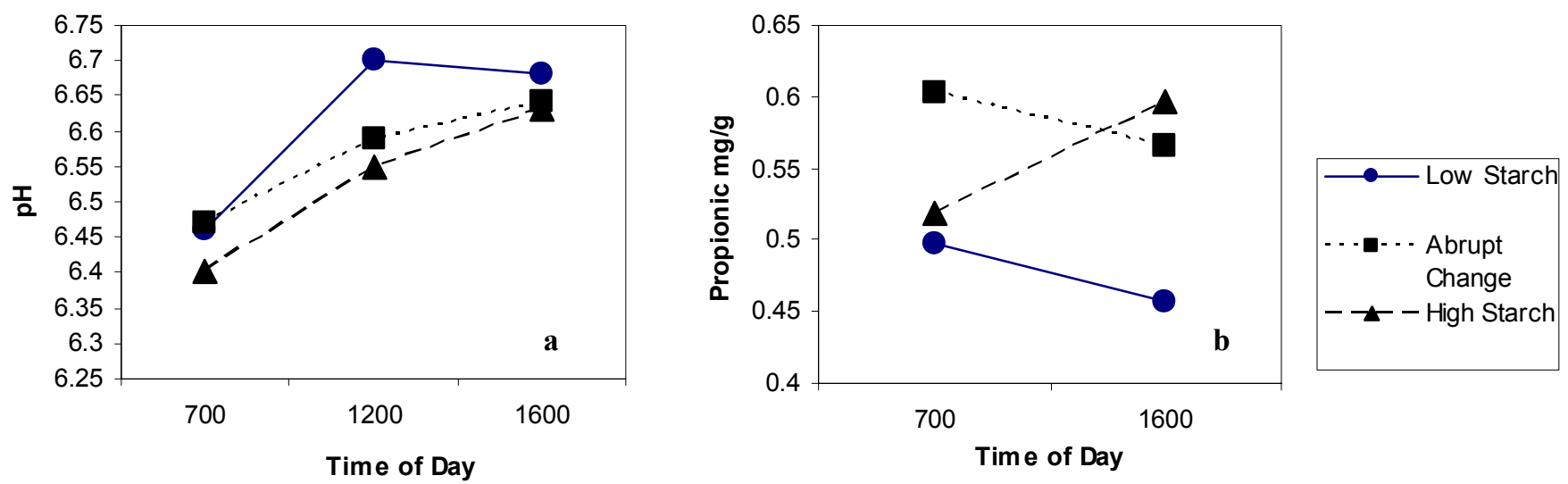

Figures 2a \& b. Relationship between collection time of day to $\mathrm{pH}$ (a) and fecal propionate concentration (b) of geldings consuming low- and high-starch concentrates with and without direct-fed lactic acid producing bacteria. There was a starch by time interaction $(P=0.04)$ fecal $\mathrm{pH}$. There was a starch by time interaction on fecal propionate concentration $(P=0.003)$. There was not a starch by time interaction on fecal acetate concentration $(P=0.61$; not shown). 


\section{APPENDIX}

\section{INTRODUCTION}

As standard practice for quality control protocol at LOC2, further Gram-stain (Gram, 1884) and catalase tests (Star-Labs Method SL-04) were conducted to assure purity of original CFU counts from Exp.1. As discussed in the literature review, grampositive bacteria have a cell wall that includes a peptidoglycan layer. Those colonies that passed the Gram-stain test were required to also pass a catalase test. The catalase test was previously described (Finegold et al., 1978) for determination of catalase-positive bacteria. Catalase-positive bacteria produce a catalase enzyme that converts hydrogen peroxide $\left(\mathrm{H}_{2} \mathrm{O}_{2}\right)$ to $\mathrm{H}_{2} \mathrm{O}+\mathrm{O}_{2}$ (oxygen gas) for protection against cellular peroxidative damage. All the LAB species used in Exp. 1 and Exp. are Gram-positive and catalasenegative. Cultures that possess colonies that are not Gram-positive and catalase negative would indicate the presence of 'wild type' species that have contaminated the sample.

\section{MATERIALS AND METHODS}

Gram-stain. After initial CFU determination described in Exp.1 using the SL-01 method, individual suspended colonies were aseptically transferred with wooden stick from agar and thinly smeared onto slides (Becton, Dickenson \& Co., Sparks, MD) with one drop of $\mathrm{H}_{2} \mathrm{O}$ in quintuplicate. Inoculated slides were dried for $10 \mathrm{~m}$ at $42^{\circ} \mathrm{C}$ then passed through a Bunsen burner flame 4-5 times to heat fix samples to slide. Using Gram-staining kits (Becton, Dickenson \& Co., Sparks, MD), slides were flooded with crystal violet dye and undisturbed for $60 \mathrm{~s}$, flooded with iodine, sat for $60 \mathrm{~s}$, then rinsed 
with $\mathrm{H}_{2} \mathrm{O}$. Slides were then flushed with decolorizer until droplets ran clear and rinsed with $\mathrm{H}_{2} \mathrm{O}$. Finally, slides were flooded with safrinin counter-stain for $30 \mathrm{~s}$, rinsed with $\mathrm{H}_{2} \mathrm{O}$, blotted with bibulous paper, then allowed to air-dry. Slides were subjected to oil immersion for 1000x microscopy visualization for determination of number of colonies that were Gram-stain positive and morphologically correct for bacilli (rod shaped and 1-8 microns in length). The percent of colonies that did not display these characteristics were excluded as lactobacilli from original CFU counts and CFU/g numbers were adjusted.

Catalase test. Using a Pasteur pipette, a drop of $3 \% \mathrm{H}_{2} \mathrm{O}_{2}$ was placed onto a sterilized plastic grid. Individual suspended colonies were aseptically transferred with wooden stick from agar and placed into $\mathrm{H}_{2} \mathrm{O}_{2}$ droplet in quintuplicate replication.

Immediate visualization of bubbling (release of $\mathrm{O}_{2}$ ) is indicative of catalase activity. Any colonies that were catalase positive were considered to be contaminated, and excluded as lactobacilli from original CFU counts and CFU/g numbers were adjusted (i.e. Bacillus subtilis is a gram positive bacilli, but it is catalase positive).

\section{RESULTS AND DISCUSSION}

The results from the Gram-stain and catalase test are presented in Figure 1. There was no difference in the percentage of colonies that were Gram-positive and catalase negate between treatment groups. These results suggest that only 12 to $13 \%$ of colonies determined in Exp. 1 were actual lactobacilli colonies. This data does not indicate if the lactobacilli present in the $\mathrm{CON}$ were from 'wild type' or treatment contamination. 


\section{FIGURE}

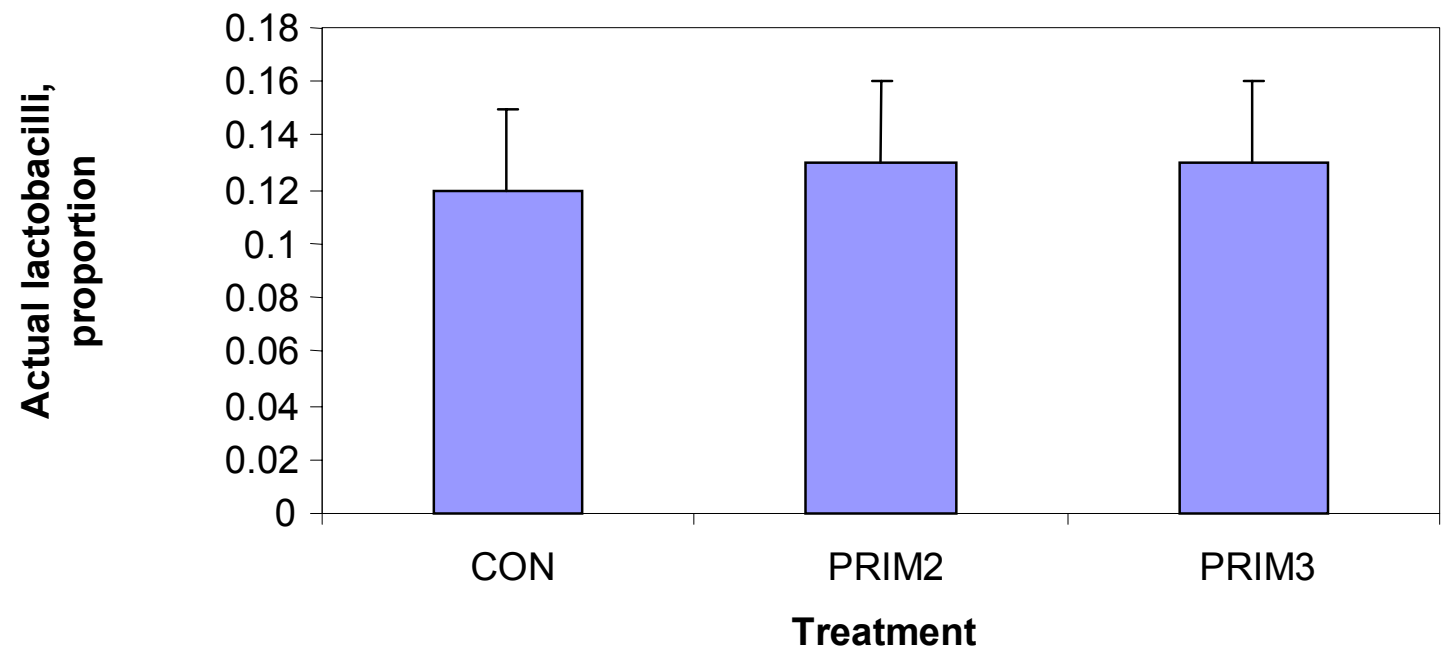

Figure 1. Percentage of lactobacilli colonies that were Gram-stain positive and catalase negative from animal feed samples made in the following order in Exp. 1: $\mathrm{CON}=$ no lactic acid bacteria, control, PRIM2 $=0.91 \mathrm{~kg} /$ ton inclusion of PrimaLac, PRIM3=1.36 $\mathrm{kg} / \mathrm{ton}$ inclusion of PrimaLac. 


\section{REFERENCES}

AAFCO. 2000. Official Publication: Association of American Feed Control Officials, Inc., West Lafayette, IN. http://www.aafco.org

AFIA. 1994. Feed Manufacturing Technology IV. American Feed Industry Association, Inc., Arlington, VA. http://www.afia.org

AOAC. 1995. Enumeration of lactic acid bacteria: colony count technique. Method 14.1: 1995. CCFRA Microbiological Methods Manual. Official Methods of Analysis. Assoc. Off. Anal. Chem., Arlington, VA.

ASM. American Society for Microbiology, Washington, D.C. www.asm.org.

Abu-Tarboush, H. M., M. Y. Al-Saiady, and A. H. Keir El-Din. 1996. Evaluation of diet containing lactobacilli on performance, fecal coliform, and lactobacilli of young dairy calves. Anim. Feed Sci. Technol. 57:39-49.

Amann, R. I., W. Ludwig and K. H. Schleifer. 1995. Phylogenetic identification and in situ detection of individual microbial cells without cultivation. Microbiol. Rev. 59:143-149.

Andrews, F. M., B. R. Buchanan, S. B. Elliot, N. A. Clariday, and L. H. Edwards. 2005. Gastric ulcers in horses. J. Anim. Sci. 83(E. Suppl.):18-21.

Angel, R., R. A. Dalloul, and J. Doerr. 2005. Performance of broiler chickens fed diets supplemented with direct-fed microbials. Poultry Sci. 84:1222-1231.

Annison, E. F., and D. G. Armstrong. 1970. Volatile fatty acid metabolism and energy supply. Pages 422-437 in Physiology of Digestion and Metabolism in the Ruminant. A. T. Phillipson, ed. Oreil Press Ltd. Newcastle-upon-Tyne, England.

Bailey, S. R., Y. Berhane, C. M. Marr, and J. Elliott. 2001. Amines from the equine hindgut may cause digital vasoconstriction by direct or indirect mechanisms. J. Vet. Intern. Med. 15:212.

Bailey, S. R., A. Rycroft, and J. Elliott. 2002. Production of amines in equine cecal contents in an in vitro model of carbohydrate overload. 2002. J. Anim. Sci. $80: 2656-2662$

Bailey, S.R., M. L. Baillon, A. Rycroft, P. A. Harris, and J. Elliott. 2003. Identification of equine cecal bacteria producing amines in an in vitro model of carbohydrate overload. Applied and Environmental Microbiology. 69:2087-2093. 
Barcroft, J., R. A. McAnally, and A. T. Phillipson. 1944. Absorption of volatile acids from the alimentary tract of sheep and other species. J. Exp. Biol. 20:120.

Beauchemin, K. A., W. Z. Yang, D. P. Morgavi, G. R. Ghorbani, W. Kautz, and J. A. Z. Leedle. 2003. Effects of bacterial direct-fed microbials and yeast on site and extent of digestion, blood chemistry, and subclinical ruminal acidosis in feedlot cattle. J. Anim. Sci. 81:1628-1640.

Bechman, T. J., J. V. Chambers, and M. D. Cunningham. 1977. Influence of Lactobacillus acidophilus on performance of young dairy calves. J. Dairy Sci. 60(Suppl. 1):74.

Berg, R. D. 1996. The indigenous gastrointestinal microflora. Trends Microbiol. 434:430-435.

Berg, J. M., J. L. Tymoczko, and L. Stryer. 2001. Biochemistry, 5th ed. W. H. Freeman and Co., New York, NY.

Berg, E. L., C. J. Fu, J. H. Porter, and M. S. Kerley. 2005. Fructooligosaccharide supplementation on the yearling horse: Effects on fecal $\mathrm{pH}$, microbial content and volatile fatty acid concentrations. J. Anim. Sci. 83:1549-1553.

Bergman, E. N. 1990. Energy contributions of volatile fatty acids from the gastrointestinal tract in various species. Physiol. Rev. 70: 567-590.

Bergman, E. N. 1983. The pools of cellular nutrients: glucose. Pages 173-196 in Dynamic Biochemistry of Animal Production. World Animal Science AS. P. M. Riis, ed. Amsterdam.

Bergman, E. N., and J. E. Wolff. 1971. Metabolism of volatile fatty acids by liver and portal-drained viscera in sheep. Am. J. Physiol. 221:586-592.

Beutler, B. 2004. Innate immunity: an overview. Mol. Immunol. 40:845-859.

Beutler, B., and E. T. Rietschel. 2003. Innate immune sensing and its roots: the story of endotoxin. Nat. Rev. Immunol. 3:169-176.

Betian, H. G., B. A. Linehan, M. P. Bryant, and L. V. Holdeman. 1977. Isolation of celluloylytic Bacteroides sp. from human feces. Appl. Environ. Microbiol. 33:1009-1010.

Biourge, V., C. Vallet, A. Levesque, R. Sergheraert, S. Chevalier, and J. Roberton. 1998. The use of probiotics in the diet of dogs. J. Nutr. 128(Suppl. 1):2730-2732. 
Brashears, M. M., D. Jaroni, and J. Trimble. 2003. Isolation, selection, and characterization of lactic acid bacteria for a competitive exclusion product to reduce shedding of Escherichia coli 0157:H7 in cattle. J. Food Prot. 66:355-363.

Breznak, J. A. 1994. Acetogenesis from carbon dioxide in termite guts. Pages 303-330 in Acetogenesis. H. L. Drake, ed. Chapman and Hall, New York, NY.

Bryant, M. P. 1978. Cellulose digesting bacteria from human feces. Am. J. Clin. Nutr. 31(Suppl. 1):113-115.

Bryant, M. P. and I. M. Robinson. 1961. Studies on the nitrogen requirements of some ruminal cellulolytic bacteria. Appl. Microbiol. 2:96-103.

Campbell, J. M., G. C. Fahey, Jr., and B. W. Wolf. 1997. Selected indigestible oligosaccharides affect large bowel mass, cecal and fecal short-chain fatty acids, $\mathrm{pH}$ and microflora in rats. J. Nutr. 127:130-136.

Chaucheyras-Durand, F., J. Madic, F. Doudin, and C. Martin. 2006. Biotic and abiotic factors influencing in vitro growth of Escherichia coli O157:H7 in ruminant digestive contents. Appl Environ Microbiol. 72(6):4136-4142.

Clarke, L. L., M. C. Roberts, and R. A. Argenzio. 1990. Feeding and digestive problems in horses: Physiologic responses to a concentrated meal. Vet. Clin. North. Am. 6:433-450.

Canganella F., S. Paganini, M. Ovidi, A. M. Vettraino, L. Vevilacqua, S. Massa and L. D. Travatelli. 1997. A microbiological investigation on probiotic pharmaceutical products used for human health. Microbiol Res. 152:171-179.

Coeuret, V., M. Gueguen, and J. P. Vernoux. 2004. Numbers and strains of lactobacilli in some probiotic products. Int J Food Microbiol. 97(2):147-156.

Conway, P. L. 1995. Human colonic bacteria: Role in nutrition, physiology, and pathology. Pages 1-24 in Microbial Ecology of the Human Large Intestine. G. R. Gibson, G. T. MacFarlane, eds. CRC Press, Boca Raton, FL.

Cooper, P. and I. S. Cornforth. 1978. Volatile fatty acids in stored animal slurry. J. Sci. Fd. Agric. 29:19-27.

Cooper, R. and T. Klopfenstein. 1996. Effect of Rumensin and feed intake variation on ruminal pH. Pages A1-A14 in Scientific Update on Rumensin/Tylan/Mycotil for the Professional Feedlot Consultant. Elanco Animal Health, Indianapolis, IN.

Cox, N. A., J. S. Bailey, J. E. Thompson, and B. J. Juven. 1983. Salmonella and other Enterobacteriaceae found in commercial poultry feed. Poult. Sci. 62(11):21692175 . 
Crozier, J. A., V. G. Allen, N. E. Jack, J. P. Fontenot, and M. A. Cochran. 1997. Digestibility, apparent mineral absorption, and voluntary intake by horses fed alfalfa, tall fescue, and caucasian bluestem. J. Anim. Sci. 75:1651-1658.

Crump, J. A., P. M. Griffin, and F. J. Angulo. 2002. Bacterial contamination of animal feed and its relationship to human foodborne illness. Clin. Infect. Dis. Food Safety. 35:859-865.

Cummings, J. H., E. W. Pomare, J. W. Branch, C. P. E. Naylor, and G. T. Macfarlane. 1987. Short chain fatty acids in human large intestine portal, hepatic and venous blood. Gut. 28:1221-1227.

Daly, K., S. S. Colin, H. J. Flint, and S. P. Shirazi-Beechey. 2001. Bacterial diversity within the equine large intestine as revealed by molecular analysis of cloned $16 \mathrm{~S}$ rRNA genes. FEMS Microbiology Ecology. 38:141-151.

Danielson, A. D., E. R. Peo, K. M. Shahani, A. J. Lewis, P. J. Whalen and M. A. Amer. 1989. Anticholesteremic property of Lactobacillus acidophilus yogurt fed to mature boars. J. Anim. Sci. 67(4):966-974.

Davies, R. H. and C. Wray. 1997. Distribution of salmonella contamination in ten animal feedmills. Vet. Microbiol. 57:159-169.

de Fombelle, A., V. Julliand, C. Drogoul, and E. Jacotot. 2001. Feeding and microbial disorders in horses: 1 - Effects of an abrupt incorporation of two levels of barley in a hay diet on microbial profile and activities. J. Equine Vet. Sci. 21:439-445.

de Fombelle, A., L. Veiga, C. Drogoul and V. Julliand. 2004. Effect of diet composition and feeding pattern on the prececal digestibility of starches from diverse botanical origins measured with the mobile nylon bag technique in horses. J. Anim. Sci. $82: 3625-3634$.

DeMan, J., C. M. Rogosa, and E. Sharpe. 1960. A medium for the cultivation of Lactobacilli. J. Appl. Bact. 23:130-135.

De Rodas, B. Z., S. E. Gilliland, and C. V. Maxwell. 1996. Hypocholesterolemic action of Lactobacillus acidophilus ATCC 43121 and calcium in swine with hypercholesterolemia induced by diet. J Dairy Sci. 79:2121-2128.

Desrochers, A. M, B. A. Dolente, M. F. Roy, R. Boston, and S. Carlisle. Efficacy of Saccharomyces boulardii for treatment of horses with acute enterocolitis. 2005. J. Am. Vet. Med. Assoc. 227(6):954-959. 
Drisko, J., B. Bischoff, C. Giles, M. Adelson, R. V. Rao, and R. McCallum. 2005. Evaluation of five probiotic products for label claims by DNA extraction and polymerase chain reaction analysis. Dig. Dis. Sci. 50(6):1113-1117.

Drogoul, C., A. de Fombelle, and V. Julliand. 2001. Feeding and microbial disorders in horses: 2-Effects of three hay:grain ratios on digesta passage rate and digestibility in ponies. J. Equine Vet. Sci. 21:487-490.

Dubois, M., K. A. Gilles, J. K. Hamilton, P. A. Reber, and F. Smith. 1956. Colorimetric method for determination of sugars and related substances. Anal. Chem. 28:350356.

Dunlop, R. H. and P. B. Hammond. 1965. D-lactic acidosis of ruminants. Ann. N Y Acad. Sci. 119(3):1109-1132.

Dunne, C. 2001. Adaptation of bacteria to the intestinal niche: probiotics and gut disorder. Inflamm Bowel Dis. 7(2):136-145.

Dunne, C., L. O’Mahony, L. Murphy, G. Thornton, D. Morrissey, S. O’Halloran, M. Feeney, S. Flynn, G. Fitzgerald, C. Daly, B. Kiely, G. C. O’Sullivan, F. Shanahan and J. K. Collins. 2001. In vitro selection criteria for probiotic strains Correlation with in vivo findings. Am. J. of Cl. Nut. 73(2):386-392.

Dunne, C., L. Murphy, S. Flynn, L. O'Mahony, S. O’Halloran, M. Feeney, D. Morrissey, G. Thornton, G. Fitzgerald, C. Daly, B. Kiely, E. M. M. Quigley, G. C. O’Sullivan, F. Shanahan, and J. K. Collins. 1999. Probiotics: from myth to reality. Demonstration of fuctionality in animal models of disease in human clinical trials. Antonie Leeuwenhoeck. 76:279-292.

Durand-Chaucheyras, F., G. Fonty, G. Bertin, M. Théveniot, and P. Gouet. 1998. Fate of Levuccell ${ }^{\circledR}$ I-1077 yeast additive during digestive transit in lambs. Reprod. Nutr. Dev. 38:275-280.

Elizalde, J. C., N. R. Merchen, and D. B. Faulkner. 1999. Supplemental cracked corn for steers fed fresh alfalfa: I. Effects on digestion of organic matter, fiber, and starch. J. Anim. Sci. 77:457-466.

Elsden, S. R., M. W. S. Hitchcock, R. A. Marshall, and A. T. Phillipson. 1946. Volatile acid in the digesta of ruminants and other animals. J. Exp. Biol. 22: 191-202.

FDA. 1995. Office of Regulatory Affairs: Compliance Policy Guides. Sec. 689.100 Direct-Fed Microbial Products (CPG 7126.41). http://www.fda.gov/ora/compliance_ref/cpg/cpgvet/cpg689-100.html. Accessed Feb. 2007. 
Fiems, L. O., B. G. Cottyn, L. Dussert, and J. M. Vanaker. 1993. Effect of a viable yeast culture on digestibility and rumen fermentation in sheep fed different types of diets. Reprod. Nutr. Dev. 33:43-49.

Finegold, S. M., W. J. Martin and E. G. Scott. 1978. Reagents and Tests. Page 482 in Bailey and Scott's Diagnostic Microbiology. $5^{\text {th }}$ rev. ed. CV Mosby Co., St. Louis, MO.

Fox, S. M. 1988. Probiotics intestinal inoculants for production animals. Vet. Med. 83:806-830.

Frape, D. 2004. Pages 20-26 and 162-165 in Equine Nutrition and Feeding, $3^{\text {rd }}$ rev. ed. Blackwell Publishing, Ames, Iowa.

Fuller, R. 1977. The importance of lactobacilli in maintaining normal microbial balance in the crop. Br. Poult. Sci. 18:85-94.

Fuller, R. 1989. A review: Probiotics in man and animals. J. Appl. Bacteriol. 66: 365378.

Fuller, R. 1992. Probiotics: the scientific basis. Campman \& Hall. London, England.

Furuta, K., I. Oku, and S. Morimoto. 1980. Effect of steam temperature in the pelleting process of chicken food on the viability of contaminating bacteria. Lab Anim. 4:293-296.

Galyean, M. L., G. A. Nunnery, P. J. Defoor, G. B. Salyer, and C. H. Parsons. 2000. Effects of live cultures of Lactobacillus acidophilus (Strains 45 and 51) and Propionibacterium freudenreichii PF-24 on performance and carcass characteristics of finishing beef steers. Burnett Center Progress Report No. 8. Available: http://www.afs.ttu.edu/burnett_center/progress_reports/bc8.pdf. Accessed Feb. 2007.

Garner, H. E., D. P. Hutcheson, J. R. Coffman, A. W. Hahn, and C. Salem. 1977. Lactic acidosis: A factor associated with equine laminitis. J. Anim. Sci. 45:1037-1041.

Garner, H. E., J. N. Moore, J. H. Johnson, L. Clark, J. F. Amend, L. G. Tritschler, J. F. Coffman, R. F. Sprouse, D. P. Hutcheson, and C. A. Salem. 1978. Changes in the cecal flora associated with the onset of laminitis. Equine Vet. J. 10:249-252.

Ghorbani, G. R., D. P. Morgavi, K. A. Beauchemin, and J. A. A. Leedle. 2002. Effects of bacterial direct fed microbials on ruminal fermentation, blood variables, and the microbial populations of feedlot cattle. J. Anim. Sci. 80:1997-1986. 
Gibson, G. R., and R. Fuller. 2000. Aspects of in vitro and in vivo research approaches directed toward identifying probiotics and prebiotics for human use. J. Nutr. 130(Suppl. 1):391-395.

Gibson, G. R. and M. B. Roberfroid. 1995. Dietary modulation of the human colonic microbiota: introducing the concept of prebiotics. J Nut. 125:1401-1412.

Gilliland, S. E. and M. L. Speck. 1977a. Antagonistic action of Lactobacillus acidophilus toward intestinal and food borne pathogens in associative cultures. J. Food Prot. 40:820-823.

Gilliland S. E. and M. L. Speck. 1977b. Enumeration and identity of lactobacilli in dairy products. J. Food Prot. 40:760-762.

Gilliland, S. E., B. B. Bruce, L. J. Bush and T. E. Staley. 1980. Comparison of two strains of Lactobacillus acidophilus as dietary adjuncts for young calves. J. Dairy Sci. 63:964-972.

Glock, R. D. and B. D. DeGroot. 1998. Sudden death of feedlot cattle. J. Anim. Sci. 76:315-319.

Gomez-Basauri, J., M. B. de Ondarza, and J. Siciliano-Jones. 2001. Intake and milk production of dairy cows fed lactic acid bacteria and mannanoligosaccharide. J. Dairy Sci. 84(Suppl. 1):283.

Goodson, J., W. J. Tyznik, J. H. Cline, and B. A. Dehority. 1988. Effects of an abrupt change from hay to concentrate on the microbial numbers and physical environment in the cecum of the pony. Appl. Environ. Microbiol. 54:1946.

Gorbach, S. L. 2000. Probiotics and gastrointestinal health. Am J Gastroenterol. 95(Suppl):1-4.

Goss, W. A., R. N. Michaud, and M. B. McGrath. 1974. Evaluation of an automated colony counter. Appl. Microbiol. 27(1):264-267.

Gram, HC. 1884. Über die isolierte Färbung der Schizomyceten in Schnitt- und Trockenpräparaten". Fortschritte der Medizin. 2:185-89.

Grunewald, K. K. 1982. Serum cholesterol levels in rats fed skim milk fermented by Lactobacillus acidophilus. J. Food Sci. 47:2078-2079.

Hall, M.B., W.H. Hoover, J.P. Jennings and T.K. Miller Webster. 1999. A method for partitioning neutral detergent soluble carbohydrates. J. Sci. Food Agric. 79:2081. 
Hamilton-Miller J. M. T., S. Shah, and J. T. Winkler. 1999. Public health issues arising from microbiological and labelling quality of foods and supplements containing probiotic microorganisms. Public Health Nutr. 2(2):223-229.

Hamilton-Miller J. M. T., and S. Shah. 2002. Deficiencies in microbiological quality and labeling of probiotic supplements. Int J Food Microbiol. 72:175-176.

Hatcher, G. E., and R. S. Lambrecht. 1993. Augmentation of macrophage phagocytic activity by cell-free extracts of selected lactic-acid producing bacteria. J. Dairy Sci. 76: 2485-2492.

Henneke, D. R., G. D. Potter, J. L. Kreider, and B. F. Yeates. 1983. Relationship between condition score, physical measurements and body fat percentage in mares. Equine Vet. J. 15:371-372.

Hillman, K., D. Lloyd, and A. G. Williams. 1985. Use of portable quadruple mass spectrometer for the measurement of dissolved gas concentrations in ovine rumen liquor in situ. Curr. Microbiol. 12:335.

Hobson, P. N. and C. S. Stewart. 1997. The Rumen Microbial Ecosystem $\left(2^{\text {nd }}\right.$ ed). Blackie Academic and Professional. Chapman and Hall. New York, NY.

Hoffman, R. M. 2003. Carbohydrate metabolism in horses. In: Recent Advances in Equine Nutrition. S.L. Ralston and H.F. Hintz, eds. IVIS, Ithaca, NY.

Horsefeeds UK. 2006. Horse Feeds UK Nutrition \& Health For Your Horse: Probiotics. http://www.horsefeeds.co.uk/index.html

Huffman, R. P., K. K. Karges, T. J. Klopfenstein, R. A. Stock, R. A. Britton, and L. D. Roth. 1992. The effect of Lactobacillus acidophilus on subacute ruminal acidosis. J. Anim. Sci. 70(Suppl. 1):87(Abstr.).

Hungate, R. E. 1966. The Rumen and its Microbes. Academic Press Inc., New York, NY.

Huntington, G. B., D. L. Harmon, and C. J. Richards. 2006. Sites, rates, and limits of starch digestion and glucose metabolism in growing cattle. J. Anim. Sci. 84(E. Suppl.):E14-E24.

Hussein, H. S., L. A. Vogedes, G. C. J. Fernandez, and R. L. Frankeny. 2004. Effects of cereal grain supplementation on apparent digestability of nutrients and concentrations of fermentation end-products in the feces and serum of horses consuming alfafa cubes. J. Anim. Sci. 82:1986-1996.

Isolauri, E., Y. Sutas, P. Kankaanpaa, H. Arvilommi, and S. Salminen. 2001. Probiotics: effects on immunity. Am. J. Clin. Nutr. 73(Suppl. 2):444-450. 
Jones, F. T. and K. E. Richardson. 2004. Salmonella in commercially manufactured feeds. Poult. Sci. 83(3):384-391.

Jones, G. W. and J. M. Rutter. 1972. Role of K88 antigen in the pathogenesis of neonatal diarrhea caused by Escherichia coli in piglets. Infect. Immun. 6:918927.

Julliand V., A. de Vaux, L. Millet and G. Fonty. 1999. Indentification of Ruminococcus flavefaciens as the predominant celluloyltic bacteria species of the equine cecum. Appl. Envir. Microbiol. 65(8):3737-3741.

Julliand V., A. de Fombelle, C. Drogoul, and E. Jacotot. 2001. Feeding and microbial disorders in horses: 3 -Effects of three hay: grain ratios on microbial profile and activities. J. Equine Vet. Sci. 21:543-546.

Kailasapathy, K. and S. Rybka. 1997. L. acidophilus and Bifidobacterium spp.: their therapeutic potential and survival in yogurt. Australian J Dairy Tech. 52:28-33.

Kailasapathy K. and J. Chin. 2000. Survival and therapeutic potential of probiotic organisms with reference to Lactobacillus acidophilus and Bifidobacterium spp. Immunol Cell Biol. 78:80-88.

Kaplan, H., and R. W. Hutkins. 2000. Fermentation of fructooligosaccharides by lactic acid bacteria and bifidobacteria. Appl. Environ. Microbiol. 66:2682-2684.

Karlsson, C. P., J. E. Lindberg, and M. Rundgren. 2000. Associative effects on total tract digestibility in horses fed different ratios of grass hay and whole oats. Livest. Prod. Sci. 65:143-153.

Kern, D. L., L. L. Slyter, J. M. Weaver, E. C. Leffel, and G. Samuelson. 1973. Pony cecum vs. steer rumen: The effect of oats and hay on the microbial ecosystem. J. Anim. Sci. 37:463-469.

Kern, D. L., L. L. Slyter, E. C. Leffel, J. M. Weaver, and R. R. Oltjen. 1974. Ponies vs. steers: microbial and chemical characteristics of intestinal ingesta. J. Anim. Sci. 38: $559-563$.

Kienzle, E. 1994. Small intestinal digestion of starch in the horse. Revue Med. Vet. (Toulouse). 145:199-204.

Kim, S. W., D. G. Standford, H. Roman-Rosario, M. T. Yokoyama, and S. R. Rust. 2000. Potential use of Propionibacterium acidipropionici, strain DH42, as a direct-fed microbial for cattle. J. Anim. Sci. 78:2431-2445. 
Kim L., P. S. Morley, J. L. Traub-Dargatz, D. Salmana and C. Gentry-Weeks. 2001. Factors associated with Salmonella shedding among colic patients at a veterinary teaching hospital. J. Am. Vet. Med. Assoc. 218(5):740-748.

King, C. 1999. Preventing Colic in Horses. Paper Horse, Cary, NC.

Koers, W. C., R. Britton, T. J. Klopfenstein, and W. R. Woods. 1976. Ruminal histamine, lactate and animal performance. J. Anim. Sci. 43(3):684-691.

Kohnke, J. R., F. Kelleher, and P. Trevor-Jones. 1999. Feeding Horses in Australia: A Guide for Horse Owners and Managers. Rural Industries Res. \& Development Corp., Barton, Australia.

Komari, R. K., Y. K. L. Reddy, J. Suresh, and D. N. Raj. 1999. Effect of feeding yeast culture (Saccharomyces cerevisae) and Lactobacillus acidophilus on production performance of crossbred dairy cows. J. Dairy Sci. 82(Suppl. 1):128.

Krehbiel, C. R., S. R. Rust, G. Zhang, and S. E. Gilliland. 2003. Bacteria direct-fed microbials in ruminant diets: Performance response and mode of action. J. Anim. Sci. 81(E. Suppl. 2):120-132.

Kresge, N., R. D. Simoni, and R. L. Hill. 2005. Otto Fritz Meyerhof and the Elucidation of the Glycolytic Pathway. J. Biol. Chem. 280(4):e3.

Kristensen, N. B., and D. L. Harmon. 2004. Splanchnic metabolism of volatile fatty acids absorbed from the washed reticulorumen of steers. J. Anim. Sci. 82:20332042 .

Kung, L., Jr. 1999. Direct-fed microbial and enzyme feed additives. Page 37 in DirectFed Microbial, Enzyme and Forage Additive Compendium. S. Muirhead, ed. Vol. 4. The Miller Publishing Co., Minnetoka, MN.

Leedle, J. A., M. P. Bryant and R. B. Hespell. 1982. Diurnal variations in bacterial numbers and fluid parameters in ruminal contents of animals fed low- or highforage diets. Appl. Environ. Microbiol. 44(2):402-412.

Leng, R. A. 1970. Formation and production of volatile fatty acids in the rumen. Pages 407-421 in Physiology of Digestion and Metabolism in the Ruminant. A. T. Phillipson, ed. Oriel Press, Newcastle-upon-Tyne, England.

Li, L., C. L. Xu, C. Ji, Q. Ma, K. Hao, Z. Y. Jin and K. Li. 2006. Effects of a dried Bacillus subtilis culture on egg quality. Poult Sci. 85(2):364-368.

Lilley, D. M. and R. H. Stillwell. 1965. Probiotics: Growth promoting factors produced by microorganisms. Science. 147: 747-748. 
Maciorowski, K. G., P. Herrera, F. T. Jones, S. D. Pillai, and S. C. Ricke. 2007. Effects on poultry and livestock of feed contamination with bacteria and fungi. Animal Feed and Science Tech. 133:109-136.

Macy, J. M., J. R. Farrand, and L. Montgomery. 1982. Cellulolytic and non-cellulolytic bacteria in rat gastrointestinal tracts. Appl. Environ. Microbiol. 44(6):14281434.

Maeng, W. J., C. W. Kim, and H. T. Shin. 1987. Effect of a lactic acid bacteria concentrate (Streptococcus faecium Cernelle 68) on growth rate and scouring prevention in dairy calves. J. Dairy Sci. 9:204-210.

Maki, L. R. and E. M. Foster, 1957. Effect of roughage in the bovine ration on types of bacteria in the rumen. J. Dairy Sci. 50:905-913.

Mann, S. O., C. Grant, and P. N. Hobson. 1980. Interactions of E. coli and lactobacilli in gnotobiotic lambs. Microbios Lett. 15:141-144.

Mansmann, R. A., and C. King. 2000. Preventing Laminitis in Horses. Paper Horse, Cary, NC.

Martin, S. A., and M. N. Streeter. 1995. Effect of malate on in vitro mixed ruminal microorganism fermentation. J. Anim. Sci. 73:2141-2145.

Martin, S. A., and D. J. Nisbet. 1992. Effect of direct-fed microbials on ruminal microbial fermentation. J. Diary Sci. 75:1736-1744.

McAnally, R. A. 1944. The determination of total volatile fatty acids in blood. J. Exp. Biol. 20:130-131.

McLean, B. M. L., J. J. Hyslop, A. C. Longland, D. Cuddeford, and T. Hollands. 2000. Physical processing of barley and its effects on intra-caecal fermentation parameters in ponies. Anim. Feed Sci. Technol. 85:79-87.

McClymont, G. L. 1952. Specific dynamic actions of acetic acid and heat increment of feeding ruminants. Aust. J. Agric. Res. 5(3):374-383.

Medina, B., I. D. Girard, E. Jacotot, and V. Julliand. 2002. Effect of preparation of Saccharomyces cerevisiae on microbial profiles and fermentation patterns in the large intestine of horses fed a high fiber or high starch diet. J. Anim. Sci. 80:2600-2609.

Medzihradsk, F., and Lamprecht, W. 1966. Stoffwechseluntersuchungen mit Essig-, Milch- und Zitronensaure. Lebensm. Unters. Forsch. 130:171-180.

Metchnikoff, E. 1907. Prolongation of Life. G. P. Putnam and Sons, New York. 
Merritt, A. M., and D. A. Smith. 1980. Osmolarity and volatile fatty acid content of feces from horses with chronic diarrhea. Am J Vet Res. 41(6):928-31.

Michalet-Doreau, B., I. Fernandez, and G. Fonty. 2002. A comparison of enzymatic and molecular approaches to characterize the cellulolytic microbial enzymes of the rumen and the cecum. J. Anim. Sci. 80:790-796.

Milinovich, G. J., D. J. Trott, P. C. Burrell, A. W. van Eps, M. B. Thoefner, L. L. Blackall., R. A. M. Al Jassim, J. M. Morton, and C. C. Pollitt. 2006. Changes in equine hindgut bacterial populations during oligofructose-induced laminitis. Environ. Microbiol. 8(5):885-898.

Miller-Webster, T., W. H. Hoover, M. Holt, and J. E. Nocek. 2002. Influence of yeast culture on ruminal microbial metabolism in continuous culture. J. Dairy Sci. 85:2009-2014.

Mitsuoka, T. 1990. Bifidobacteria and their role in human health. Journal of Industrial Microbiology. 6:263-268.

Moat, A. G., J. W. Foster, and M. P. Spector. 2002. Microbial Physiology $4^{\text {th }}$ edition. Wiley-Liss, Inc., New York.

Mohan, B., R. Kadirvel, M. Bharskaran, and A. Natarajan. 1995. Effect of probiotic supplementation on serum/yolk cholesterol and on egg shell thickness in layers. Br Poult Sci. 36(5):799-803.

Moore Agri-Sales. 2006. Fastrack ${ }^{\circledR}$ probiotic for horses. http://www.mooreagrisales.com. Marion, TX.

Moore, B. E., and K. E. Newman. 1993. Influence of feeding yeast culture (Yea-Sacc) on cecum and colon $\mathrm{pH}$ of the equine. J. Anim. Sci. 71(Suppl 1):261(Abstr).

Muralidhara, K. S., G. G. Sheggeby, P. R. Elliker, D. C. England, and W. E. Sandine. 1977. Effect of feeding lactobacilli on the coliform and Lactobacillus flora of intestinal tissue and feces from piglets. J. Food Prot. 40:288-295.

NRC. 2007. Nutrient Requirements of Horses. $6^{\text {th }}$ rev. ed. Natl. Acad. Press, Washington, D.C.

Nagaraja, T. G., C. J. Newbold, C. J. Van Nevel, and D. I. Demeyer. 1997. Manipulation of ruminal fermentation. Pages 523-632 in The rumen microbial ecosystem. P. N. Hobson and C. S. Stewart, ed. Blackie Academic, New York. 
Newbold, C. J., P. E. V. Williams, and N. McKain, A. Walker and R. J. Wallace. 1990. The effects of yeast culture on yeast numbers and fermentation in the rumen of sheep. Proc. Nutr. Soc. 49(1):47A.

Newbold, C. J., R. J. Wallace, and F. M. McIntosh. 1993. The stimulation of rumen bacteria by Saccharomyces cerevisiae is dependent on the respiratory activity of the yeast. J. Anim. Sci. 71(Suppl. 1):280(Abstr.).

Newbold, C. J., R. J. Wallace, and F. M. McIntosh. 1996. Mode of action of the yeast Saccharomyces cerevisiae as a feed additive for ruminants. Brit. J. Nutr. 76:249261.

Nordlund, K. V., E. F. Garrett, and G. R. Oetzel. 1995. Herd-based rumenocentensis: A clinical approach to the diagnosis of subacute rumen acidosis. Compend. Contin. Educ. Pract. Vet. 17:548-556.

Novicki, T. J., J. M. Schapiro, B. K. Ulness, A. Sebeste, L. Busse-Johnston, K. M. Swanson, S. R. Swanzy, W. Leisenring, and A. P. Limaye. 2003. Convenient selective differential broth for isolation of vancomycin-resistant Enterococcus from fecal material. J. Clin. Microbiol. 42(4):1637-1640.

Oba, M., and M. S. Allen. 2003. Effects of corn grain conservation method on ruminal digestion kinetics for lactating dairy cows at two dietary starch concentrations. J. Dairy Sci. 86:184-194.

Ogawa, M., K. Shimizu, K. Nomoto, R. Tanaka, T. Hamabata, S. Yamasaki, T. Takeda, and Y. Takeda. 2001. Inhibition of in vitro growth of Shiga toxin-producing Escherichia coli $\mathrm{O} 157: \mathrm{H7}$ by probiotic Lactobacillus strains due to production of lactic acid. Int. J. Food Microbiol. 68:135-140.

Ohya, T., T. Marubashi, and H. Ito. 2000. Significance of fecal volatile fatty acids in shedding of Escherichia coli 0157 from calves; experimental infection and preliminary use of probiotic product. J. Vet. Med. Sci. 62:1151-1155.

Ordakowski-Burk, A. L., R. W. Quinn, T. A. Shellem, and L. R. Vough. 2006. Voluntary intake and digestibility of reed canarygrass and timothy hay fed to horses. J. Anim. Sci. 84:3104-3109.

Orskov, E. R., D. A. Grubb, J. S. Smith, A. J. Webster, and W. Corrigall. 1979. Efficiency of utilization of volatile fatty acids for maintenance and energy retention by sheep. Br. J. Nutr. 41:541-50.

Orskove, E. R. 1986. Starch digestion and utilization in ruminants. J. Anim. Sci. 63(5): 1624-1633. 
Orskov, E. R., E. R. Macleod, and Y. Nakashima. 1991. Effect of different volatile fatty acid mixtures on energy metabolism in cattle. J. Anim. Sci. 69: 3389-3397.

O'Sullivan, G. C., P. Kelly, S. O'Halloran, C. Collins, J. K. Collins, C. Dunne and F. Shanahan. 2005. Probiotics: an emerging therapy. Current Pharm. Design. 11:3-10.

Ouwehand, A. C., P. Niemi, S. J. Salminen. 1999. The normal feacal microflora does not affect the adhesion of probiotic bacteria in vitro. FEMS Microbiol Lett. 177:35-38.

Owens, F. N., D. S. Secrist, W. J. Hill, and D. R. Gill. 1998. Acidosis in cattle; a review. J. Anim. Sci. 76:275-286.

Pagan, J. D. 1998. Carbohydrates in equine nutrition. Pages 57-70 in Advances in Equine Nutrition. J. D. Pagan, ed. Nottingham Univ. Press, Nottingham, U.K.

Parraga, M. E., S. J. Spier, M. Thurmond and D. Hirsh. 1997. A clinical trial of probiotic administration for prevention of Salmonella shedding in the postoperative period in horses with colic. J. Vet. Int. Med. 11:36-41.

Parker, R. B. 1974. Probiotics, the other half of the antibiotic story. Anim. Nutr. Health 29:4-8.

Peterson, A. B., and L. W. Douglass. 2005. Adopting new techniques: statistical procedures to determine the agreement between two laboratory methods. Pages $1-13$ in $18^{\text {th }}$ Northeast SAS Users Group Proc., Portland, ME.

Potter, G. D., F. F. Arnold, D. D. Householder, D. H. Hansen, and K. M. Brown. 1992. Digestion of starch in the small or large intestine of the equine. Pferdeheilkunde. 1:107-111.

Ralston, S. L. 1995. Bicarbonate supplementation of young horses fed high grain ration. Pages 4-5 in Proc. $14^{\text {th }}$ Equine Nutr. Physiol. Symp., Equine Nutr. Physiol. Soc., Savoy, IL.

Reeves, M. J., M. D. Salman, and G. Smith. 1996. Risk factors for equine acute abdominal disease (colic): Results from a multi-centered case-control study. Prev. Vet. Med. 26:285-301.

Rettger, L. F., and Chaplin, H. A. 1921. Treatise on the transformation of the intestinal flora with special referfence to the implantation of Bacillus acidophilus. Yale University Press. New Haven, Connecticut.

Reynolds, C. K., G. B. Huntington, T. H. Elsasser, et al. 1989. Net metabolism of hormones by portal drained viscera and liver. J. Diary Sci. 72:1459-68. 
Riordan, D. C. R., G. Duffy, J. J. Sheridan, R. C. Whiting, I. S. Blair, and D. A. McDowell. Effects of acid adaptation, product $\mathrm{pH}$, and heating on survival of Escherichia coli 0157:H7 in pepperoni. Appl. Environ. Microbial. 66, 17261729.

Rowe, J. B., M. J. Lees, and D. W. Pethick. 1994. Prevention of acidosis and laminitis associated with grain feeding in horses. J. Nutr. 124:2742S-2744S.

Rust, S. R., K. Metz, and D. R. Ware. 2000. Effect of Bovamine rumen culture on the performance and carcass characteristics of feedlot steers. Pages 22-26 in Mich. Agric. Exp. Sta. Beef Cattle, Sheep, and Forage Sys. Res. Dem. Rep. No. 569, East Lansing.

SAS Institute Inc. SAS Online Doc., Version 9.1.2. SAS User's Guide, 2004 Cary, NC.

Sauvant, D., P. Chapoutot, and H. Archimede. 1994. La digestion des amidons par les ruminants et ses consequences. INRA Prod. Anim. 7:115-124.

Savage, D. C. and M. Fletcher. 1985. Effects of host animals of bacteria adhering to epithelial surfaces. Pages 437-463 in Bacterial Adhesion. D. C. Savage and M. Fletcher, ed. Mechanisms and physiological significance. Plenum Publishing Corp., New York.

Savage, D. C. 1991. Gastrointestinal microbial ecology; possible modes of action of direct-fed microbials in animal production. Pages 11-81 in Direct-fed Microbials in Animal Production. National Feed Ingredients Association. Des Moines, IA.

Scheele, C. The collected papers of Carl Wilhelm Scheele. 1931 ed. 1782 G. Bell London, UK.

Schiffrin, E., J. F. Rochat, H. Link-Amster, J. M. Aeschlimann, and A. Donnet-Hughes. 1995. Immunomodulation of human blood cells following the ingestion of lactic acid bacteria. J. Dairy Sci. 78: 491-497.

Sherman, F. 1998. An introduction to the genetics and molecular biology of the yeast Saccharomyces cerevisiae. Modified from: F. Sherman, Yeast genetics. Pages 302-325 in The Encyclopedia of Molecular Biology and Molecular Medicine, Vol. 6. R. A. Meyers, ed., VCH Pub., Weinheim, Germany.

Siciliano-Jones, J. and Murphy, M. R. 1989. Production of volatile fatty acids in the rumen and cecum-colon of steers as affected by forage-concentrate and forage physical form. J. Dairy Sci. 72:485-492. 
Simpson, P. J., C. Stanton, G. F. Fitzgerald, and R. P. Ross. 2003. Genomic diversity and relatedness of bifidobacteria isolated from a procine cecum. J. Bacteriol. 185(8): 2571-2581.

Slyter, L. L. 1976. Influence of acidosis on rumen function. J. Anim. Sci. 43:910-29.

Spoto M. H. F., C. R. Gallo, A. R. Alcarde, M. S. A. Gurgel, L. Blumer, J. M. M. Walder, and R. E. Domarco. 2000. Gamma irradiation in the control of pathogenic bacteria in refrigerated ground chicken meat. Scientia Agricola. 57(3):389-394.

Sprouse, R. F., H. E. Graner, and E. M. Green. 1987. Plasma endotoxin levels in horses subjected to carbohydrate induced laminitis. Equine Vet. J. 19:25-28.

Star-Labs. 2006. Direct-fed Microbial. http://www.primalac.com/probiotics.html. Clarksdale, MO.

Stedman, T. L. 1982. Stedman's Medical Dictionary. Williams and Wilkins, Baltimore, MD.

Swanson, C. A., D. S. Kronfeld, R. M. Hoffman, and R. K. Splan. 2003. Effects of diet and probiotic supplementation on stress during weaning in Thoroughbred foals. Page 243 in Proc. $18^{\text {th }}$ Equine Nutr. Physiol. Soc. Symp., East Lansing, MI.

Swinney-Floyd, D., B. A. Gardiner, F. N. Owens, T. Rehberger, and T. Parrott. 1999. Effects of inoculation with either strain P-63 alone or in combination with Lactobacillus acidophilus LA53545 on performance of feedlot cattle. J. Anim. Sci. 77(Suppl. 1):77 (Abstr.).

Swyers, K. L., A. O. Burk, C. R. Angel, E. M. Ungerfeld, L. W. Douglass, K. L. Poorman and R. V. Kapadia. 2007. Effects of Viability of lactic acid bacteria in animal feed after pelleting and storage. M. S. Thesis. University of Maryland, College Park.

Swyers, K. L., A. O. Burk, T. G. Hartsock, E. M. Ungerfeld and J. L. Shelton. 2007. Effects of direct-fed microbial supplementation on digestibility and fermentation end-products in horses fed low- and high-starch concentrates. M. S. Thesis. University of Maryland, College Park.

Tannock, J. 1999. Probiotics: a critical review. ed. Horizon Scientific Press. Norfolk, UK.

Tappeiner, H. 1884. Untersuchungen uber die garung der cellulose insbesondere uber deren losung in darmkanale. Z. Biol. 20:52-134. 
Todar, K. 2005. http://textbookofbacteriology.net. Todar's Online Textbook of Bacteriology. University of Wisconsin-Madison Department of Bacteriology.

Traub-Dargatz, J. L., C. A. Kopral, A. H. Seitzinger, L. P. Garber, K. Forde, and N. A. White. 2001. Estimate of the national incidence of and operation-level risk factors for colic among horses in the United States, spring 1998 to spring 1999. J. Am. Vet. Med. Assoc. 219:67-71.

Tubbs, P. 1965. The metabolism of D-alpha-hydroxy acids in animal tissues. Ann. N. Y. Acad. Sci. 119:920-926.

Turner, T. N. 1971. The sudden death syndrome in feedlot cattle: A practitioner's analysis. Vet. Med. Small Anim. Clin. 88:803-808.

Van Heugten, E., D. W. Funderburke, and K. L. Dorton. 2003. Growth performance, nutrient digestibility, and fecal microflora in weanling pigs fed live yeast. J. Anim. Sci. 81:1004-1012.

Van Koevering, M. T., F. N. Owens, D. S. Secrist, R. H. Anderson, and R. E. Herman. 1994. Cobactin II for feedlot steers. J. Anim. Sci. 72(Suppl 1):83.

Van Niel, C. W., C. Feudtner, M. M. Garrison, and D. A. Christakis. 2002. Lactobacillus therapy for acute infectious diarrhea in children: a meta-analysis. Pediatrics. 109(4):678-684.

Van Soest, P. J., J. B. Robertson, and B. A. Lewis. 1991. Methods for dietary fiber, neutral detergent fiber, and non-starch polysaccharides in relation to animal nutrition. J. Dairy Sci. 74:3583-3597.

Vets Plus, Inc. 2006. For healthy microbial balance. http://www.probios.com/aboutus.htm. Knapp, WI.

Wallace, R. J. 1994. Ruminal microbiology, biotechnology, and ruminant nutrition: progress and problems. J. Anim. Sci. 72:2992-3003.

Ware, D. R., P. L. Read, and E. T. Manfredi. 1988. Pooled summary of eight feedlot trials evaluating performance and carcass characteristics of steers fed Lactobacillus acidophilus strain BT1386. J. Anim. Sci. 66(Suppl. 1):436(Abstr.).

Ward D. M., R. Weller, and M. M. Bateson. 1990. 16S rRNA sequences reveal numerous uncultured micro-organisms a natural community. Nature. 345:63-65.

Wedekind, K. J., H. R. Mansfield, and L. Montgomery. 1988. Enumeration and isolation of cellulolytic and hemicellulolytic bacteria from human feces. Appl. Environ. Microbiol. 54(6):1530-1535. 
Weese, J. S. 2001. A Review of Probiotics: Are They Really "Functional Foods"? AAEP Proc. 47:27-31.

Weese J.S. 2002. Microbiologic evaluation of commerical probiotics. J Am Vet Med Assoc. 220:794-797.

Weese, J. S. 2003. Probiotics, Preobiotics and Synbiotics. Pages 711-714 in Current Therapy in Equine Medicine $5^{\text {th }}$ edition. Saunders. St. Louis, MO.

Weese, J. S., M. E. C. Anderson, A. Lowe, and G. J. Monteith. 2003. Preliminary investigation of probiotic potential of Lactobacillus rhamnosus strain GG in horses: fecal recovery following oral administration and safety. Can. Vet. J. 44:299-302.

Weese, J. S. and L. Arroyo. 2003. Bacteriological evaluation of dog and cat diets that claim to contain probiotics. Can Vet J. 44(3):212-215.

Weese, J. S., M. E. C. Anderson, A. Lowe, R. Penno, T. M. Da Costa, L. Button, and K. C. Goth. 2004. Screening of the equine intestinal microflora for potential probiotic organisms. Equine Vet. J. 36(4):351-355.

Weese, J. S. and J. Rousseau. 2005. Evaluation of Lactobacillus pentosus WE7 for prevention of diarrhea in neonatal foals. J. Am. Vet. Med. Assoc. 226(12):20312034.

Whistler, R. L. and J. R. Daniel. 1984. Molecular structure of starch. Pages 153-182 in Starch, $2^{\text {nd }}$ ed. R. L. Whistler, J. N. BeMiller and E. F. Paschall. Academic Press, New York.

Williams, D. E. 1976. Sudden death syndrome. Pages 20-35 in Proc. Acad. Vet. Consultants. Cecil Reedy Workshop on Sudden Death, Amarillo, TX.

Williams, D. E. 1977. Sudden death syndrome. Pages 1-57 in Proc. Acad. Vet. Consultants. Cecil Reedy Workshop on Sudden Death, Amarillo, TX.

Weyenberg, S. V., J. Sales, G. P. J. Janssens. 2006. Passage rate of digesta through the equine gastrointestinal tract: a review. Livest. Sci. 9:3-12

Wolin, M. J. and T. L. Miller. 1994. Acetogenesis from $\mathrm{CO}_{2}$ in the human colonic ecosystem. Pages 365-385 in Acetogenesis. H. L. Drake, ed. Chapman and Hall, New York, NY.

Yeo, J., and K. I. Kim. 1997. Effect of feeding diets containing an antibiotic, a probiotic, or yucca extract on growth and intestinal urease activity in broiler chicks. Poult Sci. 76(2):381-385. 
Yoon, I. K., and M. D. Stern. 1995. Influence of direct-fed microbials on ruminal fermentation and performance of ruminants: a review. Austrailian J. Anim. Sci. 8:533-555.

Yuyama, T., S. Yusa, S. Takai, S. Tsubaki, Y. Kado and M. Morotomi. 2004. Evaluation of a host-specific Lactobacillus probiotic in neonatal foals. Int. J. Appl. Res. Vet. Med. 2(1):26-33.

Zani, G., B. Biavate, F. Crociani, and D. Matteuzzi. 1974. Bifidobacteria from the faeces of piglets. J. Appl. Bacteriol. 37:537-547.

Zhao, T., M. P. Doyle, B. G. Harmon, C. A. Brown, P. O. Mueller, and A. H. Parks. 1998. Reduction of carriage of enterohemorrhagic Escherichia coli 0157:H7 in cattle by inoculation with probiotic bacteria. J. Clin. Microbiol. 36(3):641-647. 